\title{
Explorando variedade em consultas por similaridade
}

Lúcio Fernandes Dutra Santos 
SERVIÇO DE PÓS-GRADUAÇÃO DO ICMC-USP

Data de Depósito:

Assinatura:

\section{Explorando variedade em consultas por similaridade}

\section{Lúcio Fernandes Dutra Santos}

Orientador: Prof. Dr. Caetano Traina Júnior

Dissertação apresentada ao Instituto de Ciências Matemáticas e de Computação - ICMC-USP, como parte dos requisitos para obtenção do título de Mestre em Ciências - Ciências de Computação e Matemática Computacional. VERSÃO REVISADA 
Ficha catalográfica elaborada pela Biblioteca Prof. Achille Bassi e Seção Técnica de Informática, ICMC/USP, com os dados fornecidos pelo(a) autor(a)

\begin{tabular}{|c|c|}
\hline \multirow[t]{3}{*}{ s237e } & $\begin{array}{l}\text { Santos, Lúcio Fernandes Dutra } \\
\text { Explorando variedade em consultas por } \\
\text { similaridade / Lúcio Fernandes Dutra Santos; } \\
\text { orientador Caetano Traina Júnior. -- São Carlos, } \\
2012 \text {. } \\
\quad 52 \text { p. }\end{array}$ \\
\hline & $\begin{array}{l}\text { Dissertação (Mestrado - Programa de Pós-Graduação en } \\
\text { Ciências de Computação e Matemática Computacional) -- } \\
\text { Instituto de Ciências Matemáticas e de Computação, } \\
\text { Universidade de São Paulo, 2012. }\end{array}$ \\
\hline & $\begin{array}{l}\text { 1. Diversidade em respostas. 2. Consultas por } \\
\text { similaridade. 3. Busca em espaços métricos. 4. Banco } \\
\text { de dados. I. Traina Júnior, Caetano, orient. II. } \\
\text { Título. }\end{array}$ \\
\hline
\end{tabular}



À minha esposa Ailana, com amor, admiração e gratidão por sua compreensão, carinho, presença e incansável apoio ao longo do período de elaboração deste trabalho. À minha filha Bianca, por cada sorriso e por sua compreensão nos momentos de ausência. 



\section{Agradecimentos}

\section{À Deus.}

Ao meu orientador, Prof. Dr. Caetano Traina Júnior, agradeço o apoio e a confiança que dispensou durante a elaboração deste trabalho, mesmo nos momentos que eu não acreditava. À $\operatorname{Prof}^{a} \operatorname{Dr}^{a}$ Agma Juci Machado Traina, devido aos conselhos e sugestões. À $\operatorname{Prof}^{a} \operatorname{Dr}^{a}$ Elaine Parros Machado de Sousa, por ter conduzido o encontro com o Prof. Caetano.

À minha querida esposa, Ailana, e a minha filha, Bianca, pelo amor, apoio incondicional, carinho e paciência me fortalecendo nos momentos difíceis.

Aos meus pais, pelo amor, carinho, dedicação e exemplo em todos os momentos da minha vida.

Aos meus sogros, pela maravilhosa família da qual tenho a graça de pertencer.

Aos grandes amigos que fiz no GBdI, em especial os que tive o prazer de discutir ideias e risadas: Willian Denner, Alceu Ferraz, Pedro Lopes, Sérgio, Mônica, Marcos Bêdo, Ives Pola, Arthur, Felipe Louza, Daniel Chino, Ândrea, Marcelo Ponciano, Letrícia e Robson; e os demais amigos do grupo. Muito obrigado pela oportunidade de compartilhar tantos momentos com vocês.

Aos funcionários e professores do ICMC-USP.

À FAPESP (Fundação de Amparo à Pesquisa do Estado de São Paulo) e ao CNPq (Conselho Nacional de Desenvolvimento Científico e Tecnológico), pelo apoio financeiro à realização deste trabalho. 



\section{Resumo}

A complexidade dos dados armazenados em grandes bases de dados aumenta sempre, criando a necessidade de novas formas de consulta. As consultas por similaridade vêm apresentando crescente interesse para tratar de dados complexos, sendo as mais representativas a consulta por abrangência $(R q$-Range query) e a consulta aos $k$-vizinhos mais próximos $(k-N N q$ - $k$-Nearest Neighboor query). Até recentemente, essas consultas não estavam disponíveis nos Sistemas de Gerenciamento de Bases de Dados (SGBD). Agora, com o início de sua disponibilidade, tem se tornado claro que os operadores de busca fundamentais usados para executá-las não são suficientes para atender às necessidades das aplicações que as demandam. Assim, estão sendo estudadas variações e extensões aos operadores fundamentais, em geral voltados às necessidades de domínios de aplicações específicas. Além disso, os seguintes problemas vêm impactando diretamente sua aceitação por parte dos usuários e, portanto, sua usabilidade: (i) os operadores fundamentais são pouco expressivos em situações reais; (ii) a cardinalidade dos resultados tende a ser grande, obrigando o usuário analisar muitos elementos; e (iii) os resultados nem sempre atendem ao interesse do usuário, implicando na reformulação e ajuste frequente das consultas. O objetivo desta dissertação é o desenvolvimento de uma técnica inédita para exibir um grau de variedade nas respostas às consultas aos $k$-vizinhos mais próximos em domínios de dados métricos, explorando aspectos de diversidade em extensões dos operadores fundamentais usando apenas as propriedades básicas do espaço métrico sem a solicitação de outra informação por parte do usuário. Neste sentido, são apresentados: a formalização de um modelo de variedade que possibilita inserir diversidade nas consultas por similaridade sem a definição de parâmetros por parte do usuário; um algoritmo incremental para responder às consultas aos $k$-vizinhos mais próximos com variedade; um método de avaliação de sobreposição de variedade para as consultas por similaridade. As propriedades desses resultados permitem usar as técnicas desenvolvidas para apoiar a propriedade de variedade nas consultas aos $k$-vizinhos mais próximos em Sistemas de Gerenciamento de Bases de Dados.

Palavras Chave: Diversidade em respostas; Consultas por similaridade; Busca em espaços métricos. 



\section{Abstract}

The data being collected and generated nowadays increases not only in volume, but also in complexity, leading to the need of new query operators. Similarity queries are one of the most pursued resources to retrieve complex data. The most studied operators to perform similarity are the Range Query $(R q)$ and the $k$-Nearest Neighbor Query $(k-N N q)$. Until recently, those queries were not available in the Database Management Systems. Now they are starting to become available, but since its earliest applications to develop real systems, it became clear that the basic similarity query operators are not enough to meet the requirements of the target applications. Therefore, new variations and extensions to the basic operators are being studied, although every work up to now is only pursuing the requirements of specific application domains. Furthermore, the following issues are directly impacting their acceptance by users and therefore its usability: (i) the basic operators are not expressive in real situations, (ii) the result-set cardinality tends to be large, imposing to the user the need to analyze to many elements, and (iii) the results do not always meet the user's interest, resulting in the reformulation and adjustment of the queries.

The goal of this dissertation is the development of a novel technique to enable a degree of variety the answers of $k$-nearest neighbor queries in metric spaces, investigating aspects of diversity in extensions of the basic operators using only the properties of metric spaces, never requesting extra information from the user. In this monograph, we present: the formalization of the variety model that allows to support diversity in similarity queries without requiring diversification parameters from the user; a greedy algorithm to obtain answers for similarity queries to the $k$-nearest neighbors with variety; an evaluation method to assess the diversification ratio existing on a subset of elements in metric space. The properties of those results allow using our proposed techniques to support variety in $k$-nearest neighbor queries in Database Management Systems.

Keywords: Result diversification; Similarity queries; Similarity search in metric space. 



\section{Sumário}

Sumário ix

Lista de Figuras $\quad$ xi

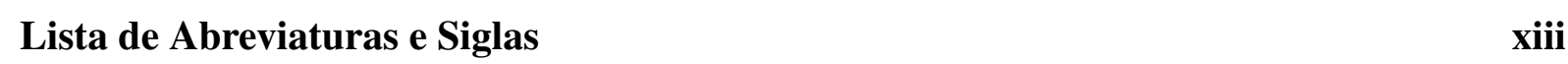

$\begin{array}{ll}\text { Lista de Símbolos } & \text { xv }\end{array}$

1 Introdução 1

1.1 Motivação e Objetivo . . . . . . . . . . . . . . . . . . . 2

1.2 Organização do documento . . . . . . . . . . . . . . . . 3

2 Conceitos Fundamentais 5

2.1 Considerações Iniciais $\ldots \ldots \ldots \ldots$. . . . . . . . . . . . . . 5

2.2 Medidas de Similaridade . . . . . . . . . . . . . . . . . . . 5

$2.2 .1 \quad$ Função de Distância de Levenshtein . . . . . . . . . . . . . . . . . . 6

2.2 .2 Funções de distância de Minkowski . . . . . . . . . . . . . . . 6

2.3 Consultas por Similaridade . . . . . . . . . . . . . . . . 7

2.3 .1 Consulta por abrangência . . . . . . . . . . . . . . . 8

2.3.2 Consulta aos $k$-vizinhos mais próximos . . . . . . . . . . . 8

2.4 Método de Acesso Métrico . . . . . . . . . . . . . . . . . . . 9

2.4 .1 Slim-tree . . . . . . . . . . . . . . . . . . . . 9

2.5 Considerações Finais $\ldots \ldots \ldots$. . . . . . . . . . . . . . . . . . 10

\begin{tabular}{lll}
\hline Modelos de Diversidade & 11
\end{tabular}

3.1 Considerações Iniciais $\ldots \ldots \ldots$. . . . . . . . . . . . . . . . . 11

3.2 O conceito de Diversidade . . . . . . . . . . . . . . . . . . . 11

3.3 Estratégias para Diversificação de Resultados . . . . . . . . . . . . . . . . . . . . 12

3.3 .1 Diversidade Baseada em Atributo . . . . . . . . . . . . . . . . . . 12

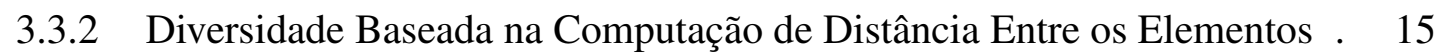

3.3.3 Diversidade Baseada na Distância de Separação . . . . . . . . . . . . . 21

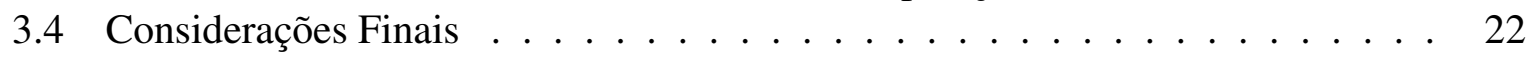

4 Variedade em Consultas por Similaridade 23

4.1 Considerações Iniciais . . . . . . . . . . . . . . . . . . . . . 23 
4.2 Modelo de Variedade . . . . . . . . . . . . . . . . . . . . . . . . . . . 24

4.3 Algoritmo BRAD . . . . . . . . . . . . . . . . . . . . . 27

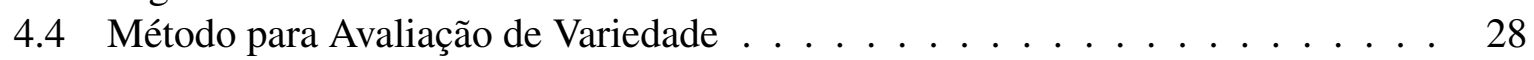

4.5 Considerações Finais $\ldots \ldots \ldots \ldots$. . . . . . . . . . . . . . . 30

$\begin{array}{lll}5 & \text { Experimentos } & 31\end{array}$

5.1 Materiais e Métodos . . . . . . . . . . . . . . . . . . . . . 31

5.2 Desempenho e Avaliação de Qualidade . . . . . . . . . . . . . . . . . . 32

5.2.1 Experimentos com o conjunto de dados Cidades Americanas . . . . . . 32

5.2 .2 Experimentos com o conjunto de dados Aloi . . . . . . . . . . . . . . 35

5.2 .3 Experimentos com o conjunto de dados words . . . . . . . . . . . . . 36

5.3 Teste de Escalabilidade $\ldots \ldots \ldots \ldots \ldots \ldots$

5.4 Considerações Finais $\ldots \ldots \ldots \ldots$. . . . . . . . . . . . . . . . . 38

6 Conclusões e Trabalhos Futuros $\quad 41$

6.1 Principais Contribuições $\ldots \ldots \ldots \ldots \ldots$. . . . . . . . . . . . . . . . . . . . . . . 42

6.2 Contribuições Complementares . . . . . . . . . . . . . . . . . . . . . . 42

6.3 Proposta para Trabalhos Futuros . . . . . . . . . . . . . . . . . . . . . . . . 42

6.3 .1 Extensões ao conceito de variedade . . . . . . . . . . . . 42

6.3.2 Desenvolvimento de algoritmos que tratem de variedade . . . . . . . . 44

6.3 .3 Extensões da variedade a necessidades específicas . . . . . . . . . . . 45

\begin{tabular}{|l|l}
\hline Referências Bibliográficas & 47
\end{tabular} 


\section{Lista de Figuras}

2.1 Representação das formas geométricas geradas para as funções de distância $L_{1}, L_{2}$ e $L_{\infty}$ para os pontos equidistantes à distância $\varepsilon$ a partir do elemento central $s_{q} \ldots$. . . 7

2.2 Exemplo de consultas por similaridade num espaço bi-dimensional Euclidiano . . . 8

2.3 Representação da distribuição espacial e estrutura lógica de uma Slim-tree . . . . . . 10

3.1 Consulta à palavra chave "São Paulo" em uma máquina de busca da web . . . . . . 12

3.2 Exemplo de taxonomia de livros utilizada no site Amazon.com. Imagem adaptada

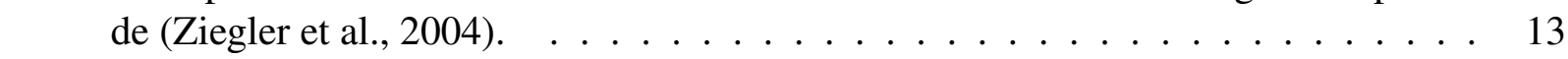

3.3 Exemplo de agrupamentos formados para a consulta pelo termo ambíguo "jaguar". Imagem adaptada de (Van Leuken et al., 2009). . . . . . . . . . . . . . . . . . . 14

3.4 Conjunto de resposta com elementos muito similares para a consulta aos 5-vizinhos

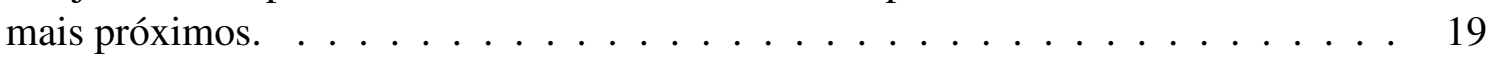

3.5 Conjunto de resposta com elementos muito similares para a consulta aos 5-vizinhos diversos mais próximos, solução ótima. f . . . . . . . . . . . . . . 20

3.6 Conjunto de resposta com elementos similares para a consulta aos 20-vizinhos

diversos mais próximos ilustrando o abismo de diversidade. . . . . . . . . . . . 21

3.7 Conjunto de resposta para a consulta aos 5-vizinhos distintos mais próximos com exclusão por uma distância de separação. . . . . . . . . . . . . . . . . 22

4.1 O conjunto de similaridade induzido pelo elemento dominante $s_{p}$. Os pontos representam os elementos que estão mais próximos de $s_{q}$ do que $s_{p}$. Os quadrados representam os elementos que fazem parte do conjunto de similaridade induzido, ou seja, são dominados por $s_{p}$ e podem ser ignorados como candidatos a dominante. Os triângulos representam os elementos que não são dominados por $s_{p} . . \ldots$. . . . 26

4.2 Construção do conjunto de resposta para busca aos 3-vizinhos variados mais próximos num espaço bi-dimensional euclidiano. (a) Primeiro dominante. (b) Segundo dominante. (c) Os 3 vizinhos variados mais próximos. . . . . . . . . . . . 28

4.3 Exemplo de como a sobreposição dos conjuntos de similaridade detecta a variedade entre dois elementos no conjunto de resposta. . . . . . . . . . . . . . . . 29

5.1 (a) Tempo de execução e (b) análise de qualidade das respostas para o conjunto de dados cidades americanas variando $k$ de 10 a 40 elementos. . . . . . . . . . . . 33

5.2 Resultado do algoritmo GNE para o conjunto de dados cidades americanas. . . . . . 34

5.3 Resultado do algoritmo BRAD para a consulta aos $k$-vizinhos variados mais próximos para o conjunto de dados cidades americanas. $\ldots \ldots \ldots . \ldots . \ldots 35$ 
5.4 (a) Tempo de execução e (b) análise de qualidade das respostas para o conjunto de dados Aloi variando $k$ de 10 a 40 elementos. . . . . . . . . . . . . . . . . . 35

5.5 Conjunto de resposta para a consulta aos 20-vizinhos mais próximos para um conjunto de imagens. . . . . . . . . . . . . . . . . 36

5.6 Conjunto de resposta para a consulta aos 20-vizinhos variados mais próximos para um conjunto de imagens. . . . . . . . . . . . . . . . . 36

5.7 (a) Tempo de execução e (b) análise de qualidade das respostas para o conjunto de dados Words variando $k$ de 10 a 40 elementos. . . . . . . . . . . . . . . . . . 37

5.8 (a) Escalabilidade em relação a cardinalidade do conjunto Sintético3D. (b) Nível de sobreposição de variedade em relação o aumento da cardinalidade do conjunto. . . 38

5.9 (a) Escalabilidade em relação a dimensionalidade do conjunto SintéticoD. (b) Nível de sobreposição de variedade em relação o aumento de dimensionalidade do conjunto. 38 


\section{Lista de Abreviaturas e Siglas}

$\begin{array}{ll}\text { SGBD } & \text { Sistemas de Gerenciamento de Bases de Dados } \\ \text { ROT } & \text { Relação de Ordem Total } \\ C B I R & \text { Recuperação de Imagens por Conteúdo (Content-Based Image Retrieval) } \\ \text { TBIR } & \text { Recuperação de Imagens por Contexto (Tag-Based Image Retrieval) } \\ k-N N q & \text { Consulta aos } k \text {-vizinhos mais próximos ( } k \text {-nearest neighbor query) } \\ R q & \text { Consulta por abrangência (Range query) } \\ \text { MAM } & \text { Método de Acesso Métrico } \\ \text { MAP } & \text { Método de Acesso Pontual } \\ \text { DF-tree } & \text { Distance Field tree } \\ V P-t r e e & \text { Vantage Point tree } \\ M V P-t r e e & \text { Multi-Vantage Point tree } \\ k-N D N q & \text { Consulta aos } k \text {-vizinhos diversos mais próximos ( } k \text {-nearest diverse neighbor query) } \\ S Q L & \text { Structured Query Language } \\ \text { MMR } & \text { Maximal Marginal Relevance } \\ \text { MDP } & \text { Problema da diversidade máxima (Maximum Diversity Problem) } \\ \text { MSD } & \text { Max-Sum Diversification } \\ G R A S P & \text { Greedy Randomizer Adaptive Search Procedure } \\ \text { GMC } & \text { Greedy Marginal Contribution } \\ \text { GNE } & \text { Greedy Randomized with Neighborhood Expansion } \\ \text { mmc } & \text { maximum marginal contribution } \\ \text { RCL } & \text { Lista restrita de candidatos (Restricted Candidate List) } \\ \text { FM } & \text { First-Match } \\ \text { CM } & \text { Centroid-Match } \\ \text { BRAD } & \text { Better Results With Adaptative Diversification } \\ k-N V N q & k \text {-vizinhos variados mais próximos } \\ R V q & \text { Consulta por abrangência variada } \\ & \end{array}$





\section{Lista de Símbolos}

$n \quad$ Número de elementos num conjunto de dados

$s_{q} \quad$ Elemento central da consulta

$\mathbb{S} \quad$ Domínio dos dados elementos válidos

$\delta \quad$ Função de distância ou métrica

$\mathbb{R}^{+} \quad$ Domínio dos números reais positivos

$s_{i} \quad$ Elemento $i$

$\varepsilon_{q} \quad$ Raio de consulta ou grau de dissimilaridade máximo

$k \quad$ Número de elementos a serem retornados pela consulta aos $k$-vizinhos mais próximos

$S \quad$ Conjunto de dados

E Dimensão

oid $_{i} \quad$ Ponteiro para um elemento $i$

$s_{\text {rep }} \quad$ Elemento representante de um nó da árvore

$\Theta_{F} \quad$ Fator de diversificação

$\lambda \quad$ Preferência de diversidade

$\delta_{\text {sim }} \quad$ Função de distânica para o cálculo de similaridade dos elementos

$\delta_{d i v} \quad$ Função de distânica para o cálculo de diversidade dos elementos

$R \quad$ Conjunto de resposta retornadas

$r_{i} \quad$ Elemento $i$ do conjunto candidato de resposta

M Espaço métrico

$c_{i} \quad$ Cadeia de caracteres $i$

MinDiv limiar para a diversidade esperada no conjunto de resposta

$\delta_{d i v}^{l} \quad$ Função de distânica da diversidade dos elementos que ainda não fazem parte da resposta

$\xi_{p} \quad$ Distância de similaridade

$s_{p} \quad$ Elemento dominante para a distância $\xi_{p}$

$\tilde{S} \quad$ Conjunto de similaridade induzido por um elemento dominante

$\omega \quad$ Função de avaliação do nível de sobreposição de variedade

$\bar{\omega} \quad$ Função de avaliação do nível de sobreposição de variedade normalizada 



\section{Capítulo 1}

\section{Introdução}

Os Sistemas de Gerenciamento de Bases de Dados (SGBD) foram criados para o armazenamento e recuperação de grandes volumes de dados, garantindo que a recuperação seja executada de maneira eficiente, fornecendo sempre respostas exatas às consultas. Tradicionalmente, estes sistemas sempre suportaram apenas números e pequenas cadeias de caracteres, conhecidos como "dados escalares". Com a evolução das aplicações, vem se tornando necessário armazenar, organizar e recuperar dados mais complexos, como exemplo, informações geo-referenciadas, dados vetoriais, dados multimídia (imagens, áudio e vídeo), séries temporais, grafos, seqüências de proteínas, os quais genericamente são chamados de dados complexos. Comparações baseadas em igualdade (ou seja, usando os operadores $=\mathrm{e} \neq$ ) têm pouca utilidade em consultas sobre dados complexos, pois é raro existirem dois elementos exatamente iguais. Os operadores de comparação relacionais $(<, \leq,>\mathrm{e} \geq)$, baseados na precedência de um dos elementos de um par qualquer, em geral também não são aplicáveis, pois dados complexos usualmente são representados em domínios que não atendem às propriedades da Relação de Ordem Total (ROT).

$\mathrm{Na}$ grande maioria das vezes, a busca em coleções de dados complexos não é feita comparando-se diretamente os elementos originais, mas usando atributos ou características que descrevem o elemento complexo. Existem duas técnicas para associar atributos aos elementos complexos. A primeira, chamada de "recuperação por contexto", como por exemplo, Recuperação de Imagens por Contexto (TBIR do inglês - Tag-Based Image Retrieval), é a associação de atributos, em geral de tipo textual, cujos valores são obtidos externamente ao elemento complexo ( $\mathrm{Wu}, 2012)$. Exemplos dessa técnica são a associação de descrições e palavras-chave a imagens feitas por pessoas, tais como laudos em imagens de exames médicos, e a associação automática de textos próximos às imagens em páginas da web. A segunda técnica é chamada de "recuperação por conteúdo", por exemplo, a Recuperação de Imagens por Conteúdo (CBIR do inglês - Content-Based Image Retrieval) (Deserno et al., 2008; Welter et al., 2012). Esta técnica corresponde à associação de atributos obtidos a partir do próprio elemento complexo, extraídos automaticamente por algoritmos de processamento de imagens. Os atributos extraídos são chamados "vetores de características", e tanto podem formar vetores no sentido matemático do termo, quando as "características" são todas de um mesmo tipo numérico e medidas na mesma unidade - como é o caso dos histogramas de cor ou textura de imagens - quanto podem ser sequências mais gerais, envolvendo medidas diferentes 
para diferentes características ou com quantidade diferente de características entre elementos distintos do mesmo domínio - como é o caso das poligonais que descrevem formas nas imagens (Liu et al., 2007; Traina et al., 2010).

Com a emergência do suporte a dados multimídia em SGBD, os operadores de busca baseados em comparação por similaridade vêm despertando crescente interesse, principalmente para a recuperação por conteúdo. Um operador de busca por similaridade básico recupera os elementos que atendem a um determinado critério de similaridade, expresso com referência a um elemento do domínio de dados $s_{q} \in \mathbb{S}$, chamado "elemento central de consulta" (Hu and Lee, 2006). Em geral, são considerados dois critérios de seleção por similaridade fundamentais: os que expressam as consultas por abrangência (similarity range queries - $R q$ ) e os que expressam as consulta aos $k$-vizinhos mais próximos ( $k$-nearest neighbor queries - $k$-NNq) (Chakrabarti et al., 2004, Korn et al., 1996.

Para os operadores de consulta por similaridade serem aplicáveis a um determinado domínio de dados, é necessário que uma função de similaridade esteja definida nesse domínio, também chamada de função distância ou métrica. Uma função de distância quantifica quão similar dois elementos são, e habilita a representação de consultas baseadas na similaridade dos elementos. As funções de distância, que atendem as propriedades de simetria, não-negatividade e desigualdade triangular, associadas a um domínio de dados, criam o que se denomina de espaço métrico.

No entanto, a crescente capacidade de produzir dados pelas aplicações como centros de imagens médicas, sensores remotos em diversas estações meteorológicas, sistemas governamentais para transações de nota fiscal, aplicações em redes sociais, aplicações científicas, etc., desafiam tanto a eficiência quanto a eficácia das buscas realizadas nos SGBDs. Neste cenário, os operadores de similaridade tendem a perder sua expressividade, retornando não apenas respostas similares ao elemento central de consulta como também elementos que são similares entre si no conjunto de resposta. De fato, com o aumento da cardinalidade dos conjuntos é comum ter elementos similares a outros no conjunto de resposta nas consultas por similaridade. O problema de "elementos duplicados" é que eles não adicionam nova informação na resposta e, ao serem associados a quantidade de elementos no resultado, obrigam o usuário a uma análise manual de vários elementos, sendo uma tarefa tediosa. Outro problema relacionado a elementos duplicados, é a indução por parte do usuário de que muitos dos elementos na base de dados são iguais à resposta fornecida, o que resulta na reformulação e o ajuste das consultas com muita frequência, nem sempre de uma maneira intuitiva para o usuário (Chen and Li, 2007).

\subsection{Motivação e Objetivo}

Nas últimas décadas muitas pesquisas foram realizadas para tornar a execução das consultas por similaridade mais eficientes, por meio de estruturas de indexação (Skopal et al., 2009). Tais estruturas apresentam desempenho satisfatório em relação a grande quantidade de dados complexos disponível, possibilitando a mudança de foco das pesquisa para definir técnicas para melhorar a eficácia (qualidade) das respostas, evitando, por exemplo, elementos duplicados no conjunto de resposta. Para evitar que elementos duplicados façam parte do conjunto de resposta, as áreas de sistemas de recomendação (Agrawal et al., 2009; Santos et al., 2010; Ziegler et al., 2005), recuperação de informação (Dang and Croft, 2012; Gil-Costa et al., 2011; Mao et al., 2012; McCay-Peet and Toms, 2010; Qin et al., 2012; Santos et al., 2011; Toms, 2000; Zhang et al. 2002; Zheng et al., 2011) e máquinas de busca de páginas da web (Agrawal et al., 2009; Capannini et al., 2011; Dou et al., 2011; Van Leuken et al., 2009; Vee et al., 2008; Zhou et al., 2010) vem conduzindo estudos para inserção da propriedade de diversidade nos conjuntos de 
resposta, sob o título de "diversificação de resultado". O principal objetivo da diversificação de resultado é retornar elementos que sejam similares ao elemento central de consulta e, ao mesmo tempo, sejam diversos entre si, formando um conjunto de resposta mais heterogêneo.

A maioria das abordagens para diversificação de resultado utiliza informação externa aos dados, por exemplo, taxonomia de termos na busca por palavras-chave (Agrawal et al., 2009, Ziegler et al., 2005), estrutura espacial dos dados num espaço multidimensional (Vee et al., 2008), rótulos de classes em dados previamente classificados (Chen and Li, 2007; Van Leuken et al. 2009) e log de consultas e expectativa da maioria dos usuários nas buscas em páginas da web (Capannini et al., 2011). Nesses trabalhos, a qualidade dos resultados é dependente da disponibilidade de informação externa aos dados à priori, e mesmo quando estão disponíveis, possuem alto custo computacional para o processamento destas (Vieira et al., 2011).

Outra maneira de incluir a diversidade nas consultas é modelar o problema como um caso de otimização combinatória em que a similaridade e a diversidade competem entre si, resultando num problema cuja solução ótima tem complexidade computacional NP-Difícil (Agrawal et al. 2009). De modo geral, o processo de diversificação utiliza um conjunto de resposta inicialmente produzido por um algoritmo que utiliza apenas a similaridade ao elemento central de consulta como critério de busca. Posteriormente, os elementos são avaliados segundo a similaridade entre si, e os elementos muito similares são substituídos por outros não tão similares ao elemento central de consulta, mas que aumentam à diversidade em relação a outros elementos no conjunto de resposta. O equilíbrio entre a similaridade e a diversidade é controlado por um parâmetro de "preferência de diversidade", definido pelo usuário. No entanto, a definição de um valor para o parâmetro de diversidade e a escolha de quantos elementos devem fazer parte do conjunto inicial de similaridade para a diversificação de uma dada consulta, têm se mostrado difíceis e não intuitivos para o usuário (Angel and Koudas, 2011).

Visando contribuir para melhorar as respostas obtidas pelos operadores de busca pelos $k$-vizinhos mais próximos, o objetivo desta dissertação é definir um modelo de diversidade independente de parâmetros específicos para que o usuário possa obter o resultado desejado mais rapidamente às consultas por similaridade, em especial a consulta aos $k$-vizinhos mais próximos. Para alcançar o objetivo de permitir que as consultas por similaridade exibam um determinado grau de variedade, foi definido um modelo de diversidade independente de parâmetros específicos de diversidade para que seja aplicado em domínios de dados métricos, bem como um algoritmo e um método de avaliação para o modelo desenvolvido.

O objetivo desta dissertação é definir um modelo de diversidade independente de parâmetros específicos para que o usuário possa obter o resultado desejado mais rapidamente às consultas por similaridade, em especial a consulta aos $k$-vizinhos mais próximos. O modelo desenvolvido irá contribuir para melhorar as respostas obtidas pelos operadores de busca pelos $k$-vizinhos mais próximos. Neste sentido, foi definido um modelo de diversidade independente de parâmetros específicos de diversidade para que seja aplicado em domínios de dados métricos, bem como um algoritmo para busca aos $k$-vizinhos vizinhos mais próximos com variedade e um método de avaliação para a qualidade dos elementos inseridos no conjunto de resultados para o modelo de variedade desenvolvido.

\subsection{Organização do documento}

Além deste capítulo introdutório, esta dissertação é organizada em mais cinco capítulos:

Capítulo 2 - Conceitos Fundamentais. São apresentados conceitos básicos de consultas por similaridade, formalizando os tipos de consultas por similaridade: por abrangência e aos 
$k$-vizinhos mais próximos. Além disso, são apresentados os métodos de acesso métricos.

Capítulo 3 - Modelos de Diversidade. São apresentados os principais modelos de diversidade existentes na literatura.

Caítulo 4 - Variedade em Consultas por Similaridade. É apresentado o modelo de variedade desenvolvido nesta monografia, bem como o algoritmo e o método de avaliação.

Caítulo 5 - Experimentos. É apresentado o ambiente de testes utilizado para avaliação do algoritmo desenvolvido e descreve os resultados dos experimentos realizados, comparando os resultados obtidos com os modelos encontrados na literatura.

Caítulo 6 - Conclusões e Trabalhos Futuros. Encerra esta dissertação, apresentando as contribuições e as propostas de trabalhos futuros. 


\section{Capítulo 2}

\section{Conceitos Fundamentais}

\subsection{Considerações Iniciais}

Consultas por similaridade são operações importantes para aplicações em bases de dados que envolvem elementos complexos. Por definição, uma consulta por similaridade busca os elementos de um conjunto de dados que sejam similares a um elemento dado na consulta, baseando-se numa medida de comparação.

Este capítulo trata dos aspectos relacionados a consultas por similaridade em espaços métricos. Na Seção 2.2 apresenta as medidas de similaridade. A Seção 2.3 são apresentadas as principais consultas por similaridade. Na Seção 2.4. os métodos de indexação para dados no espaço métrico são apresentados e as conclusões são apresentadas na Seção 2.5 .

\subsection{Medidas de Similaridade}

Para que um sistema possa responder à consultas por similaridade e retornar os elementos que mais se assemelham a um dado elemento de consulta, é necessário quantificar o quão dissimilares são os elementos envolvidos nesta consulta. Para isso, uma função de distância $\delta_{\text {sim }}$ é definida para calcular a distância entre dois objetos e retornar um valor real positivo. Por convenção, adota-se que quanto mais similares dois elementos são entre si, menor o valor dessa função. Consequentemente, valores maiores são retornados para elementos muito distintos. A função $\delta_{\text {sim }}$ definida para o cálculo de dissimilaridade entre pares de elementos deve garantir algumas propriedades interessantes para permitir que técnicas de indexação possam ser usadas para agilizar as operações de busca por similaridade (Güld et al., 2007; Traina et al., 2009).

Como as operações de consulta em conjuntos de imagens geralmente são baseadas em similaridade, é interessante que os dados sejam representados em um espaço métrico. Assim, no lugar de propriedades baseadas em ROT, usam-se as propriedades dos espaços métricos para se construir as estruturas de dados que agilizem estas consultas (Venkateswaran et al., 2008; Zezula et al., 2006). Formalmente, um espaço métrico é definido conforme apresentado na Definição 1 .

Definição 1. Espaço métrico. Seja $\left\langle\mathbb{S}, \delta_{\text {sim }}>\right.$ uma par, onde $\mathbb{S}$ é o conjunto de todos os elementos que atendem aos requisitos do espaço (também chamado de domínio de dados), e 
$\delta_{\text {sim }}: \mathbb{S} \times \mathbb{S} \rightarrow \mathbb{R}^{+}$é uma função de distância, chamada também de métrica, que atende às três seguintes propriedades (Lima L. Elon, 1993):

- simetria: $\delta_{\text {sim }}\left(s_{1}, s_{2}\right)=\delta_{\text {sim }}\left(s_{2}, s_{1}\right)$;

- não-negatividade: $0<\delta_{\text {sim }}\left(s_{1}, s_{2}\right)<\infty$ se $s_{1} \neq s_{2} \operatorname{com} \delta_{\text {sim }}\left(s_{1}, s_{1}\right)=0$; e

- desigualdade triangular: $\delta_{\text {sim }}\left(s_{1}, s_{2}\right) \leq \delta_{\text {sim }}\left(s_{1}, s_{3}\right)+\delta_{\text {sim }}\left(s_{3}, s_{2}\right), \forall s_{1}, s_{2}, s_{3} \in \mathbb{S}$.

Em geral, as funções de distância $\delta_{\text {sim }}$ são definidas para aplicações específicas ou para domínios de aplicações. Por isso, uma função de distância é normalmente definida por um especialista da aplicação. Porém, a definição dessa função não se restringe a um tipo de consulta que possa ser necessária. Nessa seção, são apresentados exemplos de funções de distância relevantes que podem ser aplicadas a vários tipos de dados e que são importantes para os experimentos desenvolvidos neste projeto de Mestrado.

Contudo, antes de apresentar essas funções de distância, vamos diferenciá-las conforme o valor de retorno (contradomínio):

- função de distância discreta: o conjunto de valores de retorno da função é um conjunto relativamente pequeno de valores;

- função de distância contínua: o conjunto de valores de retorno da função é infinito ou um conjunto muito grande.

A função de distância de Levenshtein (descrita a seguir) aplicada em palavras de um dicionário é um exemplo de função de distância discreta, enquanto que a função de distância Euclidiana é um exemplo de função de distância contínua.

\subsubsection{Função de Distância de Levenshtein}

A função de distância de Levenshtein (Levenshtein, 1966), conhecida também como $L_{\text {edit }}$ ou distância de edição, é comumente utilizada para avaliar a similaridade entre duas cadeias de caracteres. A similaridade é calculada como o menor número de operações de edições elementares (inserções, remoções e substituições de caracteres) necessário para transformar uma cadeia de caracteres $c_{1}$ numa outra cadeia $c_{2}$. Uma generalização dessa métrica altera $o$ cálculo definindo custos diferentes (pesos) para cada tipo de operação de edição elementar e também permite definir custos diferentes para cada par de caracteres (Zezula et al., 2006).

Apesar dessa generalização alterar o resultado final do cálculo da função de distância, uma característica da função de distância de Levenshtein e de suas derivações é que o menor valor do cálculo é zero e no máximo, em muitas línguas e dicionários reais, dificilmente representa um valor grande, ou seja, a capacidade de discriminação oferecida pela função de distância tende a ser pequena. Por isto, esta função de distância é classificada como função de distância discreta.

\subsubsection{Funções de distância de Minkowski}

As funções de distância de Minkowski (Beyer et al., 1999), conhecidas como $L_{p}$, são empregadas em espaços multidimensionais. Deste modo, é possível utilizar distâncias geométricas da família $L_{p}$ para comparar dados de dimensão fixa. Suponha que $s_{1}=\left\{s_{1_{1}}, s_{1_{2}}, \ldots, s_{1_{E}}\right\}$ e $s_{2}=\left\{s_{2_{1}}, s_{2_{2}}, \ldots, s_{2_{E}}\right\}$ sejam dois elementos de um espaço multidimensional de dimensão $E$. A família de distâncias $L_{p}$ é definida como: 


$$
L_{p}\left(s_{1}, s_{2}\right)=\left(\sum_{i=1}^{E}\left|s_{1_{i}}-s_{2_{i}}\right|^{p}\right)^{1 / p}
$$

Os membros da família $L_{p}$ mais conhecidos:

- City-Block: $L_{1}\left(s_{1}, s_{2}\right)=\sum_{i=1}^{E}\left|s_{1_{i}}-s_{2_{i}}\right|$

- Euclidiana: $L_{2}\left(s_{1}, s_{2}\right)=\left(\sum_{i=1}^{E}\left|s_{1_{i}}-s_{2_{i}}\right|^{2}\right)^{1 / 2}$

- Chebychev: $L_{\infty}\left(s_{1}, s_{2}\right)=\max _{i=1}^{E}\left|s_{1_{i}}-s_{2_{i}}\right|$

A função de distância $L_{1}$, também conhecida como City-Block, corresponde ao somatório do módulo das diferenças entre as dimensões dos elementos. Nesse caso, o conjunto de pontos de mesma distância $\varepsilon$ de um centro forma um losango, como representado na Figura 2.1(a). A função de distância $L_{2}$, mais conhecida como distância Euclidiana, corresponde à função usual para distância entre vetores. $\mathrm{O}$ conjunto de pontos à mesma distância de um centro segundo a distância $L_{2}$ forma uma circunferência, conforme mostrado na Figura 2.1(b), Calculando-se o limite da Equação 2.1, quando $p$ tende ao infinito, obtém-se a função de distância $L_{\infty}$, também conhecida como Chebychev ou $L_{\text {infinity }}$, na qual o conjunto de pontos a distância de um centro forma um quadrado, como representado na Figura 2.1(c). A Figura 2.1(d) apresenta as formas geométricas em relação aos pontos equidistantes à distância $\varepsilon$ a partir do mesmo elemento central $s_{q}$ para esses três membros da família $L_{p}$.

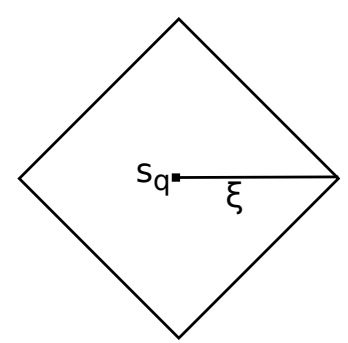

(a)

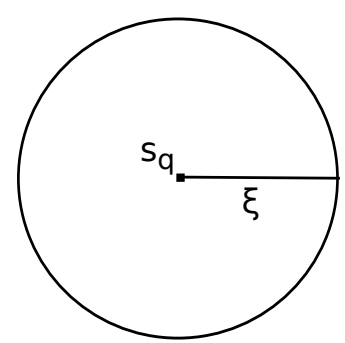

(b)

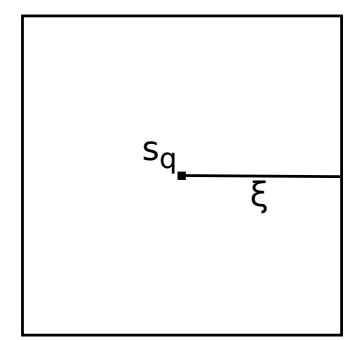

(c)

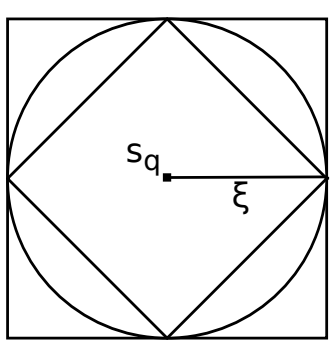

(d)

Figura 2.1: Representação das formas geométricas geradas para as funções de distância $L_{1}, L_{2}$ e $L_{\infty}$ para os pontos equidistantes à distância $\varepsilon$ a partir do elemento central $s_{q}$

\subsection{Consultas por Similaridade}

Da mesma maneira que as consultas baseadas em ROT, as consultas por similaridade são baseadas em critérios de comparação, chamados de critérios de similaridade. Um operador de busca por similaridade básico recupera os elementos que atendem a determinado critério de similaridade, expresso com referência a um elemento do domínio de dados $s_{q} \in \mathbb{S}$, chamado de "elemento central da consulta" (Hu and Lee, 2006). Em geral, existem dois critérios de seleção por similaridade fundamentais: os que expressam as consultas por abrangência e os que expressam as consultas aos $k$-vizinhos mais próximos (Chakrabarti et al., 2004; Korn et al., 1996; Zezula et al., 2006) . Além dos critérios fundamentais, existem outros tipos de consultas por similaridade, principalmente as junções por similaridade (Jacox and Samet, 2007; Thonangi et al., 2009; Xiao et al., 2009), as consultas por similaridade agregada (Deng et al., 2009, 
Papadias et al., 2004, Razente et al., 2008, Wu et al., 2000) e a consulta aos $k$-vizinhos mais próximos reversos (Korn and Muthukrishnan, 2000; Tao et al., 2006; Yao et al., 2009). A seguir, são apresentadas as consultas por abrangência e aos $k$-vizinhos mais próximos.

\subsubsection{Consulta por abrangência}

Uma consulta por abrangência $R q\left(s_{q}, \varepsilon_{q}\right)$ recebe como parâmetros o elemento central de consulta $s_{q}$ e um grau de dissimilaridade máximo $\varepsilon_{q}$, e recupera todos os elementos da base de dados que diferem do elemento central de consulta por, no máximo, a dissimilaridade indicada. A definição mais formal desta consulta é apresentada na Definição 2 .

Definição 2. Consulta por abrangência. Seja um subconjunto de dados $S=\left\{s_{1}, s_{2}, \ldots, s_{n}\right\}$ onde $S \in \mathbb{S}$ e uma função de distância $\delta_{\text {sim. }}$. Uma consulta por abrangência com o elemento de consulta $s_{q} \in \mathbb{S}$ e com uma dissimilaridade máxima $\varepsilon_{q}$ retorna:

$$
R q\left(s_{q}, \varepsilon_{q}\right)=\left\{s_{i} \mid s_{i} \in S, \delta_{s i m}\left(s_{i}, s_{q}\right) \leq \varepsilon_{q}\right\} .
$$

A Figura 2.2(a) mostra um exemplo de consulta por abrangência centrada no elemento $s_{q}$ com raio $\varepsilon_{q}$ num espaço bi-dimensional com função de distância Euclidiana. Um exemplo de consulta por abrangência em uma base de dados de imagens é "Selecione as imagens que difiram desta imagem $s_{q}$ dada por até 10 unidades", sendo que unidade de distância depende da maneira como a função de dissimilaridade foi definida.
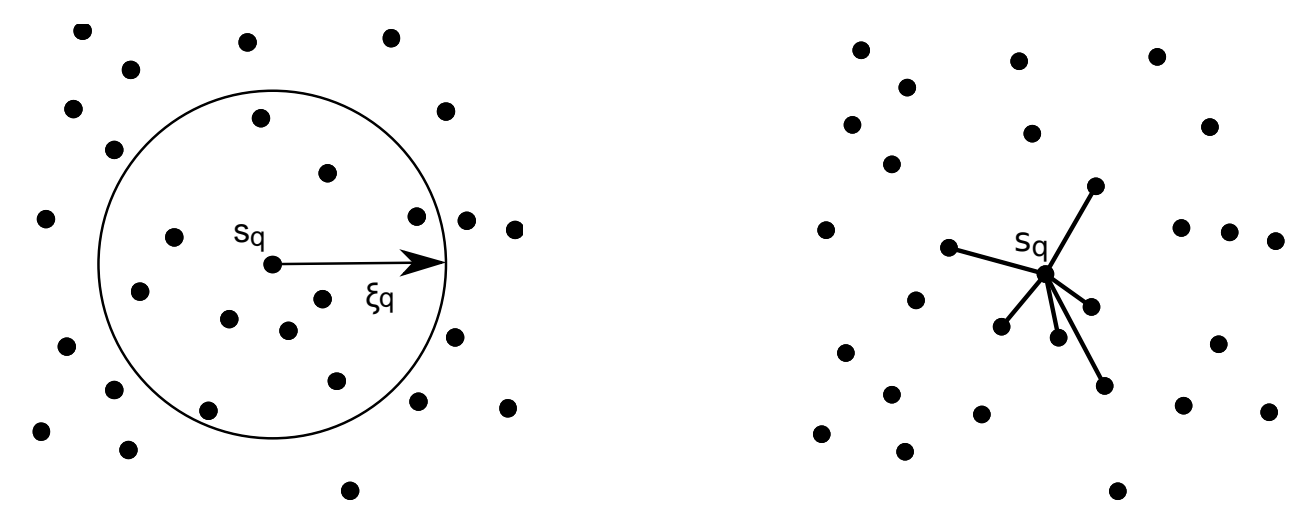

(a) Consulta por abrangência com grau de dissimilari- (b) Consulta aos $k$-vizinhos mais próximos com $k=7$ dade $\varepsilon_{q}$

Figura 2.2: Exemplo de consultas por similaridade sobre o elemento $s_{q}$ num espaço bi-dimensional Euclidiano. (a) Consulta por abrangência. (b) Consulta aos $k$-vizinhos mais proximos.

É importante notar que o elemento $s_{q}$ não precisa fazer parte da coleção de elementos que serão consultados, porém ele deve pertencer ao domínio métrico que define o conjunto de dados $\mathbb{S}$. Quando o grau de dissimilaridade de consulta $\varepsilon_{q}=0$, a consulta por abrangência é chamada de consulta pontual (point query), cujo objetivo é identificar se o elemento de consulta está armazenado na base de dados.

\subsubsection{Consulta aos $k$-vizinhos mais próximos}

Uma consulta aos $k$-vizinhos mais próximos $k-N N q\left(s_{q}, k\right)$ recebe como parâmetros o elemento central de consulta $s_{q}$ e uma quantidade $k$, retornando os $k$ elementos mais próximos 
do elemento central de consulta. A definição formal desta consulta é apresentada na Definição 3.

Definição 3. Consulta aos $k$-vizinhos mais próximos. Seja um subconjunto de dados $S=$ $\left\{s_{1}, s_{2}, \ldots, s_{n}\right\}$ onde $S \in \mathbb{S}$, e uma função de distância $\delta_{\text {sim }}$. Uma consulta aos $k$-vizinhos mais próximos com o elemento de consulta $s_{q} \in \mathbb{S}$ e um número de objetos a ser retornados igual a $k$ é dada por:

$$
k-N N q\left(s_{q}, k\right)=A=\left\{s_{j}\left|s_{j} \in S, \forall s_{i} \in S-A: \delta_{s i m}\left(s_{q}, s_{j}\right) \leq \delta_{s i m}\left(s_{q}, s_{i}\right),\right| A \mid=k\right\} .
$$

Um exemplo de consulta por vizinhos mais próximos em uma base de dados de imagens é "Selecione as 10 imagens mais similares a esta imagem $s_{q}$ dada”. A Figura 2.2(b) ilustra uma consulta aos $k$-vizinhos mais próximos em um domínio bi-dimensional empregando uma função de distância Euclidiana com número de elementos $k=7$.

\subsection{Método de Acesso Métrico}

Os métodos de acesso métricos (MAMs) são estruturas de dados especializadas para indexar dados em espaços métricos. O objetivo dessas estruturas é a redução do número de cálculos de distância e a redução do número de acessos a disco para a realização de consultas por similaridade, onde são exploradas propriedades métricas como a simetria e a desigualdade triangular para possibilitar acesso eficiente aos dados. Na literatura são encontradas diversas estruturas de indexação, como a VP-tree (Vantage Point tree) (Yianilos, 1993) e a MVP-tree (Multi-Vantage Point tree) (Bozkaya and Ozsoyoglu, 1997), que são MAMs que constróem a estrutura de indexação utilizando todo o conjunto de dados disponível numa única operação, e não permitem operações posteriores de inserção e remoção de elementos, sendo por isso denominados métodos estáticos. Outros métodos como a $M$-tree (Ciaccia et al., 1997) e Slim-tree (Traina et al., 2002), são exemplos de MAMs dinâmicos balanceados que dispõem da operação de inserção para uma estrutura já construída, porém não da operação de remoção de elementos, que é feita apenas marcando os elementos removidos, mas não os remove efetivamente. No entanto, em (Bueno et al., 2008) foi desenvolvida uma técnica para remoção definitiva dos elementos na Slim-tree. Uma revisão dos principais métodos pode ser encontrada em (Samet, 2005; Zezula et al., 2006).

\subsubsection{Slim-tree}

A Slim-tree é um MAM construído com a estratégia bottom-up, isto é, cresce a partir das folhas em direção à raiz. Ela agrupa os elementos em páginas de tamanho fixo, sendo que cada página corresponde a um nó da arvoré. Os elementos são armazenados nas folhas e as entradas dos nós internos definem a hierarquia de organização dos dados. Os nós folhas contém todos os elementos indexados, enquanto os nós internos replicam os elementos escolhidos como representantes. Cada entrada do nó folha contém o identificador do elemento, as informações do elemento para o cálculo de distância e a distância ao elemento representante, o qual está armazenado também no nó pai.

A Figura 2.3 (a) representa uma Slim-tree em um espaço bi-dimensional Euclidiano, onde os círculos brancos indicam os nós folha e os círculos cinzas os nós índice. Os pontos pretos indicam os elementos representantes $s_{\text {rep }}$ e cada nó da árvore possui um elemento representante 


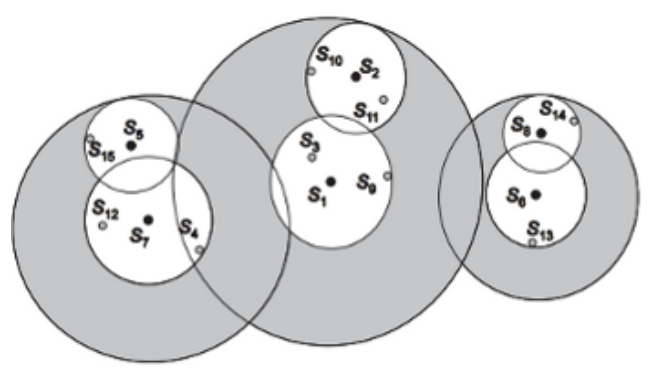

(a) Distribuição espacial.

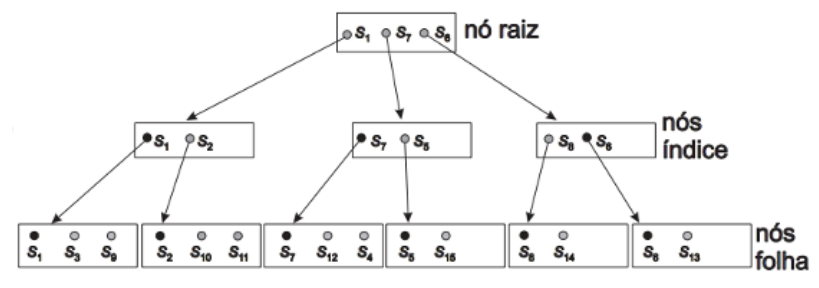

(b) Estrutura lógica.

Figura 2.3: Representação de uma Slim-tree com 15 elementos organizados em 3 níveis hierárquicos e com número máximo de elementos por nó igual a 3. (Razente, 2009)

e um raio de cobertura do nó. A Figura 2.3 (b) apresenta a estrutura lógica da árvore. A Slim-tree é o primeiro MAM dinâmico que possui recursos para a avaliação do grau de sobreposição entre seus nós (Fat-Factor) e um algoritmo para minimizar o problema de sobreposição, denominado Slim-down. Mais detalhes sobre o Fat-Factor e o slim-down podem ser encontrados em (Traina et al., 2002, 2000).

\subsection{Considerações Finais}

Este capítulo abordou sucintamente os conceitos fundamentais relacionados as consultas por similaridade e os métodos de acesso métricos. Um SGBD é o ambiente natural para a integração das diversas técnicas envolvidas para a realização de consultas por similaridade de imagens. Contudo, há necessidade do desenvolvimento de operadores mais expressivos para aumentar a relevância dos resultados incluindo, por exemplo, propriedades de diversidade para evitar que apenas a similaridade entre o elemento central de consulta e os elementos no conjunto de dados seja utilizada como referencia para resposta. No próximo capítulo serão apresentados os modelos e os conceitos envolvidos sobre diversidade em consultas por similaridade. 


\section{Capítulo 3}

\section{Modelos de Diversidade}

\subsection{Considerações Iniciais}

Uma consulta aos $k$-vizinhos mais próximos $k-N N q\left(s_{q}, k\right)$ recebe como parâmetros o elemento central de consulta $s_{q}$ e uma quantidade $k$, retornando os $k$ elementos mais próximos do elemento central de consulta. Assim, essa consulta leva em consideração apenas a relevância individual de cada elemento computado pela função de distância em relação ao elemento central de consulta. Porém, essa consulta não é capaz de considerar o relacionamento dos elementos entre si, o que possibilita a presença de elementos bastante similares no conjunto de resposta. $\mathrm{O}$ problema de respostas similares entre si é que torna necessária a análise de vários elementos por parte do usuário que tende a perder o interesse em elementos que são retornados repetidamente (Ziegler et al., 2005). Nesse cenário, é importante possibilitar que às respostas as consultas por similaridade apresentem diversidade entre os elementos de resposta, com objetivo de aumentar a relevância das respostas e diminuir o custo de análise por parte do usuário.

Este capítulo apresenta os modelos de diversidade encontrados na literatura, com enfâse nos modelos aplicados aos espaços métricos. Na Seção 3.2 é apresentado o conceito de diversidade. $\mathrm{Na}$ Seção 3.3 são apresentas técnicas encontradas na literatura para inclusão de diversidade nas consultas aos vizinhos mais próximos. Por fim, são apresentadas as conclusões na Seção 3.4 .

\subsection{O conceito de Diversidade}

O estudo da propriedade de diversidade nas consultas aos vizinhos mais próximos vem sendo realizado ultimamente pelas áreas de sistemas de recomendação (Agrawal et al., 2009, Santos et al., 2010; Ziegler et al., 2005), recuperação de informação (Dang and Croft, 2012; Gil-Costa et al., 2011; Mao et al., 2012; McCay-Peet and Toms, 2010; Qin et al., 2012; Santos et al., 2011; Toms, 2000; Zhang et al., 2002; Zheng et al., 2011) e máquinas de busca de páginas da web (Agrawal et al., 2009; Capannini et al., 2011; Dou et al., 2011; Van Leuken et al., 2009; Vee et al., 2008; Zhou et al., 2010) sob o título de diversificação de resultado. Para essas áreas, a diversidade é utilizada para tornar mais relevantes as recomendações feitas aos usuários em sites de consulta de viagem, restaurantes, filmes e em sites de conteúdo social (Yu et al., 2009). 


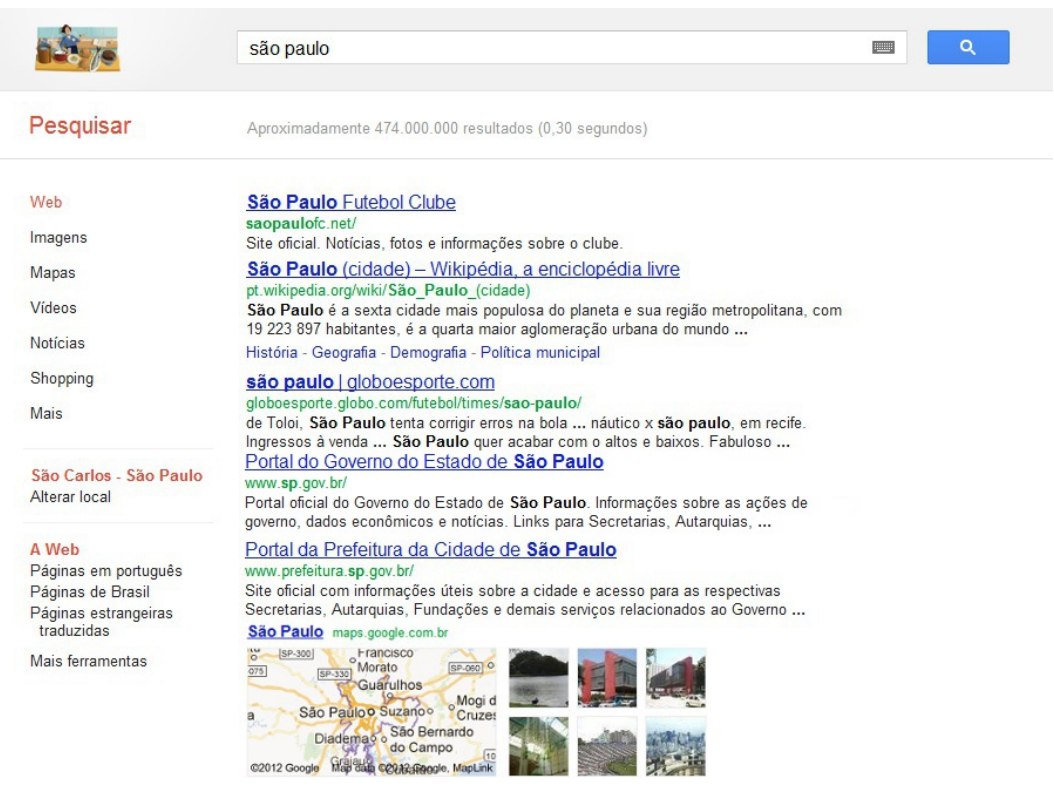

Figura 3.1: Consulta à palavra-chave "São Paulo" em uma máquina de busca da web, resultou em links para os sites (time de futebol, prefeitura, governo do estado) e imagens com diversidade entre os atributos de texto relacionados com as imagens (estádio, mapa da cidade, pontos turistícos). Consulta realizada em 15/08/2012.

A propriedade diversidade tem por objetivo recuperar o conjunto de elementos mais próximo ao elemento central de consulta e, ao mesmo tempo, diversos entre si (Vieira et al., 2011).

A Figura 3.1 representa um exemplo já clássico na literatura à busca de páginas na internet utilizando palavras-chave. É fácil observar que a busca pela palavra-chave "São Paulo" possui resultados mais interessantes quando há referências sobre a cidade, o estado, o time, o porta-aviões, o santo, etc. No exemplo, a diversidade apresentada possibilita explorar os diversos significados que a palavra-chave possui, por exemplo, a palavra-chave pode referenciar tanto o time de futebol quanto a cidade ou o estado. Nesse cenário, o usuário pode refinar a busca, caso o interesse específico seja em apenas pelo time de futebol, por exemplo.

A computação da diversidade para a consulta aos vizinhos mais próximos pode ser dada de várias maneiras. Na Seção 3.3 serão apresentadas estratégias para diversificação de resultados.

\subsection{Estratégias para Diversificação de Resultados}

Na literatura existem dois grupos de estratégias para a diversificação de resultados, a baseada em atributos e a beaseada apenas na computação de distância entre os elementos. A estratégia mais conhecida e utilizada é a baseada em atributos (Attribute-based)(McNee et al., 2006), que consiste em comparar o quanto cada valor do atributo que compõe a descrição dos dados difere de outros no conjunto de resposta. A seguir, apresentaremos alguns modelos de diversidade baseados nessa estratégia.

\subsubsection{Diversidade Baseada em Atributo}

A abordagem proposta em Ziegler et al. (2005) adiciona diversificação entre os elementos nas listas de recomendação por meio de uma métrica de similaridade. A idéia é reorganizar as listas utilizando um fator de diversificação $\left(\Theta_{F}\right)$ para definir qual é o grau de dissimilaridade 
que deve ser empregado na resposta final. Utilizando a métrica proposta em Ziegler et al. (2004) é possível aumentar ou diminuir a diversidade dos seus elementos de acordo com a taxonomia de classificação dos atributos (mostrada na Figura 3.2). Contudo, apesar de sua proposta ter perdido a precisão média dos resultados, foi demonstrado experimentalmente que os usuários preferiam listas de recomendação mais diversificadas do que listas muito precisas, o que evidencia que ao se tratar da satisfação do usuário nem sempre as respostas mais precisas são as melhores.

De forma similar, Agrawal et al. (2009) propõe comparar documentos de acordo com sua taxonomia. Porém, isto é feito para resolver o conflito de consultas com palavras-chave ambíguas (por exemplo, Jaguar, Windows) que fazem parte de mais de uma categoria. Esse trabalho considera tanto a relevância dos documentos retornados quanto a diversificação da resposta, diferentemente de Ziegler et al. (2005) que não considera a importância das diferentes categorias para um mesmo termo. O objetivo da estratégia de Agrawal et al. (2009) é maximizar a probabilidade do usuário encontrar pelo menos um resultado interessante em uma resposta final com $k$ elementos, utilizando uma função sub-modular para evitar o gasto de tempo computacional para incluir novos elementos em categorias que já pertencem ao conjunto de resposta, o que possibilita a procura de documentos em outras categorias que ainda não foram analisadas.

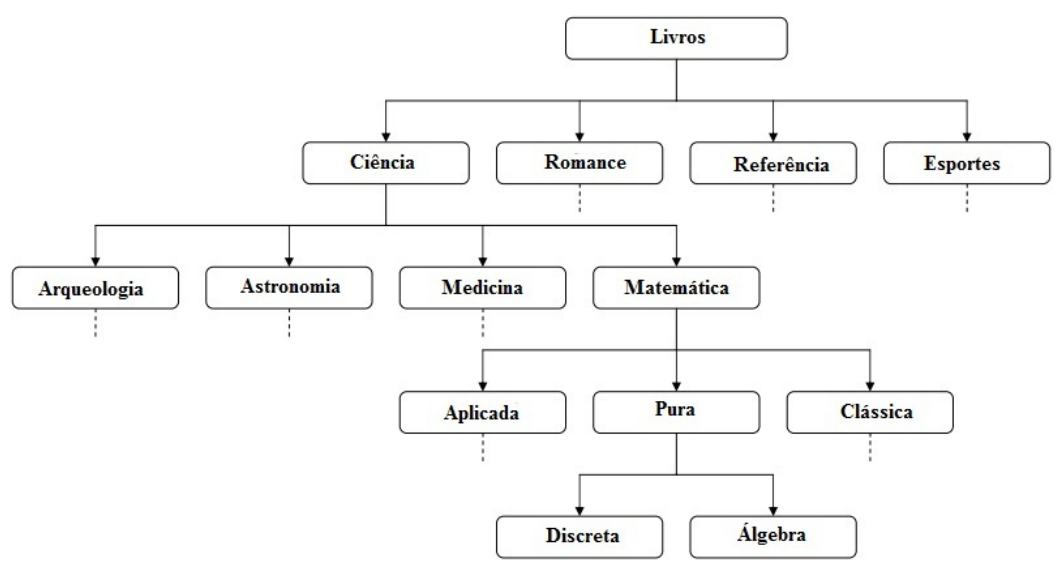

Figura 3.2: Exemplo de taxonomia de livros utilizada no site Amazon.com. Imagem adaptada de (Ziegler et al., 2004).

Em Vee et al. (2008), a proposta de diversificação é realizada usando dados estruturados. A idéia foi utilizar uma lista de índices invertidos contendo os identificadores dos itens de pesquisa para criar uma hierarquia de diversidade para os elementos. Por exemplo, considere um banco de dados que armazena informações sobre marca, modelo, cor e ano de produção de automóveis. Dada uma consulta sobre modelos de automóveis, pode-se diversificar primeiro pela marca, depois pelo modelo, cor e ano de produção. A idéia de diversificação é em relação à frequência com que os elementos aparecem na base de dados. Embora a diversidade esteja presente em seus experimentos, sua abordagem fica restrita à ordem dos elementos estruturados com relacionamentos bem definidos.

Em seus estudos, Van Leuken et al. (2009), tratou da diversidade em consultas ambíguas no contexto de recuperação de imagens na web. A estratégia foi diversificar os resultados em relação às características visuais do conjunto de respostas recuperadas textualmente. Para isso, são formados agrupamentos (clusters) de acordo com as características visuais (cor, forma e textura) e um representante do agrupamento é escolhido para ser exibido ao usuário. A Figura 
3.3 ilustra os agrupamentos formados por uma consulta pelo termo ambíguo "jaguar", que pode ser, por exemplo, um modelo de carro, um mamífero todo preto ou um mamífero com pelagem de tigre. Foi detectado tanto o aspecto ambíguo do ponto de vista semântico (carro, mamífero) quanto do ponto de vista das características visuais.

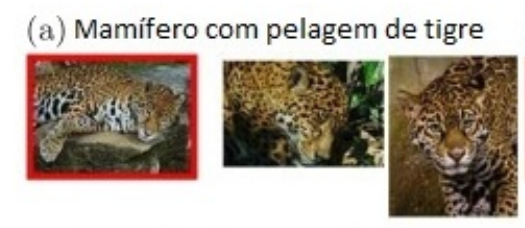

(c) Animal preso em jaula
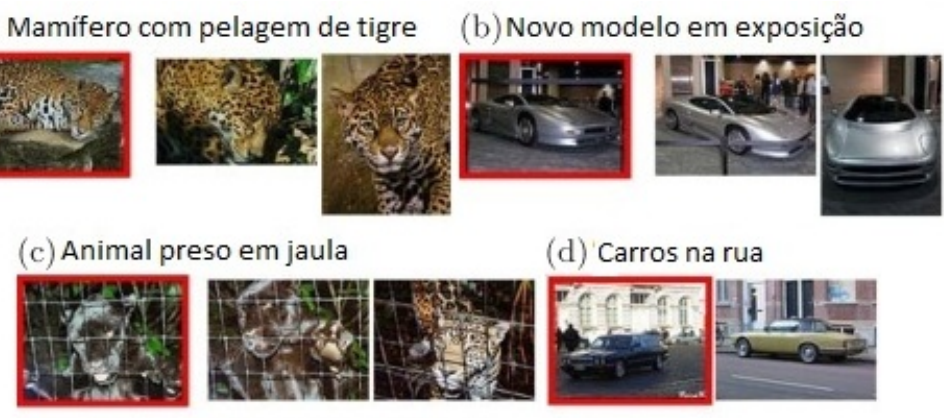

(d) Carros na rua
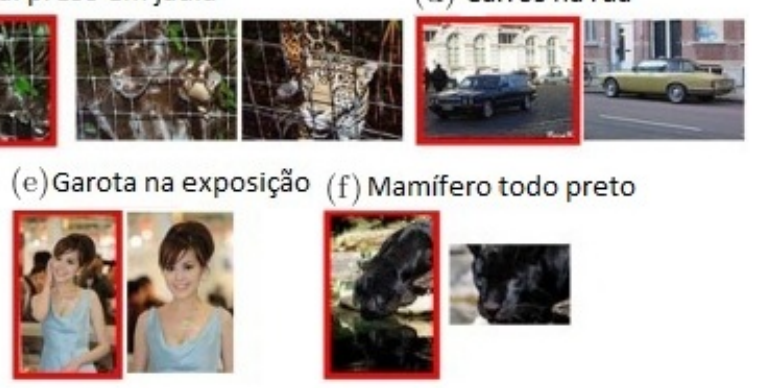

Figura 3.3: Exemplo de agrupamentos formados para a consulta pelo termo ambíguo "jaguar". Os representantes dos agrupamentos estão marcados em vermelho. $\mathrm{O}$ algoritmo proposto diferenciou fotos de carros em exposição e identificou uma garota na exposição. A imagem com borda vermelha identifica o elemento mais relevante do agrupamento. Imagem adaptada de (Van Leuken et al., 2009).

Em Chen and Li (2007), a estratégia de agrupamentos foi utilizada para visualizar os resultados de consultas $S Q L$ - Structured Query Language - e capturar a percepção das diversas preferências do usuário. Foi apresentado que o usuário geralmente não consegue formular adequadamente consultas para responder exatamente a seus interesses. Ao invés disso, ele utiliza uma consulta com uma condição generalizada e realiza posteriormente várias outras para refinar seus interesses até chegar a resposta desejada. Desse modo, para incluir as preferências do usuário, foi proposto um método pós-processado para inferir as preferências do usuário baseando-se no histórico de suas consultas. A diversidade nesse método ocorre do seguinte modo: primeiro, de maneira offline, é utilizado o histórico de consulta para construir um conjunto de agrupamentos não sobrepostos com todos os tipos de preferências do usuário, onde cada um representa uma preferência de usuário associada com a probabilidade dos usuários estarem interessados nesse aglomerado; segundo, para apresentar o resultado da consulta, é utilizada uma árvore de navegação contendo todos os agrupamentos para tal consulta, permitindo ao usuário escolher qual agrupamento mais se aproxima da sua resposta. A idéia proposta por Chen and Li (2007), não é selecionar os agrupamentos mais importantes para o usuário, mas sim apresentar ao usuário as diferenças entre os agrupamentos.

Em Dou et al.(2011) é apresentada uma visão multidimensional para análise da cobertura de subtemas para consultas na web. É discutido que uma consulta pode possuir termos ambíguos (como, por exemplo, eclipse, Defender, Jaguar, tênis) em diversos níveis e que apenas a utilização de uma única dimensão, fonte de dados, não consegue fornecer toda informação necessária para cobertura dos subtemas de interesse do usuário. Além disso, Dou et al. (2011) constatou de maneira similar a Chen and Li (2007) que o usuário precisa realizar várias consultas para explicitar qual o tópico que mais se aproxima das suas necessidades de informação. 
No entanto, Chen and Li (2007) adotou a solução baseada em agrupamentos para melhorar a apresentação dos resultados aos usuário, enquanto que Dou et al. (2011) adota abordagem de realizar a mineração de dados em diferentes fontes de dados, com o intuito de que cada base forneça um aspecto diferente em relação a ambiguidade do termo da consulta. Assim, se uma consulta é realizada com o termo "defender"; ela pode referenciar ao modelo de carro fabricado pela montadora Land Rover ou ao jogo clássico para o video game ATARI ou ao software produzido pela Microsoft que fornece proteção a spywares (anti-vírus), dentre outras ocorrências para o termo. Se o usuário está interessado no software desenvolvido pela Microsoft, é possível resolver a ambiguidade anteriormente apresentada, mas ainda existem vários subtemas relacionados ao anti-vírus como, por exemplo, a página oficial do anti-vírus, o repositório para download, fóruns de discussão para iniciantes e resolução de problemas relacionados ao software.

Desse modo, Dou et al. (2011) utilizou quatro dimensões para seus experimentos, sendo elas: o texto âncora (anchor text) é útil no caso de um novo usuário no sistema ou para uma nova consulta solicitada, pois normalmente eles indicam de forma significativa o documento de destino; o log de consulta, fornece a visão real das requisições dos usuários ao final do conjunto de buscas realizadas para um termo específico; o agrupamento (clusters) funciona de forma similar a solução proposta por Chen and Li (2007) e, ao invés de diversificar os elementos na lista, os resultados são agrupados e permitem ao usuário navegar nos grupos que mais se aproximam da sua real intenção da consulta dos resultados e por fim os sites de pesquisa fornecem uma visão sobre a funcionalidade que se procura com a informação como, por exemplo, wikipédia. Os resultados de pesquisa são geralmente bons quando a tarefa é buscar informação, pois serão relacionados vários termos resultando numa maior riqueza de informação. Assim, usando múltiplas dimensões é possível resolver a diversidade por meio de pedaços de informação, sendo que cada fonte de dado apresenta uma perspectiva sobre o tema buscado.

Apesar da abordagem de diversidade baseada em atributo ter apresentado bons resultados para área de recomendação e sistema de recuperação na $w e b$, ela depende que o atributo possua um valor significativo ou que os dados estejam organizados hierquicamente de acordo com uma taxonomia. Além disso, ao se trabalhar com dados complexos (imagem, vídeo e som) em espaços métricos, torna-se difícil utilizar a estratégia baseada em atributo devido ao fato da descrição dos atributos possuírem baixo nível de significado individual (Deserno et al., 2009: et al., 2008), sendo mais interessante, trabalhar com a diversidade utilizando apenas o conceito de similaridade entre os elementos.

\subsubsection{Diversidade Baseada na Computação de Distância Entre os Elementos}

Para a diversificação de resultados com dados complexos (imagem, vídeo e som) em espaços métricos, é preciso definir a propriedade de diversidade de maneira que não seja necessária a utilização dos valores dos atributos pois, como foi dito anteriormente, não se pode contar com valores de atributos com significados compreensíveis no espaço métrico.

Dessa maneira, a diversidade precisa ser modelada utilizando apenas os próprios elementos de dados e a distância entre eles. Uma proposta precursora da literatura na junção dos conceitos de similaridade e diversidade é encontrada em Carbonell and Goldstein (1998). Essa associação foi chamada de marginal relevance (importância marginal) e consiste na combinação linear entre similaridade e diversidade. Um elemento recuperado possui maior marginal relevance, 
se for tão similar ao elemento de consulta quanto dissimilar aos elementos anteriormente selecionados.

O problema foi formalizado do seguinte modo. Seja $S=\left\{s_{1}, s_{2}, \ldots, s_{n}\right\}$ um conjunto de dados com $n$ elementos, $s_{q}$ o elemento central de consulta e $k(k \leq n)$ um inteiro que representa a quantidade de elementos no conjunto de resposta. A medida de similaridade é representada pela função de distância $\left(\delta_{\text {sim }}\right)$ que considera o quanto os elementos são similares em relação ao elemento central de consulta; assim, quanto maior a similaridade entre os elementos, maior o valor atribuído. A medida de diversidade é considerada por meio da função de distância $\left(\delta_{d i v}\right)$ que considera a diversidade entre os elementos no conjunto de resposta. Assim, o problema de diversificação se resume em definir um conjunto de resposta $R \subseteq S$ com tamanho $|R|=k$ em que cada elemento em $R$ é tanto similar a $s_{q}$ com relação a $\delta_{\text {sim }}$, quanto, diversos em relação aos outros elementos em $R$ com relação a $\delta_{d i v}$, maximizando a função objetivo de diversificação (apresentada na Equação 3.1).

$$
\operatorname{MMR}\left(s_{i}\right)=(1-\lambda) \delta_{\text {sim }}\left(s_{i}, s_{q}\right)+2 \lambda \sum_{r_{j} \in R} \delta_{d i v}\left(s_{i}, r_{j}\right) .
$$

A Equação 3.1 é uma função objetivo de critério duplo, ou seja, busca-se maximizar, tanto a similaridade dos elementos do conjunto de resposta $R$ em relação ao elemento central de consulta $s_{q}$ quanto maximizar a dissimilaridade entre os elementos já pertencentes a $R$. O parâmetro de preferência de diversidade $(\lambda)$ representa o limiar de compromisso entre a similaridade e a diversidade no intervalo $[0,1]$. Para valores de $\lambda=0$, o problema é resumido em encontrar os $k$-vizinhos mais próximos, porém para $\lambda>0$, o problema é NP-Difícil (Agrawal et al. 2009). Em Drosou and Pitoura (2010) é discutido que o usuário tende a preferir respostas que apresentem contribuição de diversidade $\operatorname{com} \lambda>0.4 \mathrm{em}$ relação as respostas em que apenas a similaridade é considerada. Porém, para valores próximos de $\lambda=1 \mathrm{o}$ interesse do usuário tende a diminuir.

A formulação desse problema é denominada problema da diversidade máxima (Maximum Diversity Problem - MDP). Esse problema consiste em selecionar um conjunto ótimo de $k$ elementos diversos entre si de um conjunto de dados. Tipicamente, o processo de diversificação utiliza a resposta inicial retornada por um algoritmo que utiliza apenas similaridade como critério de busca, onde os elementos são os mais similares em relação ao elemento central de consulta $s_{q}$, e posteriormente realiza a permuta dos elementos por outros não tão próximos de $s_{q}$, mas que, ao mesmo tempo, são mais diversos em relação uns aos outros.

Desse modo, a estratégia amplamente utilizada consiste em utilizar algoritmos gulosos com construção incremental para encontrar respostas determinísticas (Vieira et al., 2011). Por exemplo, o método Maximal Marginal Relevance (MMR) (Carbonell and Goldstein, 1998) (Algoritmo 3.1) inicialmente constrói o conjunto de diversidade pela escolha do elemento com maior similaridade para ser inserido no conjunto de resposta $R$ independente do valor de $\lambda$; posteriormente, de forma incremental, são selecionados elementos que maximizem a Equação 3.1 de acordo com os elementos que já foram inseridos na resposta. No entanto, a qualidade dos resultados é definida pela escolha do primeiro elemento e como esse método escolhe sempre o mais similar ao elemento central de consulta $s_{q}$, para valores mais próximos de $\lambda=1 \mathrm{a}$ qualidade é bem inferior quando comparado a outros métodos da literatura (Vieira et al., 2011).

A proposta definida por Jain et al. (2004) implementa o conceito de diversidade nas consultas aos $k$-vizinhos mais próximos em espaços multidimensionais. Dada uma variável MinDiv que define um limiar para a diversidade esperada no conjunto de resposta, uma função booleana é utilizada para filtrar os elementos da resposta. Se um elemento possui diversidade maior que o limiar definido, então ele é adicionado ao conjunto de diversidade. Apesar dessa 


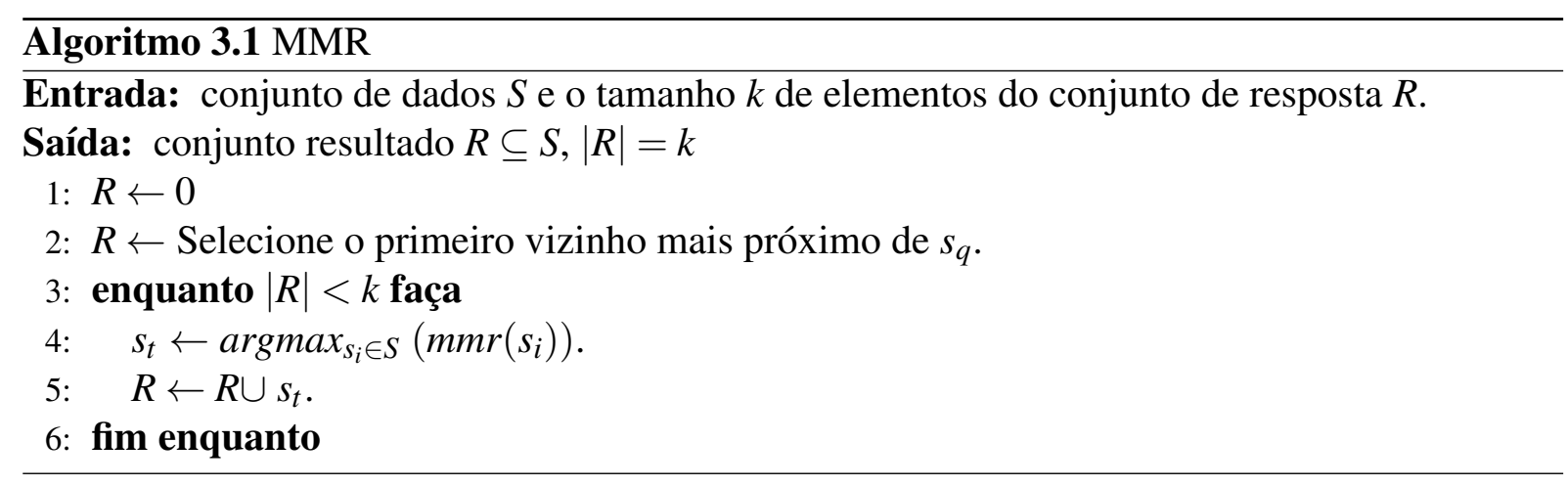

estratégia incluir um grau de diversidade nas consultas $k-N N q$, ela não utiliza a função objetivo para maximizar a diversidade como em Carbonell and Goldstein (1998), mas apenas para formar conjuntos de similaridade com valor de diversidade superior ao MinDiv. Da mesma maneira que o MMR (Carbonell and Goldstein, 1998), o algoritmo Motley (Algoritmo 3.2) proposto por Jain et al. (2004) tem a qualidade do seus resultados limitada a escolha do primeiro elemento do conjunto de respostas, pois depois da inserção do primeiro elemento a escolha dos próximos elementos é feita buscando manter a MinDiv superior ao valor definido pelo usuário.

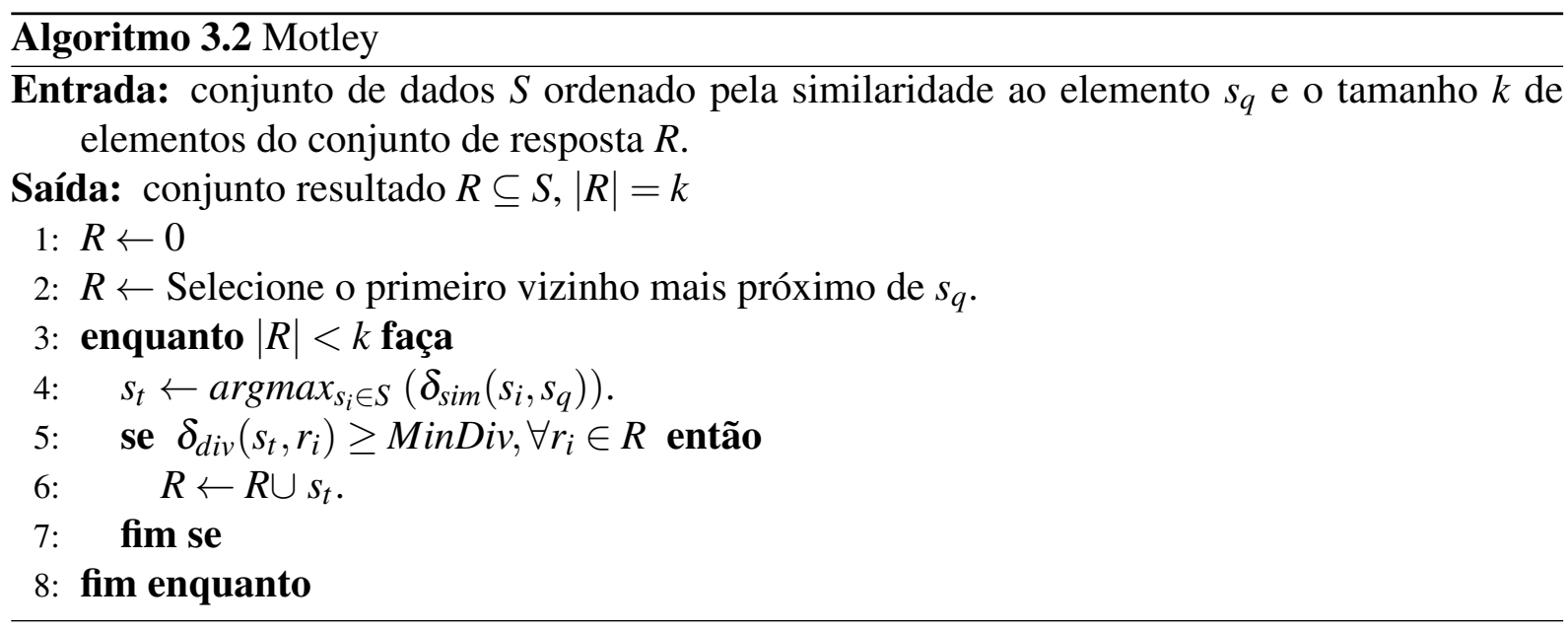

Em Gollapudi and Sharma (2009) é apresentada uma plataforma axiomática, definindo 8 axiomas (invariância escalar, consistência, riqueza, estabilidade, independência de atributos irrelevantes, monotonicidade, força da relevância e força da similaridade) que os sistemas de diversificação de resultados deveriam satisfazer e um teorema em que mostra que nenhuma função objetivo é capaz de satisfazer a todos os axiomas simultaneamente. Além disso, são apresentadas três funções objetivo de diversificação de critério duplo, max-sum diversification, max-min diversification e mono-objective, bem como um algoritmo guloso com construção incremental chamado MSD (Max-Sum Dispersion). O algoritmo MSD (Algoritmo 3.3) constrói o conjunto de resposta $R$ incrementalmente pela escolha de pares de elementos que sejam tanto similares ao elemento central de consulta $s_{q}$ quanto diversos entre si. Assim, em cada iteração são escolhidos dois elementos do conjunto de dados $s_{i}, s_{j} \in S$ que maximizem a função objetivo (Equação 3.2). De acordo com essa equação, é necessário a análise par a par de elementos; caso seja escolhido um valor de $k$ ímpar, o método escolhe aleatoriamente qualquer elemento em $S$ como parte da resposta, na última iteração. Além disso, o problema considera a diversidade entre os pares de elementos no momento de escolha destes, porém não verifica se a inserção do novo par de elementos não resulta na promixidade dos pares de elementos anteriormente escolhidos. 


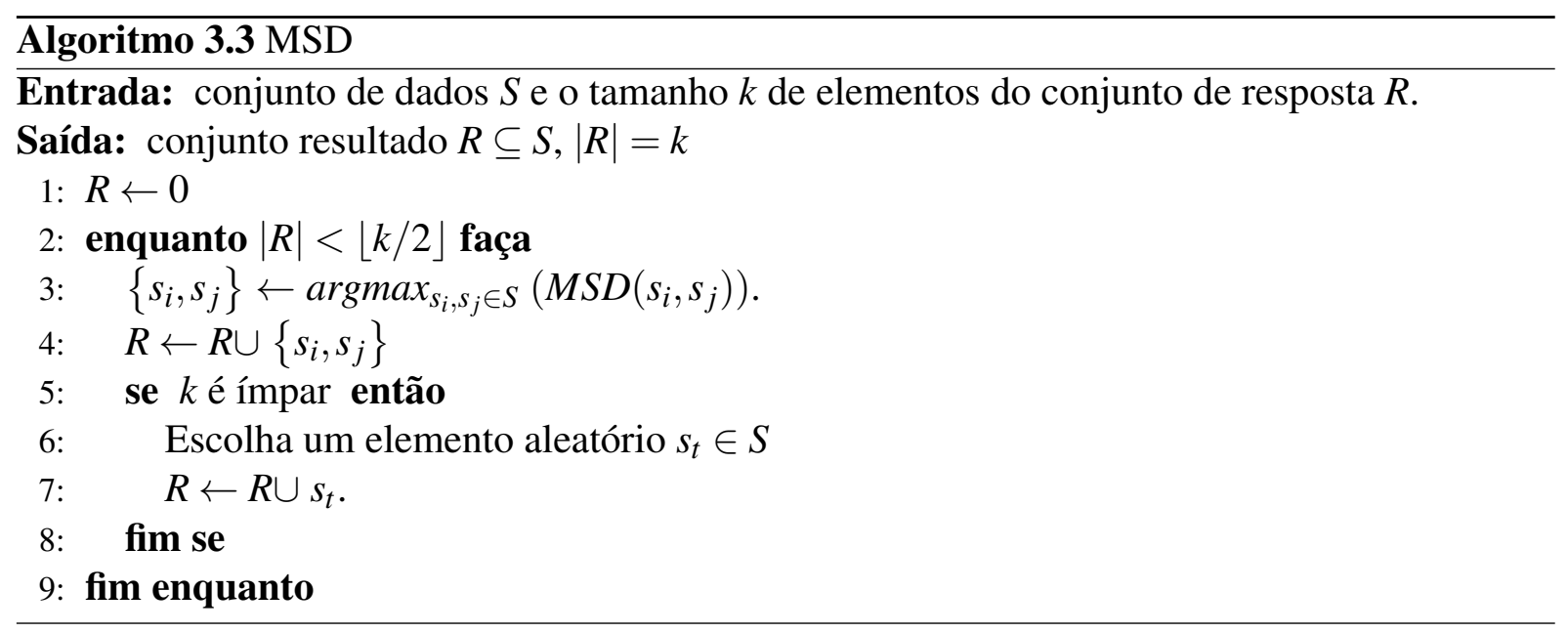

$$
\operatorname{MSD}\left(s_{i}, s_{j}\right)=(1-\lambda)\left(\delta_{s i m}\left(s_{q}, s_{i}\right)+\delta_{s i m}\left(s_{q}, s_{j}\right)\right)+2 \lambda \delta_{d i v}\left(s_{i}, s_{j}\right)
$$

Em Vieira et al. (2011) é apresentada uma plataforma de avaliação dos algoritmos propostos por Gollapudi and Sharma (2009); Jain et al. (2004); Yu et al. (2009) e apresenta os métodos GMC (Greedy Marginal Contribution) e GNE (Greedy Randomized with Neighborhood Expansion). A função objetivo (Equação 3.3) definida é muito similar a definida por Gollapudi and Sharma (2009), evitando-se apenas a comparação por pares de elementos.

$$
F\left(s_{q}, R\right)=(k-1)(1-\lambda) \cdot \operatorname{sim}\left(s_{q}, R\right)+2 \lambda \cdot \operatorname{div}(R) .
$$

A principal diferença entre o GMC e os algoritmos Motley, MSD, MMR, que constróem o resultado de forma incremental, é a função de avaliação de contribuição para o conjunto de resposta, chamada de maximum marginal contribution - mmc (Equação 3.4). O mmc considera tanto a contribuição do elemento $s_{i} \in S$ para a função objetivo $F$, utilizando a similaridade do elemento $s_{i}$ em relação ao elemento $s_{q}\left(\delta_{\text {sim }}\right)$, os elementos já inseridos na resposta $R_{p-1}\left(\delta_{d i v}\right)$ e os elementos que não foram inseridos no conjunto de resposta $s_{j} \in S-s_{i}\left(\delta_{d i v}^{l}\right)$.

$$
m m c\left(s_{i}\right)=(1-\lambda) \cdot \delta_{s i m}\left(s_{i}, s_{q}\right)+2 \lambda \sum_{s_{j} \in R_{p-1}} \delta_{d i v}\left(s_{i}, s_{j}\right)+2 \lambda \sum_{l=1}^{l \leq k-p} \delta_{d i v}^{l}\left(s_{i}, s_{j}\right) .
$$

Em relação a diferença entre os algoritmos GNE e GMC, o primeiro utiliza uma adaptação da meta-heurística GRASP - Greedy Randomized Adaptive Search Procedure (Feo, 1995; Resende, 2009), escolhendo de forma aleatória os elementos que mais contribuem para resposta. O GNE (Algoritmo 3.4) é dividido em duas etapas, a de construção e de busca local. A etapa de construção da solução consiste em selecionar um conjunto parcial de forma iterativa. Como podem existir muitos candidatos, é utilizada uma lista de tamanho fixo $k$, denominada de lista restrita de candidatos (Restricted Candidate List - RCL). Desse modo, são escolhidos os $k$ elementos do conjunto parcial de acordo com a contribuição associada a sua inclusão na solução parcial por meio de uma função de avaliação gulosa (greedy), Equação 3.4 . A partir da $R C L$, são escolhidos elementos de forma aleatória para compor uma solução inicial que será explorada pela fase de busca local. Portanto, a etapa de busca local, é uma tentativa de melhoria da solução obtida na fase de construção. Nesta etapa, percorre-se a vizinhança da solução corrente buscando uma solução de melhor qualidade. Se não existir uma melhor solução na vizinhança, a solução corrente é considerada um ótimo local e a busca é encerrada. 


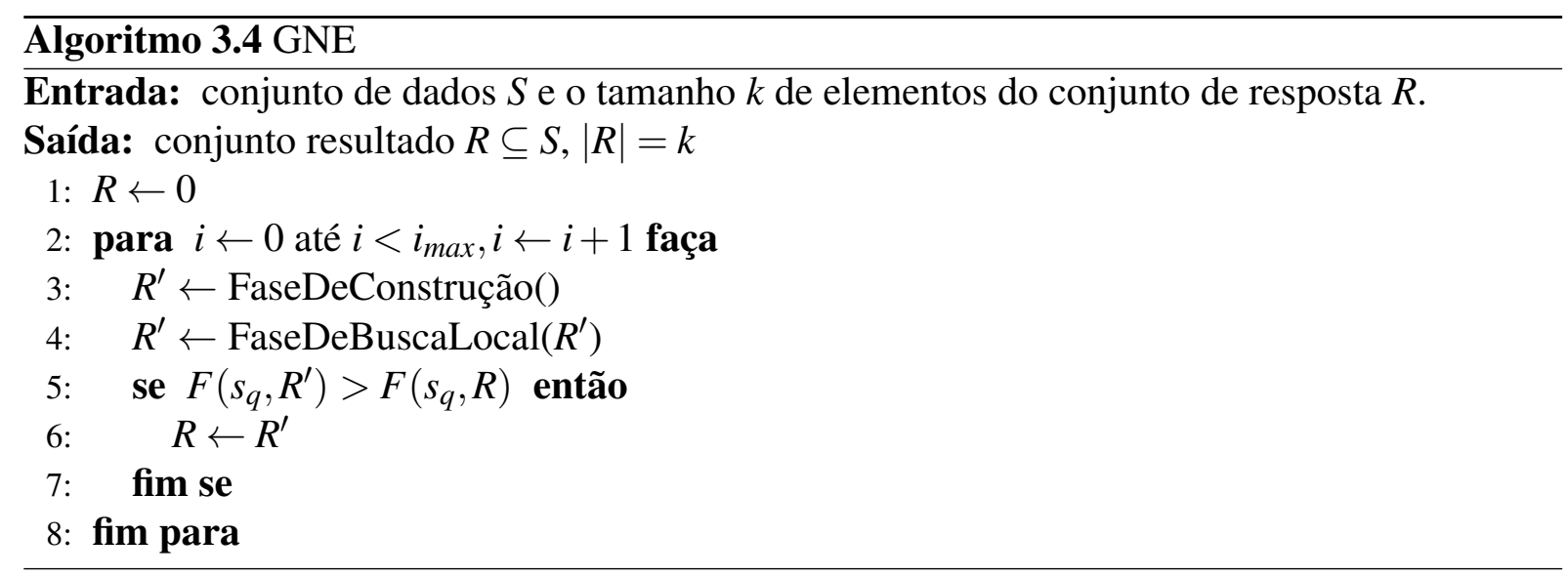

O algoritmo GMC (Algoritmo 3.5) possui os mesmos passos que o algoritmo MMR, sempre escolhendo o elemento com maior contribuição para resposta. Porém, tanto o GMC quanto o GNE utilizam o $m m c$ como função de avaliação de contribuição para escolher os elementos que farão parte do conjunto de resposta.
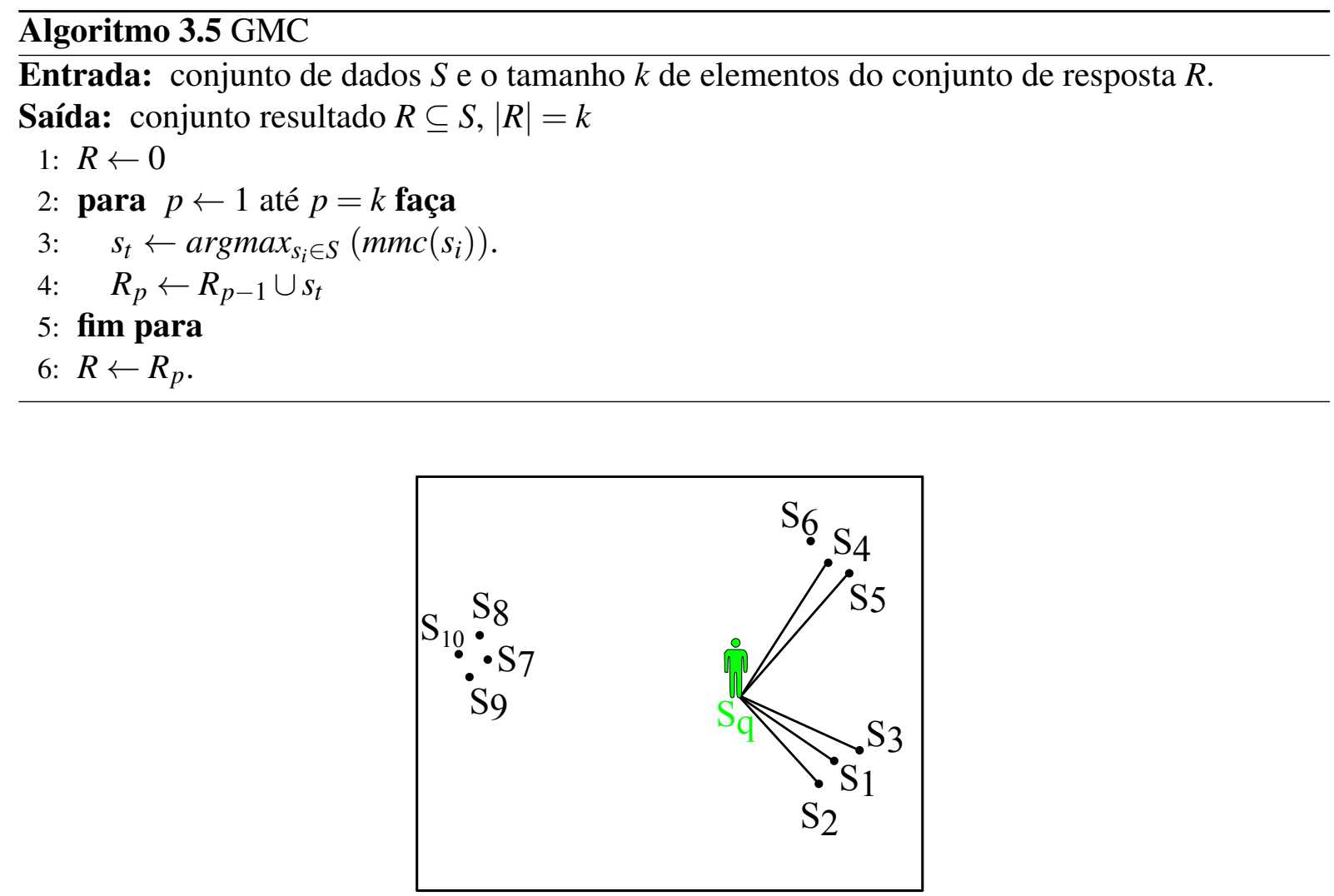

Figura 3.4: Conjunto de resposta com elementos muito similares para a consulta aos 5-vizinhos mais próximos. Os elementos $s_{2}$ e $s_{3}$ consideram o $s_{1}$ mais similar que o elemento $s_{q}$, porém essa informação não é utilizada para formar o conjunto de resposta.

Para ilustrar como a diversidade é inserida como um problema de otimização, considere um conjunto de dados $S=\left\{s_{1}, s_{2}, s_{3}, \cdots, s_{10}\right\}$. A Figura 3.4 apresenta esse conjunto num espaço Euclidiano bi-dimensional. Dada uma consulta aos 5-vizinhos mais próximos ao elemento $s_{q}$, os elementos $\left\{s_{1}, s_{2}, s_{3}, s_{4}, s_{5}\right\}$ representam a resposta. No entanto, os elementos $s_{2}$ e $s_{3}$ estão muito próximos do elemento $s_{1}$. O mesmo ocorre com o elemento $s_{5}$ em relação ao 


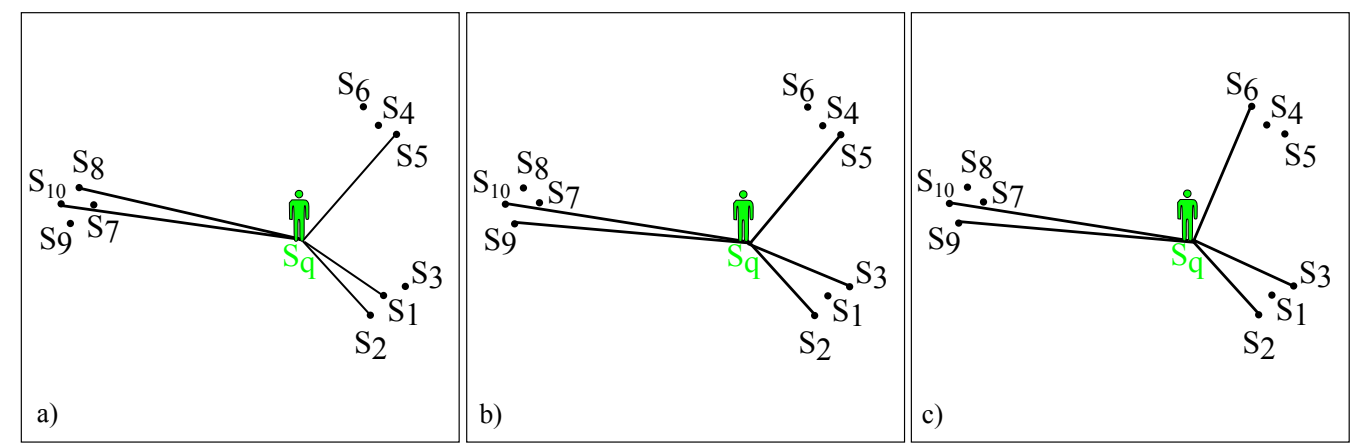

Figura 3.5: Conjunto de resposta com elementos muito similares para a consulta aos 5-vizinhos diversos mais próximos, solução ótima. (a) Preferência de diversidade $=0.3$. (b) Preferência de diversidade $=0.5$. (c) A partir da preferência de diversidade $=0.6$ a função objetivo alcança o maior valor e não há mais variação no conjunto de resposta.

elemento $s_{4}$. Porém, se considerarmos a consulta aos 5-vizinhos diversos mais próximos, com preferência de diversidade igual a $30 \%(\lambda=0.3)$ no conjunto de resposta, a Figura 3.5 (a) apresenta o resultado utilizando a Equação 3.3. É possível perceber, que os elementos $s_{3}$ e $s_{4}$ foram trocados por elementos mais distantes aos elementos $s_{1}, s_{2}$ e $s_{5}$. As Figuras 3.5 (b) e (c), apresentam os resultados para a mesma consulta com preferência de diversidade igual a $50 \%$ e $70 \%$, respectivamente.

Nesse exemplo, é possível perceber que mesmo o usuário aumentando a preferência por diversidade, houve uma troca dos elementos similares entre si quando comparamos a resposta dos 5-vizinhos mais próximos com os 5-vizinhos diversos. No primeiro, os elementos eram todos similares ao elemento central de consulta $s_{q}$. Enquanto, no último os elementos são similares a outro elemento do conjunto de resposta que maximiza a função objetivo. Em outras palavras, visualmente não há 5 elementos que sejam totalmente diversos entre si, existem apenas 3 elementos $\left\{s_{2}, s_{6}, s_{10}\right\}$ que definem a maior distância entre pares de elementos. Com o aumento do valor de $k$ os elementos tendem a se aproximar novamente, e as pequenas distâncias entre os elementos são "ocultadas".

O problema na inserção dos elementos $\left\{s_{3}, s_{9}\right\}$ no conjunto de resposta é que esses elementos são tão similares aos elementos $\left\{s_{2}, s_{10}\right\}$ que possivelmente não acrescentam novo valor a resposta. Vamos considerar essa situação num conjunto de imagens, a inserção de imagens similares a outra no conjunto de resposta forma o que chamamos de "abismo de diversidade", que corresponde a grupos de imagens similares entre si que se diferem ao serem relacionadas a outros grupos de imagens na resposta. A Figura 3.6 apresenta uma intuição de distribuição dos elementos no conjunto de resposta para uma consulta as 20 imagens diversas mais próximas, ilustrando o abismo de diversidade. A proximidade das imagens na Figura 3.6 foi definida utilizando a distância entre os elementos. O algoritmo utilizado foi o GNE (Vieira et al. (2011) e foi considerado um subconjunto com 2000 imagens mais próximas ao elemento central de consulta e a preferência de diversidade foi definida como $\lambda=0.5$.

Embora, a diversidade tem sido modelada como uma propriedade dinâmica definida pelo usuário $(\lambda)$, extrínseca aos dados, formando um problema de otimização, ela não resolve completamente o problema de diversidade pois ainda é possível ter elementos similares entre si no conjunto de resposta. Além disso, definir a preferência de diversidade é uma tarefa difícil de ser ajustada sem o conhecimento do conjunto de dados. Essas limitações motivaram o desenvolvimento do trabalho apresentado nesta dissertação.

Em Radlinski et al. (2009), é apresentado que a diversidade pode ser definida como uma 


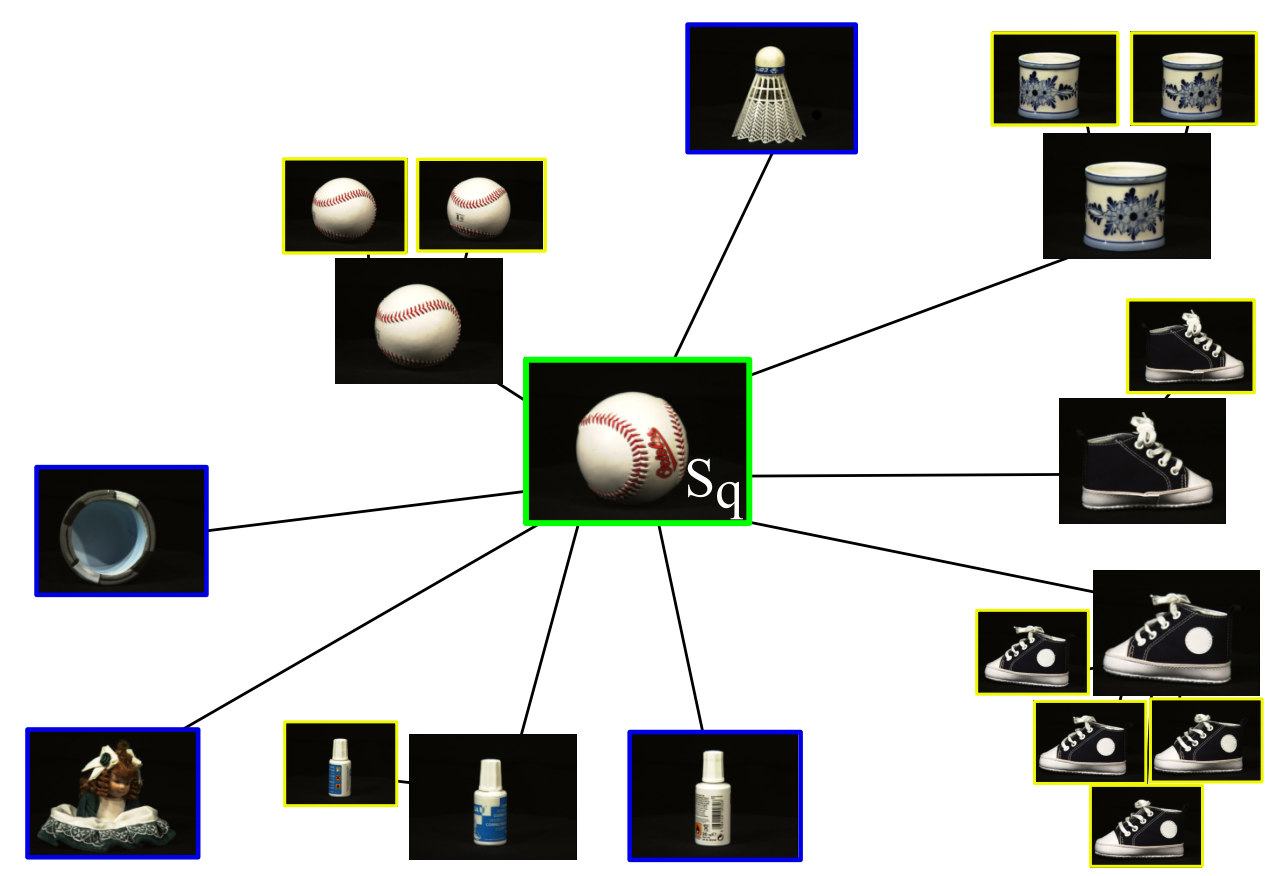

Figura 3.6: Conjunto de resposta com elementos similares para a consulta aos 20-vizinhos diversos mais próximos ilustrando o abismo de diversidade. A imagem com borda verde representa o elemento central de consulta. As imagens com bordas amarelas apresentam similaridade a um elemento do conjunto de resposta. As imagens com bordas azuis representam os elementos do conjunto de resposta que não possuem imagens similares.

propriedade inerente aos dados que serão apresentados, intríseca aos dados, sendo preciso evitar a redundância dos dados no conjunto de resposta. Vamos apresentar a seguir um trabalho relacionado a essa visão, o objetivo final é encontrar um conjunto de elementos distintos entre si. Nós consideramos esse trabalho devido a sua similaridade ao modelo desenvolvido nesta monografia.

\subsubsection{Diversidade Baseada na Distância de Separação}

Em Skopal et al. (2009) é apresentado o problema dos $k$-vizinhos distintos mais próximos. O problema consiste em recuperar os $k$ elementos distintos por uma "distância de separação" $(\Phi)$ definida pelo usuário. A motivação desse trabalho é permitir que a consulta aos $k$-vizinhos mais próximos seja mais robusta a conjuntos de dados de imagens em que a cardinalidade é tão grande que existem várias imagens consideradas quase duplicadas entre si. Desse modo, deve-se evitar escolher elementos que sejam similares entre si, possibilitando o usuário navegar em grandes conjuntos de dados de imagem.

Foram definidos dois algoritmos, o First-Match (FM) e o Centroid-Match (CM). O algoritmo $F M$ constrói o resultado incrementalmente selecionando os elementos similares ao elemento central de consulta, e a cada iteração, é verificado se a distância entre os elementos é maior que a distância de separação definida pelo usuário, como pode ser visto na Figura 3.7 . $\mathrm{O}$ algoritmo $C M$ processa o conjunto do mesmo modo, porém o elemento inserido no conjunto de resposta é o elemento centróide dos elementos considerados similares entre si. No entanto, o custo do cálculo do centróide torna o $C M$ menos eficiente que o $F M$.

Inicialmente pode parecer intuitivo permitir o usuário definir o valor da distância de separação. Porém, solicitar ao usuário valores que são dependentes da cardinalidade e distribuição 


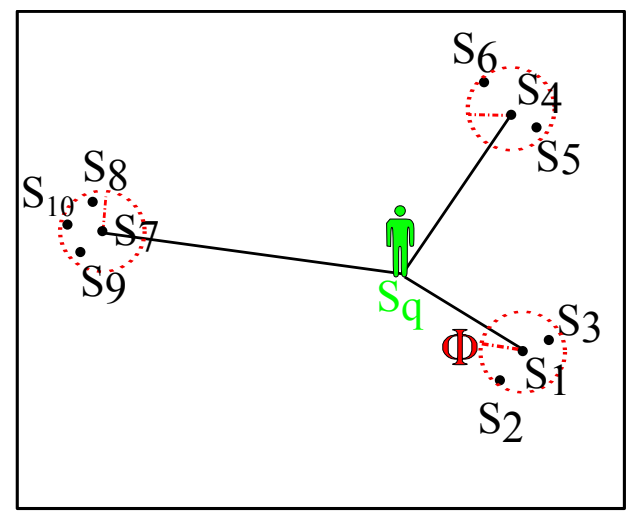

Figura 3.7: Conjunto de resposta para a consulta aos 5-vizinhos distintos mais próximos com exclusão por uma distância de separação. O conjunto possui apenas 3 elementos que são distintos entre si e ao elemento central de consulta $s_{q}$ pela distância $\Phi$.

dos dados pode possibilitar encontrar respostas não desejadas, forçando o usuário submeter a consulta várias vezes. Por exemplo, caso a distância de separação seja definida com um valor pequeno, nenhum elemento é eliminado no conjunto de resposta, tendo o comportamento da consulta aos $k$-vizinhos mais próximos tradicional. O oposto também é um problema, pois a escolha de valores muito grandes possibilita que um elemento exclua todo o conjunto de dados. Sendo então, difícil otimizar esse parâmetro para uma consulta.

\subsection{Considerações Finais}

Neste capítulo foram apresentados os modelos de diversidade para aumentar a relevância das respostas as consultas aos $k$-vizinhos mais próximos. A principal motivação desses modelos é reduzir o esforço empregado pelo usuário na busca pela informação desejada. O conceito de diversidade permite evitar que itens muito similares entre si sejam retornados, possibilidando ao usuário ter uma visão abrangente do conjunto de dados.

Verificou-se que o conceito de diversidade já foi amplamente explorado quando se trata de atributos que possuem valor semântico, por exemplo, palavras-chave. Plataformas de avaliação, como a definida por Vieira et al. (2011), possibilitam a comparação dos métodos encontrados na literatura para diversificação de resultado utilizando apenas os elementos e as distâncias entre esses. Contudo, os modelos que consideram a diversidade como um problema de otimização combinatória, requerem informações que dependem do conhecimento do conjunto de dados.

Assim, ao invés de definir a diversidade como a combinação linear da similaridade e da diversidade, definiu-se a diversidade como uma propriedade intríseca aos dados, não sendo necessário definir um parâmetro de equilíbrio entre essas duas medidas ou qualquer outra específica para diversificação.

No próximo capítulo, é apresentado o modelo de diversidade em espaços métricos que não requisita nenhuma informação ao usuário, chamado de variedade. 


\section{Capítulo 4}

\section{Variedade em Consultas por Similaridade}

\subsection{Considerações Iniciais}

Para atender às necessidades de recuperação de dados multimídia em SGBDs, os operadores de busca baseados em comparação por similaridade (veja Seção 2.3 p vêm despertando interesse crescente, principalmente para comparar dados complexos. No entanto, com o rápido crescimento da cardinalidade dos dados armazenados em banco de dados, os operadores de similaridade tendem a retornar respostas não só similares para o elemento central de consulta, mas também similares entre os próprios elementos constituintes do conjunto de resposta. Por exemplo, imagens de um mesmo exame de tomografia computadorizada, fotografias de um mesmo objeto em diferentes momentos com pequenas alterações na iluminação ou translação, etc. Essa alta similaridade entre os elementos da resposta acaba por não agregar valor a resposta, principalmente, por obrigar o usuário à analisar, na resposta obtida, muito mais dados do que o necessário, em um processo cansativo, até que a resposta desejada seja obtida. Desse modo, durante a fase exploratória de uma consulta complexa, o usuário pode não interessar-se exatamente pelas imagens mais próximas, mas as imagens que também atendam a um critério de diversidade nas respostas.

Um critério clássico na literatura para alcançar a diversificação de resultado é a modelagem de um problema de otimização combinatória em que a similaridade e diversidade competem entre si, como foi descrito no Capítulo 3 . Assim, a diversidade atua como uma propriedade externa aos dados, dependente da definição do usuário. Porém, a definição de parâmetros por parte do usuário para uma dada consulta é difícil e muita das vezes não intuitiva.

Neste capítulo é descrito o modelo de variedade desenvolvido nesta monografia. Esse modelo de variedade consiste em inserir diversidade nas consultas por similaridade utilizando apenas propriedades básicas do espaço métrico, resultando num modelo de diversidade que apresenta as seguintes propriedades:

- Independente de parâmetros - não requer nenhum parâmetro para ser configurado, assim ele pode ser usado pelo sistema de maneira completamente transparente ao usuário;

- independente de domínio - depende apenas que o conjunto de dados a ser pesquisado atenda às propriedades de um espaço métrico, assim ele pode ser aplicado a qualquer conjunto de dados para o qual tenha sido definida uma métrica; 
- independente de operação de busca - baseia-se num novo conceito (a que chamamos "variedade") que é definido sobre o conceito de similaridade, portanto ele se aplica a qualquer operação de busca que venha a ser usada para recuperar dados por similaridade.

Para completar e permitir a implementação do conceito de variedade, foram definidos um algoritmo incremental chamado Better Results With Adaptative Diversification (BRAD) e um método de avaliação do nível de variedade da resposta também aplicável aos resultados de qualquer operador de busca por similaridade.

Tais conceitos estão organizados do seguinte modo: A Seção 4.2 formaliza este modelo de variedade. A Seção 4.3 apresenta o algoritmo BRAD e a Seção 4.4 apresenta o método de avaliação de variedade. Finalmente, a Seção 4.5 que apresenta as considerações finais.

\subsection{Modelo de Variedade}

A variedade tem sido definida na literatura como uma propriedade externa aos dados, dependente da apreciação do usuário, atuando como ferramenta para re-ordenar os resultados para possibilitar uma visão heterôgenea dos dados. No entanto, a diversidade pode ser interpretada como uma propriedade inerente aos dados, fazendo parte do problema de busca por elementos similares. Considere como exemplo o caso de busca aos $k$-vizinhos mais próximos. Inicialmente, o usuário tem interesse em buscar os $k$ elementos mais similares ao padrão que ele conhece do conjunto (elemento central de consulta). Porém, quando os elementos similares ao elemento central de consulta tendem também a ser similares entre si, o usuário necessita analisar vários elementos o que torna a tarefa cansativa, pois em casos reais os conjuntos de dados podem possuir de centenas a milhares de elementos .

Assim, se for admitido que existe uma distância mínima entre pares de elementos que os leva a serem considerados similares entre si, pode-se inferir que esses elementos são tão similares que contribuem de maneira equivalente para a resposta da consulta, não sendo necessário a presença de todos. Desse modo, apenas um deles poderia representar a todos. Partindo dessa suposição é razoável assumir também que se pode utilizar cada elemento $r_{i} \in R$ retornado como similar ao elemento central de consulta $s_{q}$ e uma "distância de similaridade" $\xi_{p}$ para induzir um conjunto de elementos que são mais similares a $r_{i}$ do que ao elemento central de consulta. Isto é, é possível definir a diversidade no problema de busca por elementos similares ao permitir que cada elemento no conjunto resposta participe do processo de busca informando quais são os elementos que são mais similares a ele até uma distância $\xi_{p}$.

Contudo, a diversidade continua dependente da definição de uma distância de similaridade. Para tornar a diversidade independente de parâmetros, é necessário que a distância de similaridade mínima seja relativa à distância dos elementos de resposta ao elemento central de consulta $s_{q}$, tornando a diversidade adaptativa. Em outras palavras, a diversidade se torna incremental e relativa aos elementos inseridos no conjunto de resposta $R$ e, para cada elemento $r_{i} \in R$, é analisado quais elementos possuem similaridade menor ou igual a distância $\delta_{\text {sim }}\left(r_{i}, s_{q}\right)$ em $S$ para serem descartados como candidatos a resposta.

Para ilustrar uma consulta com distância de similaridade váriavel, considere um conjunto de dados $S$ com elemento central de consulta $s_{q}$. Considere que $\xi_{p}$ seja uma distância de similaridade qualquer tal que os elementos mais distantes do que $\xi_{p}$ de $s_{q}$, porém próximos uns dos outros são considerados similares entre si. Considere também que $s_{p}$ é o elemento mais próximo de $s_{q}$ no conjunto $S$. Portanto, $s_{p}$ é dito ser o elemento dominante para a distância de similaridade $\xi_{p}$, e esse elemento "domina" todos os elementos em $s_{i} \in S$ com distância menor que $\xi_{p}$ ao elemento $s_{p}$, ou seja, todos os elementos são considerados muito similares a 
este elemento. Assumindo que as consultas que são submetidas sobre $S$ estão imersas no espaço métrico cuja a função de distância $\delta_{\text {sim }}$ é válida, as Definições 4, 5, 6 expressam esses conceitos.

Definição 4. Elementos similares em relação a uma distância de similaridade mínima: Dado um elemento central de consulta $s_{q}$ e uma distância de similaridade qualquer $\xi_{p}$, então todos os elementos $s_{i} \in S$ tal que $\delta_{\text {sim }}\left(s_{i}, s_{q}\right)<\xi_{p}$ são então admitidos como similares para a consulta centrada em $s_{q}$ em relação à distância de similaridade $\xi_{p}$ para todos os outros elementos $s_{j} \in S$ tal que $\delta_{\text {sim }}\left(s_{i}, s_{j}\right) \leq \xi_{p}$.

Definição 5. Elemento dominante para uma distância de similaridade: Seja dado um elemento central de consulta $s_{q}$, e uma distância de similaridade qualquer $\xi_{p}$, e seja $s_{p} u m$ elemento não similar em $S$ para a distância de similaridade $\xi_{p}$ tal que não exista outro elemento $s_{j}$ em $S$ tal que $\delta_{\text {sim }}\left(s_{j}, s_{q}\right)<\delta_{\text {sim }}\left(s_{p}, s_{q}\right)$. Então, $s_{p}$ é dito ser um elemento dominante para uma consulta posicionada pelo elemento $s_{q}$ utilizando a distância de similaridade $\xi_{p}$.

Definição 6. Conjunto de similaridade ( $\dot{S})$ induzido por um elemento dominante: Dado um elemento central de consulta $s_{q}$ e um elemento dominante $s_{p}$, o conjunto de similaridade $\tilde{S}$ induzido por $s_{p}$ em $s_{q}$ é definido como:

$$
\tilde{S}\left(s_{p}, s_{q}\right)=\left\{s_{i} \in S \mid\left(\delta_{\text {sim }}\left(s_{i}, s_{p}\right) \leq \delta_{\text {sim }}\left(s_{p}, s_{q}\right)\right) \wedge\left(\delta_{\text {sim }}\left(s_{i}, s_{p}\right) \leq \delta_{\text {sim }}\left(s_{i}, s_{q}\right)\right)\right\}
$$

A Definição 4 afirma que dada uma distância de similaridade $\xi_{p}$, qualquer par de elementos que possua distância menor que essa distância $\xi_{p}$ ao elemento central da consulta é considerado muito similar entre si, ou seja, é verificado quais elementos são similares numa dada vizinhança, reduzindo o conjunto de candidatos.

A Definição 5 afirma que a distância do elemento dominante é a mínima entre todos os elementos que estão distantes do elemento central de consulta por um raio de similaridade $\xi_{p}$ e que não seja ele próprio dominado por outro elemento dominante com raio menor do que sua distância ao elemento central da consulta. Assim, se não há empate entre dois elementos, então é equivalente afirmar que $s_{p}$ é o elemento dominante mais próximo do elemento de consulta que não é considerado similar ao $s_{q}$. Dessa maneira, se um elemento dominante $s_{p}$ está presente no conjunto de resposta $R$, então nenhum dos elementos que são dominados por $s_{p}$ podem fazer parte da resposta à consulta.

A Figura 4.1 ilustra a idéia do conjunto de similaridade induzido por um elemento dominante $s_{p}$ tal como colocado na Definição6. Os pontos definidos na figura são os elementos que estão mais próximos de $s_{q}$ do que do elemento dominante $s_{p}$, sendo esses similares a $s_{q}$. Os quadrados ao redor do elemento dominante $s_{p}$, limitados pela distância $\xi_{p}$ inferido pela distância $\delta_{\text {sim }}\left(s_{p}, s_{q}\right)$, definem o conjunto de similaridade induzido $(\tilde{\mathrm{S}})$ por esse dominante. Portanto, com o elemento dominante $s_{p}$ fazendo parte da resposta, apenas os elementos definidos como triângulos podem ser escolhidos como candidatos a elementos dominantes da resposta.

A Definição 6 possibilita definir o problema de diversificação de resultado como um caso especial da busca de similaridade em espaços métricos genéricos. O problema de diversificação de resultado pode ser descrito como um conjunto $R \subseteq S$ para qualquer critério de similaridade (tanto a busca por abrangência quanto a busca pelos $k$-vizinhos mais próximos), no qual cada elemento $r_{i} \in R$ é similar ao elemento central de consulta $s_{q}$, porém não é similar por um raio de similaridade $\xi_{p}$ ao elemento $s_{q}$ e não é dominado por nenhum outro conjunto de similaridade induzido por outro elemento dominante em $R$. Assim, a Definição 6 generaliza o conceito $\tilde{\mathrm{S}}$ de diversificação para qualquer busca por similaridade no espaço métrico. O modelo apresentado 


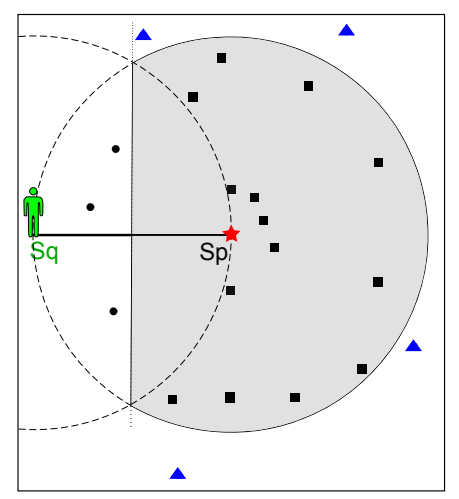

Figura 4.1: O conjunto de similaridade induzido pelo elemento dominante $s_{p}$. Os pontos representam os elementos que estão mais próximos de $s_{q}$ do que $s_{p}$. Os quadrados representam os elementos que fazem parte do conjunto de similaridade induzido, ou seja, são dominados por $s_{p}$ e podem ser ignorados como candidatos a dominante. Os triângulos representam os elementos que não são dominados por $s_{p}$.

garante que todos os elementos na resposta são elementos dominantes, ou seja, não estão contidos em nenhum $\tilde{S}$ dos elementos em $R$. Além disso, é possível utilizar a variedade na fase de busca por similaridade dos modelos de diversidade apresentados no Capítulo 3, reduzindo assim a quantidade de elementos no conjunto candidato.

Formalmente, o problema de diversificação de resultado para buscas por similaridade que evita a proximidade dos elementos na resposta por conjuntos de similaridade induzidos é definido como variedade e apresentado na Definição 7 .

Definição 7. Variedade : A busca por similaridade com variedade com elemento central de consulta $s_{q}$ deve garantir que o conjunto de resposta $R$ atenda aos seguintes requisitos:

$$
R=\left\{r_{i} \in S \mid \forall r_{j} \in R, r_{i} \neq r_{j} \Rightarrow r_{i} \notin \tilde{S}\left(r_{j}, s_{q}\right)\right\}
$$

Portanto, utilizando o conceito da Definição 7é possível inserir a propriedade de diversidade nas consultas aos $k$-vizinhos mais próximos e também nas consultas por abrangência, sem ser necessário solicitar novos parâmetros de quem formula a consulta, pois o conceito de variedade é inerente ao espaço de busca dos dados. As Definições 8 e 9 formalizam, respectivamente, as consultas aos $k$-vizinhos mais próximos e nas consultas por abrangência com variedade.

Definição 8. $k$-vizinhos variados mais próximos $(k-N V N q)$ : Dado um elemento central de consulta $s_{q}$ e um número $k$ de elementos, a consulta aos k-vizinhos variados mais próximos seleciona $k$ elementos tal que:

$$
\begin{aligned}
& k-N V N q\left(s_{q}, k\right)=R=\left\{r_{i} \in S|| R \mid \leq k \wedge\right. \\
& \forall s_{i} \in S-R:\left(\delta_{s i m}\left(r_{i}, s_{q}\right) \leq \delta_{\text {sim }}\left(s_{i}, s_{q}\right) \vee\right. \\
& \left.\left.\exists r_{m} \in R: s_{i} \in \hat{S}\left(r_{m}, s_{q}\right)\right) \wedge s_{i} \notin \tilde{S}\left(r_{i}, s_{q}\right)\right\} .
\end{aligned}
$$

Definição 9. Consulta por abrangência variada $(R V q)$ : Dado um elemento central de consulta $s_{q}$ e um limiar de similaridade máximo em relação ao elemento central de consulta $\varepsilon$, a consulta 
por abrangência variada seleciona os elementos em $S$ tal que:

$$
\begin{array}{r}
R V q\left(s_{q}, \varepsilon\right)=R=\left\{r_{i} \in S \mid \delta_{\text {sim }}\left(r_{i}, s_{q}\right) \leq \varepsilon \wedge\right. \\
\forall s_{i} \in S-R:\left(\delta_{s i m}\left(r_{i}, s_{q}\right) \leq \delta_{\text {sim }}\left(s_{i}, s_{q}\right) \vee\right. \\
\left.\left.\exists r_{m} \in R: s_{i} \in \stackrel{S}{S}\left(r_{m}, s_{q}\right)\right) \wedge s_{i} \notin \stackrel{S}{S}\left(r_{i}, s_{q}\right)\right\} .
\end{array}
$$

A definifição das consultas fundamentais com variedade ocorre de maneira homogênea e sem a requisição de novos parâmetros ao usuário. A consulta por abrangência variada (Definição 9 pode ser implementada pelos algoritmos apresentados na subseção 3.3 .3 para reduzir a cardinalidade dos conjuntos, principalmente por ser facilmente inferido um limiar máximo em relação ao elemento central de consulta, formando um conjunto de similaridade menor e mais heterôgeneo para ser utilizado como entrada aos algoritmos para diversificação de resultado como um caso de otimização combinatória.

\subsection{Algoritmo BRAD}

Como a capacidade de produzir dados é muito maior que a capacidade humana em analisá-los, é mais interessante para o usuário informar a quantidade de elementos desejados numa busca por similaridade, desse modo, para a diversificação de resultados é necessário estender os operadores existentes com base no operador de busca pelos $k$-vizinhos mais próximos. Assim, foi desenvolvido o algoritmo BRAD para a consulta aos $k$-vizinhos variados mais próximos. Dado que a principal diferença entre a consulta $R V q$ em relação aos $k-N V N q$ é o critério de parada, vamos apresentar apenas a versão do algoritmo BRAD para a consulta aos $k$-vizinhos variados mais próximos.

Para facilitar a visualização do conceito de variedade utilizado no algoritmo BRAD, será utilizado um exemplo num espaço bi-dimensional com distância euclidiana por ser mais intuitivo, porém esse conceito é válido em qualquer espaço métrico. Seja $s_{q}$ o elemento central da consulta, $S=\left\{s_{1}, s_{2}, s_{3}, s_{4}, s_{5}\right\}$ um conjunto de dados e $\delta_{\text {sim }}$ uma função de distância Euclidiana nesse conjunto. Vamos assumir que o objetivo é encontrar os 3 elementos variados mais próximos. Os elementos em $S$ estão ordenados por sua similaridade em relação ao $s_{q}$, por exemplo, $s_{1}$ é o elemento mais próximo de $s_{q}$, seguido por $s_{2}, s_{3}, s_{4}$ e $s_{5}$.

$\mathrm{O}$ algoritmo BRAD (Alg. 4.1) constrói incrementalmente o conjunto-resultado $R$ para uma consulta aos $k$-vizinhos mais próximos garantindo que os requisitos de variedade do conjunto de similaridade induzido pelo centro $s_{q}$ sejam preservados a cada inserção de um novo elemento em $R$. Além disso, é utilizado como entrada do algoritmo o conjunto de dados $S$ ordenado de acordo com a dissimilaridade cada elemento ao $s_{q}$. Enquanto o conjunto-resultado estiver vazio, não existe ainda um raio de similaridade $\xi_{p}$ definido. Portanto, o elemento em $S$ mais próximo de $s_{q}$ é inserido no conjunto-resultado (linha 2), tornando o elemento $s_{1}$ o primeiro elemento dominante e sua distância ao elemento $s_{q}$ é utilizada como a nova distância de similaridade $\xi_{p}$ (linha 3), como é mostrado na Figura 4.2(a).

A cada iteração, um elemento $s_{t}$ é escolhido no conjunto $S$, a escolha é pelo elemento mais próximo em relação ao elemento $s_{q}$ (linha 5). Assim, é verificado se a distância $\delta_{\text {sim }}\left(s_{t}, r_{1}\right)$ é menor que a distância de similaridade $\xi_{p}$ definido por $r_{1}$, e caso essa condição seja verdade, o elemento $s_{t}$ é removido dos candidatos a elemento dominante. Em outras palavras, ocorre que o elemento $s_{t}$ é dominado pelo elemento dominante $r_{1}$, fazendo parte do conjunto de similaridade induzido $\tilde{S}\left(r_{1}, s_{q}\right)$. Por exemplo, os elementos $s_{2}$ e $s_{3}$ na Figura 4.2 (b), estão no conjunto de similaridade induzido por $r_{1}$, logo eles não poderão ser considerados como futuros dominantes 
dessa consulta. O próximo elemento escolhido é o elemento $s_{4}$, esse elemento é inserido no conjunto de resposta e a distância $\delta_{\text {sim }}\left(s_{4}, s_{q}\right)$ é utilizada como a nova distância de similaridade $\xi_{p}$.

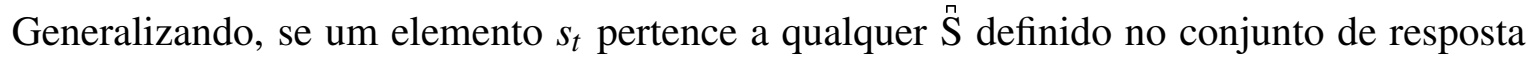
(linha 7 e 8), $s_{t}$ é ignorado como candidato a dominante do conjunto de resposta $R$ (linha 9) e o vizinho mais próximo em $S$ (linha 5) será avaliado como candidato a elemento dominante. Entretanto, se o candidato a dominante $s_{t}$ não é dominado por nenhum outro elemento em $R$, a distância $\delta_{\text {sim }}\left(s_{t}, s_{q}\right) \geq \xi_{p}$ é definida como a distância de similaridade para $s_{t}$ (linha 13) e então o elemento $s_{t}$ será aceito como dominante e inserido em $R$ (linha 15). O processo é repetido até o resultado $R$ possuir $k$ elementos ou não existir elementos em $S$ para serem analisados (linha 2).

A Figura 4.2(c) ilustra a inserção do elemento $s_{5}$ como dominante. Esse elemento é o mais próximo de $s_{q}$ e não faz parte de nenhum conjunto induzido de similaridade definido pelos elementos dominantes inseridos na resposta. Portanto, o conjunto-reposta $R$ final é formado por $\left\{s_{1}, s_{4}, s_{5}\right\}$.

\subsection{Método para Avaliação de Variedade}

Para avaliar o modelo de variedade desenvolvido nesta dissertação é preciso avaliar o nível de sobreposição dos elementos no conjunto-resultado. Em outras palavras, é preciso verificar se os elementos $r_{i}$ do conjunto-resultado $R$ são similares aos outros elementos $r_{j}$ do conjunto-resultado em relação a distância de cada elemento $r_{i}$ ao elemento central de consulta $s_{q}$. Assim, dado um conjunto-resultado $R$ e um elemento central de consulta $s_{q}$, é possível utiizar a Definição 6 para induzir o conjunto de similaridade de cada elemento no conjunto-resultado. Assim, para cada $\tilde{\mathrm{S}}\left(r_{i}, s_{q}\right)$ de elementos $r_{i} \in R$, o método verifica o nível de sobreposição em relação aos outros elementos $r_{j}$, mensurando qual o nível de variedade $\omega\left(R, s_{q}\right)$ que os elementos do conjunto de resposta possuem em relação ao elemento central de consulta $s_{q}$. Essa medida é chamada "Variedade Intrinseca" do conjunto-resposta $R$ de uma consulta centrada em $s_{q}$, e é obtida segundo a seguinte Equação 4.1 ;

$$
\omega\left(R, s_{q}\right)=\sum_{i=1}^{|k-1|} \sum_{j=i+1}^{|k|} 1-\left[\frac{\left|\tilde{\mathrm{S}}\left(r_{i}, s_{q}\right) \cap \tilde{\mathrm{S}}\left(r_{j}, s_{q}\right)\right|}{\left|\tilde{\mathrm{S}}\left(r_{i}, s_{q}\right) \cup \tilde{\mathrm{S}}\left(r_{j}, s_{q}\right)\right|}\right],
$$

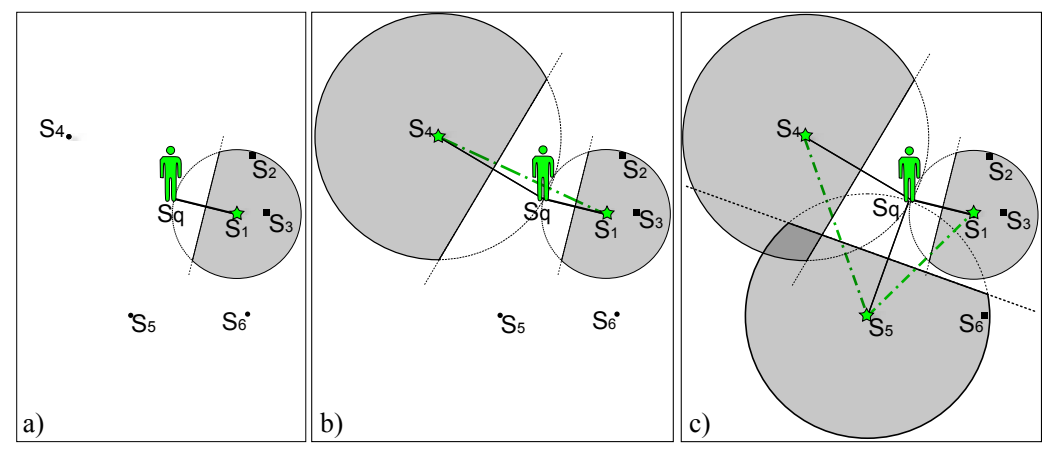

Figura 4.2: Construção do conjunto de resposta para busca aos 3-vizinhos variados mais próximos num espaço bi-dimensional euclidiano. (a) Primeiro dominante. (b) Segundo dominante. (c) Os 3 vizinhos variados mais próximos. 

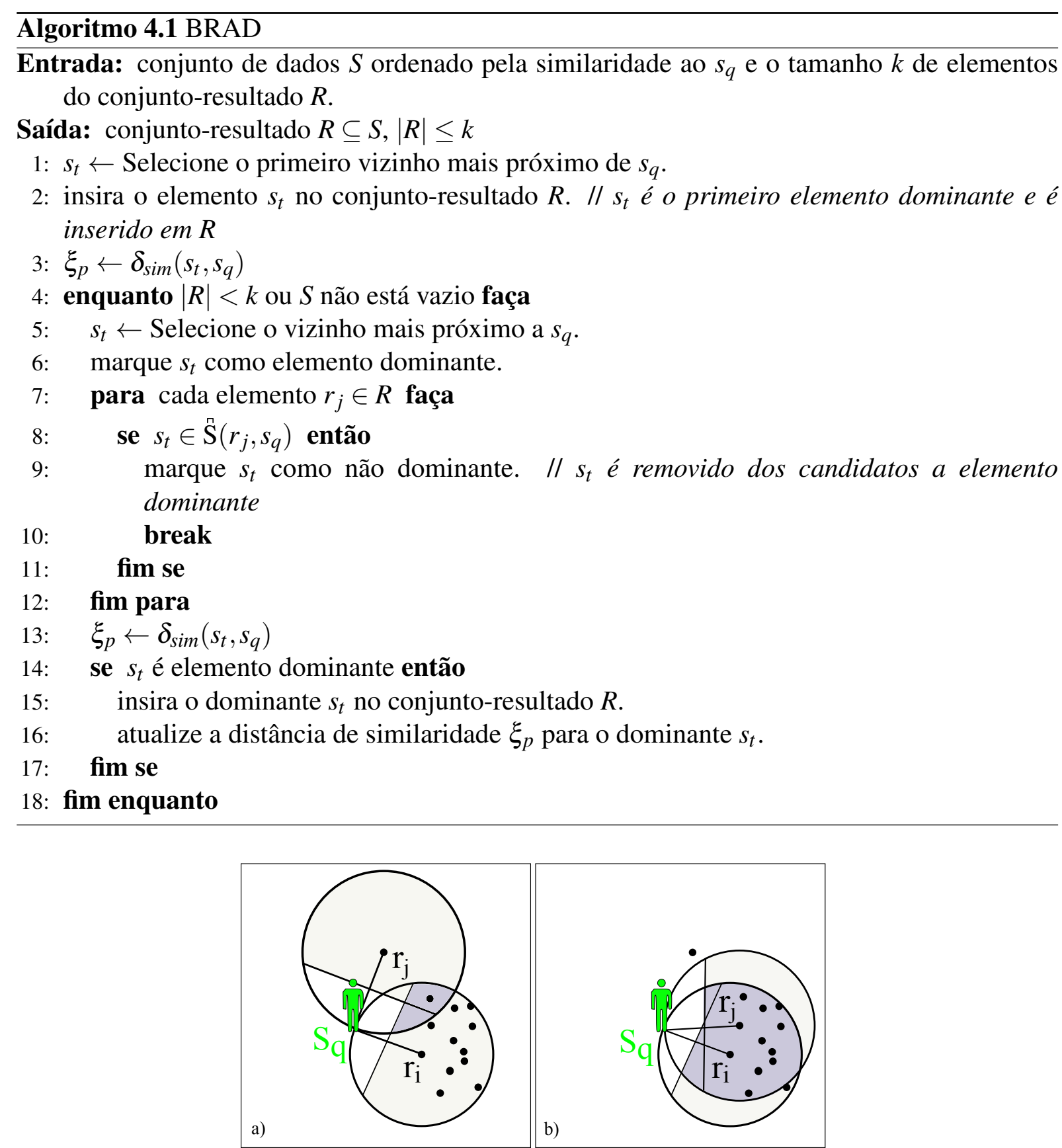

Figura 4.3: Exemplo de como a sobreposição dos conjuntos de similaridade detecta a variedade entre dois elementos no conjunto de resposta. (a) Conjunto de similaridade induzido com baixa sobreposição. (b) Conjunto de similaridade induzido com alta sobreposição.

onde $r_{i}, r_{j} \in R, r_{i} \neq r_{j}$.

Portanto, dados dois elementos $r_{i}, r_{j} \in R$, estes são considerados mais variados entre si, se $\tilde{\mathrm{S}}\left(r_{i}, s_{q}\right) \cap \overline{\mathrm{S}}\left(r_{j}, s_{q}\right)$ possui poucos elementos em comum, como é mostrado na Figura 4.3 a). Caso os conjuntos de similaridade induzidos pelos elementos $r_{i}$ e $r_{j}$ possuam vários elementos em comum, esses elementos são considerados mais similares entre si, como é mostrado na Figura 4.3 b). Dessa maneira, quanto maior o valor de $\omega$ maior a variedade obtida na resposta da consulta.

A Equação 4.1 possui valor máximo para conjunto-resultado com pouca sobreposição 
dos conjuntos de similaridade induzidos, mas o máximo valor atingível varia de consulta para consulta, em função da cardinalidade da resposta. Assim, para possibilitar a análise da sobreposição média em relação a quantidade de elementos no conjunto-resultado e a comparação entre consultas em geral, define-se a seguir a versão normalizada para o intervalo $[0,1]$ assumindo que a cardinalidade do conjunto de resposta $|R|=k$, que é obtida da seguinte maneira:

$$
\bar{\omega}\left(R, s_{q}\right)=\frac{2 \cdot \omega\left(R, s_{q}\right)}{k(k-1)}
$$

Utilizando a avaliação do nível de sobreposição normalizada $\bar{\omega}$, é possível também detectar a vizinhança de cada elemento na resposta e verificar se os elementos são similares entre si, porém diversos em relação ao elemento central de consulta $s_{q}$, capturando o abismo de diversidade (ver Figura 3.6) nos conjuntos de resposta.

\subsection{Considerações Finais}

Neste capítulo foi apresentado o modelo de diversidade baseado apenas em propriedades do espaço métrico que não depende do parâmetro de compromisso entre a similaridade e diversidade (preferência de diversidade), chamado de variedade. Foi definido o algoritmo Better Results with Adaptive Diversification para resolução do problema da consulta aos $k$-vizinhos mais próximos com variedade, chamado de $k$-vizinhos variados mais próximos. Para consolidar esse conceito, foram desenvolvidas duas medidas de avaliação para sobreposição de variedade, a Variedade Intrinseca e a Variedade Normalizada, que podem ser aplicadas a qualquer resultado de consultas por similaridade, o que inclui todos tipos de consulta por similaridade com diversidade apresentados no Capítulo 3 .

No capítulo seguinte são apresentados os resultados dos experimentos realizados, tanto em relação ao desempenho quanto a qualidade das respostas para consultas utilizando o método de avaliação de variedade nos conjuntos de resposta. 


\section{Capítulo 5}

\section{Experimentos}

\subsection{Materiais e Métodos}

A avaliação da técnica desenvolvida nesta dissertação envolveu conjuntos de dados, tanto reais quanto sintéticos, onde foram explorados diferentes valores de dimensão, tamanho dos objetos e do conjunto de dados, e a distribuição dos dados no espaço métrico. A Tabela 5.1 apresenta os conjuntos de dados utilizados nos experimentos. É indicado para cada conjunto: o nome, o número total de objetos (Nro. Objetos), a dimensão $(D)$, a função de distância $\left(\delta_{\text {sim }}\right)$ e a descrição de sua origem e composição.

A configuração do computador usado para os testes foi: 2 processadores Intel Xeon 5600, com 96 GB de memória RAM e disco rígido de 16 TB. O sistema operacional utilizado foi o CentOS Linux 6.2. O algoritmo BRAD foi comparado com três dos melhores algoritmos existentes na literatura: Greedy Marginal Contribution (GMC), Greed Randomized With Neighborhood Expansion (GNE) e First-Match (FM). Esse último representa a abordagem mais similar ao modelo apresentado nesta monografia. Todos os algoritmos foram implementados utilizando a liguagem $\mathrm{C}++$, e implementados na biblioteca de MAMs Arboretum como operadores da slim-tree. Contudo, nenhum dos algoritmos realiza busca indexada aos dados, uma vez que os algoritmos GNE e GMC não se beneficiam dessa estratégia devido a natureza do problema o qual foram modelados.

Os principais aspectos relacionados com a prepação dos testes foram:

- Os objetos de cada conjunto de dados foram inseridos de forma aleatória, simulando a situação real de inserções de objetos que ocorrem em SGBDs;

- Após a inserção, extraiu-se uma amostra de 100 elementos, correspondendo ao conjunto de dados usados como elemento central de consulta. Os elementos foram escolhidos aleatoriamente dentre todos os pertencentes ao conjunto. A mesma amostra foi usada em todas as consultas para um mesmo conjunto de dados;

- Os números de vizinhos $k$ a serem encontrados nas consultas aos vizinhos variados mais próximos $(k-N V N q)$, diversos $(k-N D N q)$ e distintos $(k-D N N q)$ foram escolhidos de acordo com os valores frequentemente usados em situações reais, variando de 10 a 40 , com incrementos de 5 elementos; 
- Os parâmetros utilizados pelos algoritmos GMC e GNE foram definidos de acordo com o trabalho original (Vieira et al., 2011). Além disso, o parâmetro de preferência de diversidade $(\lambda)$ foi definido em 0.5 , pois apresentou o melhor valor, em média, para o método de avaliação de variedade. Para o algoritmo FM, foram utilizados dois valores para o parâmetro distância de separação $\{1.0,1.3\}$, valores estes que apresentaram, em média, os melhores resultados tanto para o método de avaliação desenvolvido quanto desempenho das consultas.

Tabela 5.1: Conjunto de dados utilizados nos experimentos

\begin{tabular}{|c|c|c|c|c|}
\hline Conjunto de Dados & Nro. Objetos & Dimensão & $\delta_{\text {sim }}$ & Descrição \\
\hline Aloi & 72.000 & 144 & $L_{2}$ & $\begin{array}{l}\text { Conjunto de imagens de } 1.000 \text { obje- } \\
\text { tos diferentes, rotacionadas em } 5 \text { grau. } \\
\text { url: http://staff.science.uva. } \\
\text { nl/ } \text { aloi. }\end{array}$ \\
\hline Cidades Americanas & 25.375 & 2 & $L_{2}$ & $\begin{array}{l}\text { Latitude e Longitude de Cidades Ame- } \\
\text { ricanas. url: http://www.census. } \\
\text { gov/ }\end{array}$ \\
\hline Sintético3D & 100.000 & 3 & $L_{2}$ & $\begin{array}{l}\text { Conjunto de dados sintético com } \\
100.000 \text { elementos com distribuição } \\
\text { Gaussiana e } 5 \text { clusters. }\end{array}$ \\
\hline SintéticoD & 30.000 & 105 & $L_{2}$ & $\begin{array}{l}\text { Conjunto de dados sintético com } \\
30.000 \text { elementos com distribuição } \\
\text { Gaussiana. }\end{array}$ \\
\hline EnglishWords & 24893 & adimensional & $L_{e d i t}$ & $\begin{array}{l}\text { Palavras de um dicionário da língua } \\
\text { inglesa. }\end{array}$ \\
\hline
\end{tabular}

\subsection{Desempenho e Avaliação de Qualidade}

O conjunto de experimentos realizados envolveu tanto a análise de desempenho dos algoritmos quanto a análise da qualidade das respostas utilizando o método de avaliação de sobreposição apresentado nesta monografia. Além disso, foram realizados testes de escalabilidade com o algoritmo BRAD para verificação do comportamento assintótico com o aumento da cardinalidade e dimensionalidade do conjunto de dados.

\subsubsection{Experimentos com o conjunto de dados Cidades Americanas}

O primeiro experimento apresentado foi realizado sobre o conjunto de dados das cidades americanas, o qual apresenta baixa dimensionalidade (apenas duas dimensões: as coordenadas cartesianas). As Figuras 5.1(a) e 5.1(b) contêm respectivamente a comparação do tempo de execução, o nível de sobreposição de variedade dos resultados pelos algoritmos analisados e do algoritmo tradicional de consulta aos $k$-vizinhos mais próximos. O algoritmo dos $k$-vizinhos mais próximos foi incluído nos testes apenas para melhorar o entendimento da medida de sobreposição de variedade. O valor de $k$ variou entre 10 e 40 . É importante destacar que utilizamos todos os elementos do conjunto de dados $S=25.375$ para todos os algoritmos avaliados.

A Figura 5.1(a) ilustra o tempo de execução em escala logarítmica, como pode ser percebido. Como era previsto, os algoritmos GNE e GMC tiveram o maior tempo de execução 

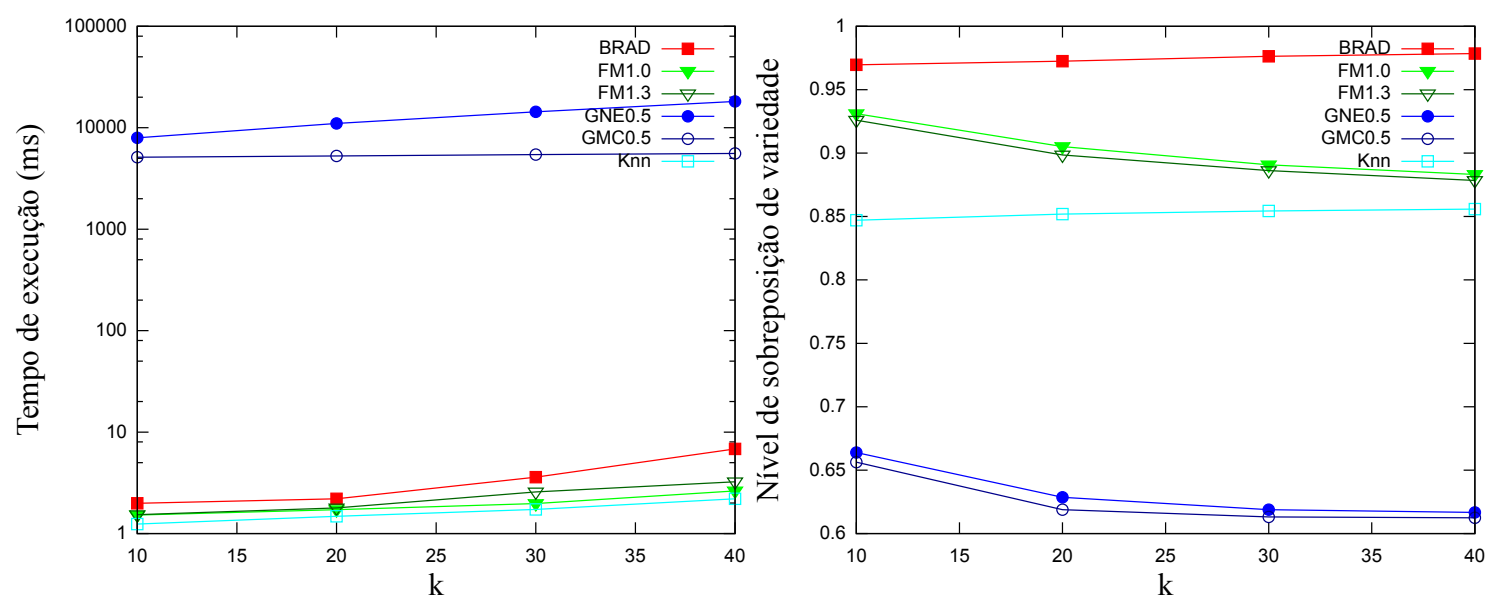

(a) Média do tempo de execução vs. quantidade de $k$ (b) Média do nível de sobreposição de variedade vs. vizinhos. quantidade de $k$ vizinhos.

Figura 5.1: (a) Tempo de execução e (b) análise de qualidade das respostas para o conjunto de dados cidades americanas variando $k$ de 10 a 40 elementos.

entre os métodos, principalmente pela necessidade de executar $n^{2}$ comparações em relação ao conjuto de dados $S$. De fato, para esse conjunto de dados, tanto GNE quanto GMC foram de 3 a 4 ordens de magnitude mais lentos que o FM e o BRAD. A Figura 5.1(b) revela que mesmo com tempos de execução maiores que os concorrentes, a qualidade da resposta apresentadas pelo GNE e GMC medida pela variedade normalizada $\bar{\omega}$ foram as piores apresentadas, não contribuindo para melhor qualidade das respostas. Além disso, tais métodos apresentaram resultado pior que o algoritmo de $k-N N q$ que pode ser explicado pelo fato que tanto o algoritmo GNE quanto GMC selecionam elementos mais distantes do elemento central de consulta, porém não é possível impedir a escolha de elementos similares em clusters mais afastados do elemento central de conjunto.

A Figura 5.2 apresenta o resultado da consulta aos 10-vizinhos diversos mais próximos com o algoritmo GNE, com preferência de diversidade para os seguintes valores $(\lambda=\{0.3,0.5,0.7\})$ e $s_{q}=$ São Francisco. Para tornar a visualização mais intuitiva para o experimento que gerou essa figura foi limitado o conjunto candidato para as 50 cidades mais próximas com população maior ou igual a 15.000 habitantes. Para valores até $\lambda=0.5$ (Figuras 5.2 (a) e (b)), os elementos no conjunto de respostas mantêm-se agrupados, seja próximo ao elemento central de consulta ou nas extremidades do conjunto candidato. A Figura 5.2 (c) mostra que quando a preferência de diversidade aumenta, os elementos no conjunto de resposta são "repelidos" do elemento central de consulta, porém é mantida a tendência a formar grupos entre os elementos mais distantes entre si.

A Figura 5.3 mostra o resultado para a consulta aos 10-vizinhos variados mais próximos uilizando o algoritmo BRAD, com $s_{q}=$ São Francisco. O conjunto também foi limitado, porém para todas as cidades americanas com população maior ou igual a 15.000 habitantes. É possível observar que mesmo sem fornecer nenhum parâmetro extra de diversidade para a consulta, os elementos no conjunto de resposta estão melhor distribuídos no espaço. Além disso, a consulta aos $k$-vizinhos variados mais próximos mantém a essência da busca aos vizinhos mais próximos, porém garante que nenhum elemento esteja no conjunto de similaridade induzido de outro elemento na resposta. Em outras palavras, inicialmente são explorados os elementos similares ao elemento central de consulta para posteriormente selecionar elementos mais variados ao $s_{q}$. 


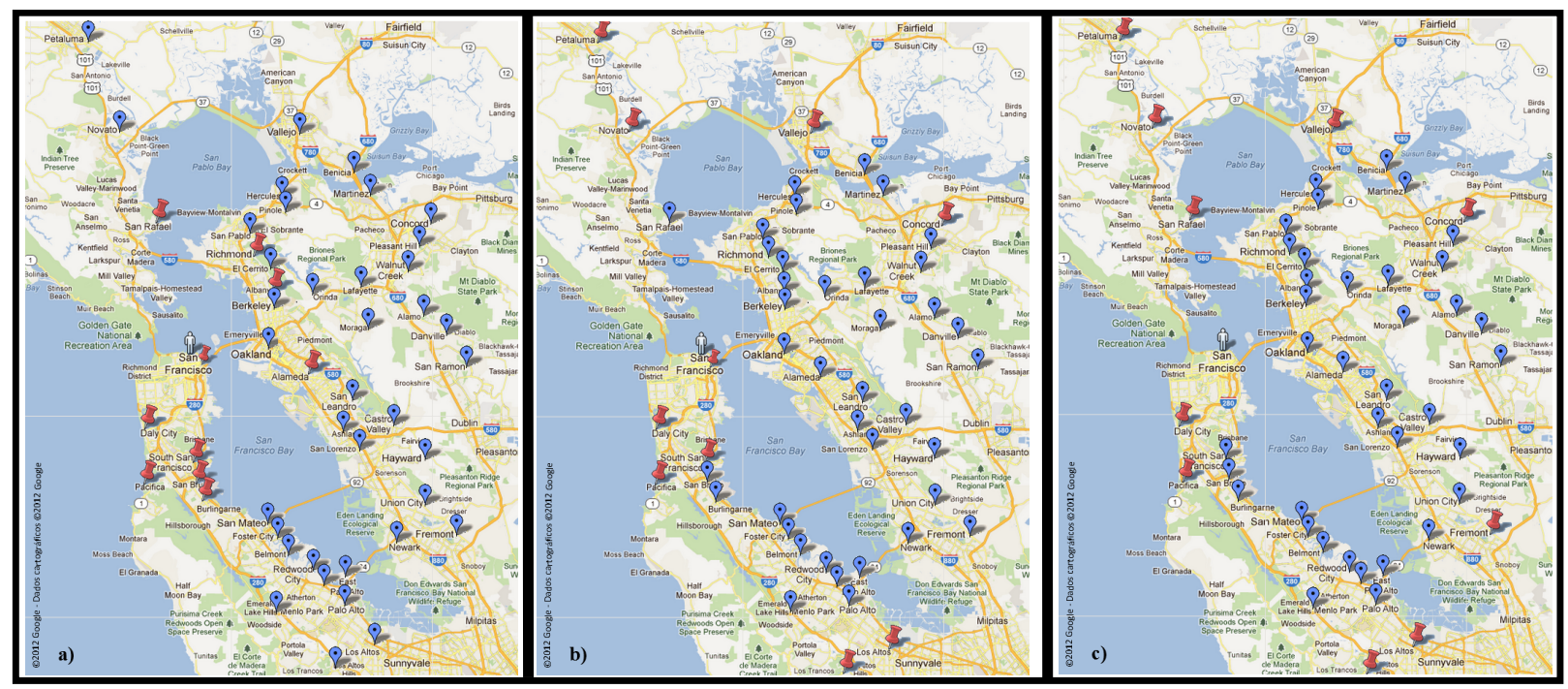

Figura 5.2: Resultado do algoritmo GNE para o conjunto de dados cidades americanas quando a preferência de diversidade é variada entre [0.3,0.7], elemento central de consulta sendo São Francisco e $k=10$. Os push-pins vermelhos representam os elementos no conjunto de resposta, enquanto os balões representam os candidatos a resposta. (a) Resultado para $\lambda=0.3$. (b) Resultado para $\lambda=0.5$. (c) Resultado para $\lambda=0.7$.

O algoritmo BRAD foi em média $70 \%$ mais lento que o algoritmo FM. Tal comportamento é esperado devido a atualização da distância de similaridade $\xi_{p}$ a cada nova inserção de dominante em $R$. A distância de similaridade no algoritmo BRAD é incrementada de acordo com a distância entre o elemento dominante e o $s_{q}$, quanto mais afastado o elemento dominante é do elemento $s_{q}$ maior é o $\xi_{p}$, o que requisita maior processamento que o algoritmo FM que utiliza um valor fixo para cada elemento.

Contudo, em relação a qualidade das respostas, o algoritmo BRAD apresentou os melhores resultados para todas as configurações testadas, como pode ser visto na Figura 5.1(b), confirmando nossa suposição que a utilização de uma distância fixa ao redor dos elementos de resposta não é a melhor solução para retirar os elementos similares entre si do conjunto de resposta. De fato, BRAD foi o único algoritmo a seguir a tendência do algoritmo tradicional $k-N N q$ ao reduzir o nível de sobreposição de variedade de acordo com o aumento dos $k$ vizinhos solicitados para resposta, sugerindo que os outros métodos tendem a incluir elementos similares aos já inseridos no conjunto, porém afastados do elemento central de consulta, tornando a consulta diversa ao elemento central de consulta, mas que não é diversa em relação aos elementos da resposta entre si.

Os algoritmos GNE e GMC apresentaram alto custo computacional, sendo até 4 ordens de magnitude mais lentos que o algoritmo BRAD e o FM num conjunto bi-dimensional. Para poder comparar os algoritmos GNE e GMC nos próximos conjuntos de dados que possuem maior cardinalidade e dimensionalidade, seria necessário escolher um subconjunto do conjunto original, porém estimar quantos elementos são necessários é uma tarefa subjetiva que impacta diretamente na qualidade dos resultados desses algoritmos. Portanto, esses algoritmos não serão mais utilizados nas comparações dos próximos conjuntos dados. 


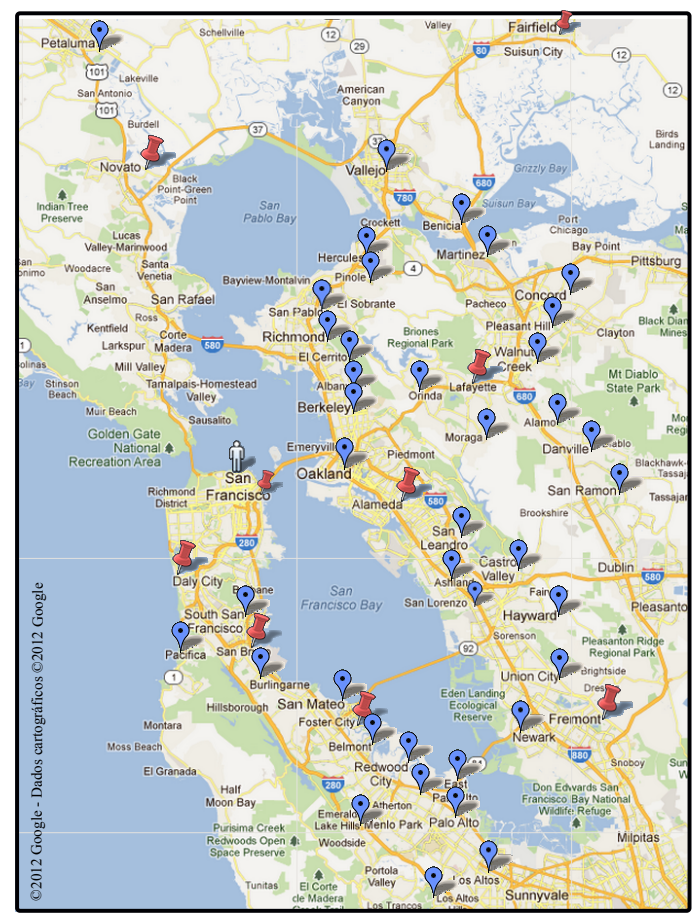

Figura 5.3: Resultado do algoritmo BRAD para o conjunto de dados cidades americanas, com elemento central de consulta sendo São Francisco e $k=10$.
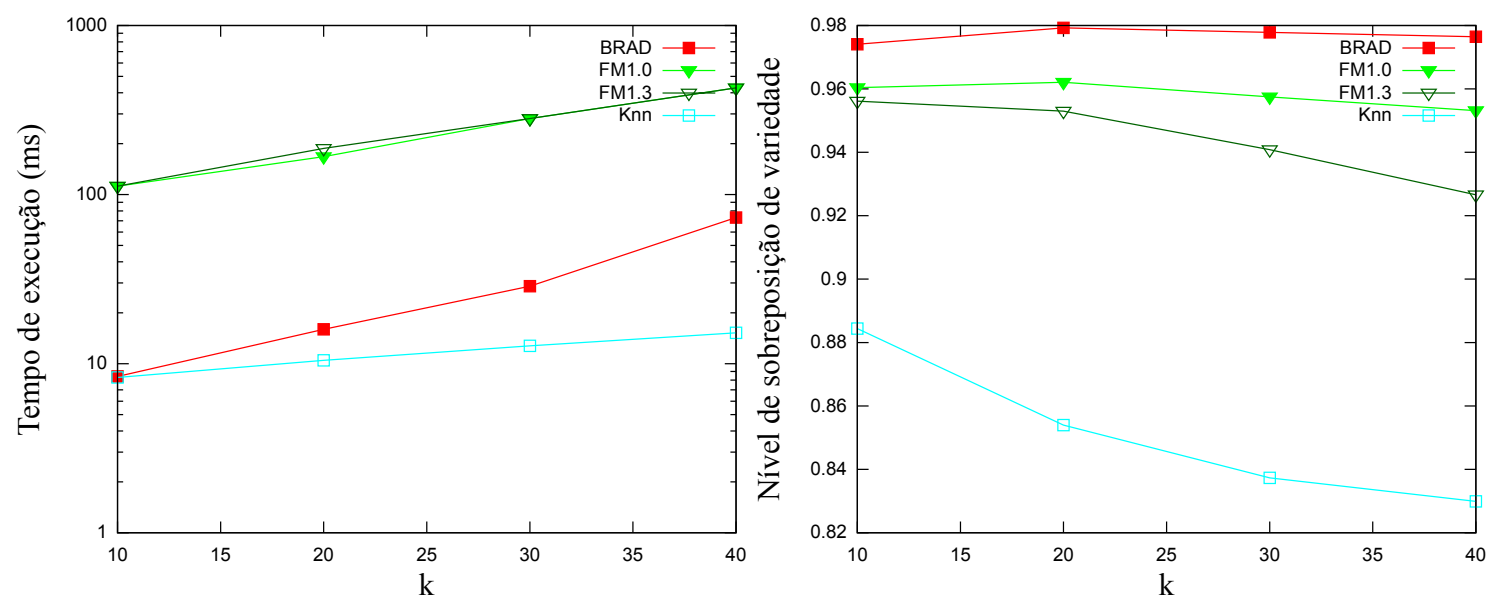

(a) Média do tempo de execução vs. quantidade de $k$ (b) Média do nível de sobreposição de variedade vs. vizinhos. quantidade de $k$ vizinhos.

Figura 5.4: (a) Tempo de execução e (b) análise de qualidade das respostas para o conjunto de dados Aloi variando $k$ de 10 a 40 elementos.

\subsubsection{Experimentos com o conjunto de dados Aloi}

O conjunto de dados Aloi é interessante por sua característica de alta dimensionalidade. Os vetores de características possuem 144 dimensões e é semelhante à maioria dos conjuntos de dados multimídia. A Figura 5.4(a) apresenta os resultados em relação ao tempo de execução. Com o aumento da dimensionalidade e cardinalidade, o algoritmo BRAD possui o menor tempo de execução sendo até uma ordem de magnitude mais rápido que o FM. Em relação à qualidade das respostas, BRAD mantém sua superioridade em relação FM e ao $k-N N q$ 


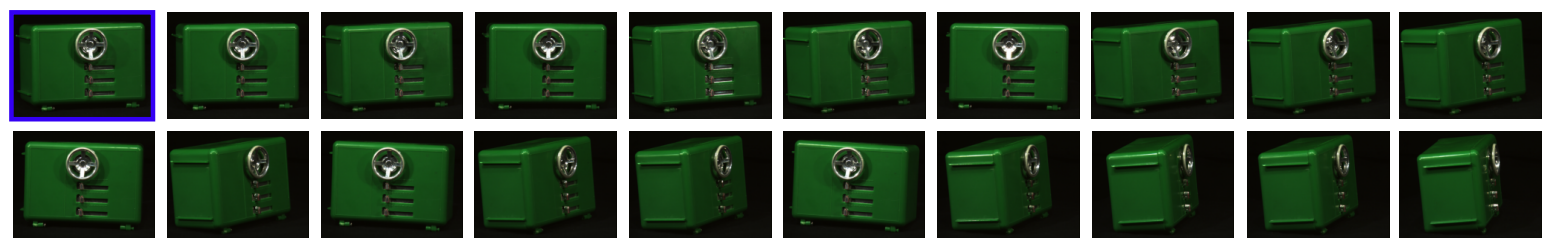

Figura 5.5: Conjunto de resposta para a consulta aos 20-vizinhos mais próximos para um conjunto de imagens. A imagem com borda azul é o elemento central de consulta.
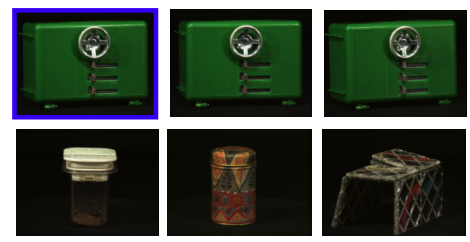
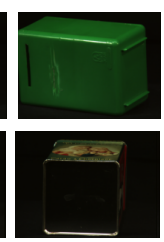
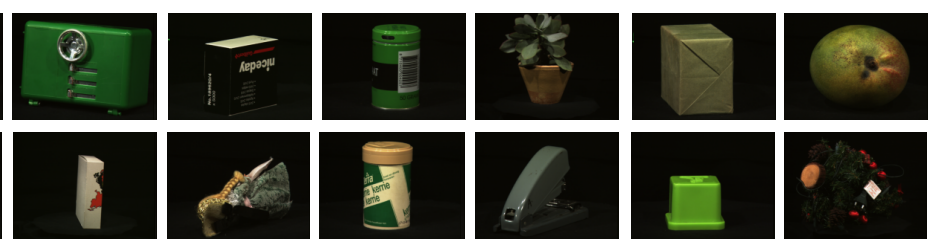

Figura 5.6: Conjunto de resposta para a consulta aos 20-vizinhos variados mais próximos para um conjunto de imagens utilizando o algoritmo BRAD. A imagem com borda azul é o elemento central de consulta.

tradicional. É interessante destacar que com o aumento da dimensionalidade do conjunto de dados e o número de $k$ vizinhos, o algoritmo tradicional $k-N N q$ obteve maior sobreposição de variedade, diferentemente do que ocorreu com o conjunto de cidades americanas 5.1(b), Esse comportamento está de acordo com o fato bem conhecido de que em altas dimensionalidades as distâncias entre os pares de elementos tendem a ser similares. Apesar do algoritmo BRAD também ser impactado pela alta dimensionalidade, isso ocorre de maneira menos acentuada.

A Figura 5.5 ilustra o resultado de uma consulta aos 20 -vizinhos mais próximos. A consulta considera apenas o elemento central de consulta (imagem com borda azul) como referência para a busca dos elementos. No entanto, se o usuário desejar verificar as imagens no conjunto de dados é preciso solicitar um valor $k$ grande o suficiente para percorrer os elementos no conjunto. A Figura 5.6 ilustra o resultado para uma consulta aos 20-vizinhos variados mais próximos, onde é possível perceber que foram apresentadas imagens similares que estavam presentes na resposta aos $k$-vizinhos mais próximos, porém foram excluídas as imagens que eram mais similares a qualquer outra do conjunto de resposta, possibilitando explorar mais elementos no espaço de busca dos dados. Além disso, não há repetição dos elementos quando esses estão mais afastados do elemento central de consulta. Desse modo, a variedade auxilia o usuário a navegar mais facilmente pelos resultados, sem obrigar que seja dada informação adicional.

\subsubsection{Experimentos com o conjunto de dados words}

Os experimentos com o conjunto de dados words, tem o objetivo de avaliar o algoritmo BRAD, num conjunto puramente métrico (adimensional). A Figura 5.7(a) apresenta os resultados em relação ao tempo de execução. Em especial nesse conjunto métrico, os elementos estão muito próximos uns dos outros, o que aumentou o tempo de execução de todos algoritmos avaliados, porém o algoritmo BRAD foi o mais rápido para todos os valores de $k$. Em relação à qualidade das respostas, o algoritmo BRAD mantém sua superioridade em relação às técnicas FM e ao $k-N N q$ tradicional. É interessante destacar novamente que o algoritmo BRAD acompanhou a tendência do $k-N N q$ tradicional, que leva a uma redução do nível de 


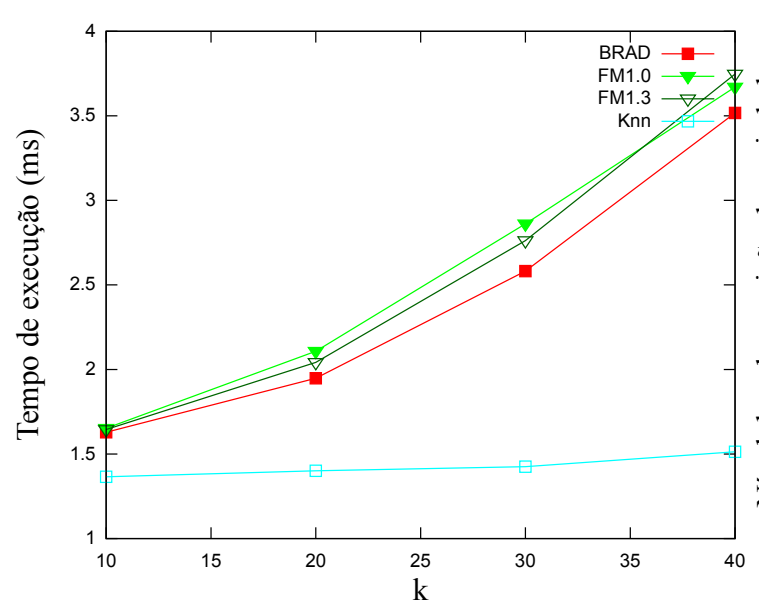

(a) Média do tempo de execução vs. quantidade de $k$ vizinhos.

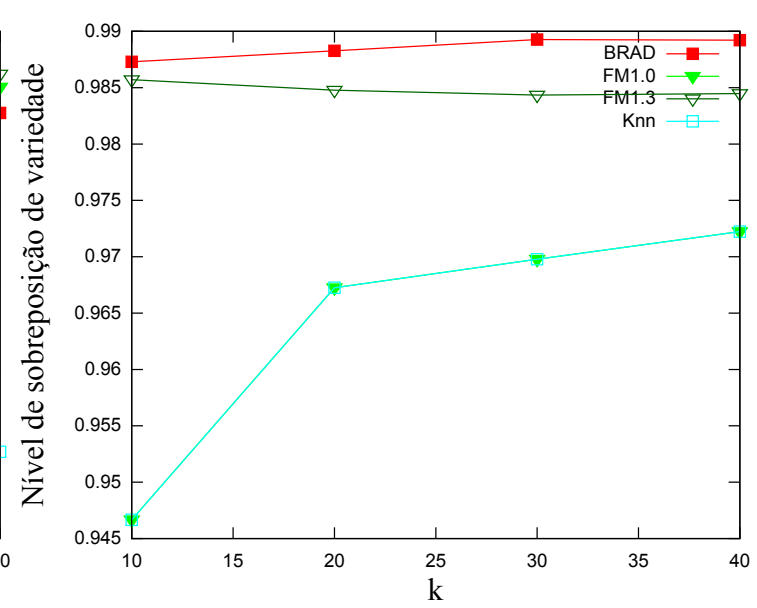

(b) Média do nível de sobreposição de variedade vs. quantidade de $k$ vizinhos.

Figura 5.7: (a) Tempo de execução e (b) análise de qualidade das respostas para o conjunto de dados Words variando $k$ de 10 a 40 elementos.

sobreposição com o aumento do valor de $k$.

\subsection{Teste de Escalabilidade}

Para os experimentos de escalabilidade, foram criados dois conjuntos de dados sintéticos utilizando a ferramenta DBGen (Bueno et al., 2004). O primeiro experimento é referente à escalabilidade do algoritmo BRAD em relação ao tamanho do conjunto de dados. O conjunto Sintético3D foi gerado utilizando distribuição Gaussiana para a geração de 5 agrupamentos em um conjunto de 3 dimensões, em que cada dimensão varia na faixa de valores $[0,1]$. Foram criados conjuntos de dados de 10.000 a 100.000 elementos aumentando a quantidade de elementos de 10.000 em 10.000 elementos. A Figura 5.8 mostra os resultados tanto em tempo de execução quanto em avaliação da sobreposição de variedade.

A cada incremento do conjunto, foram realizadas 100 consultas, do mesmo modo que na seção 5.2 e foi utilizado o tempo médio para cada consulta. Como pode ser visto na Figura 5.8, o tempo de execução aumenta linearmente, demonstrando que o método desenvolvido é escalável para grandes bases de dados.

A Figura 5.8(b) apresenta os resultados em relação à qualidade dos resultados para uma consulta $\operatorname{com} k=10$. Como pode ser visto, o algoritmo é estável em relação a qualidade dos resultados mesmo com o aumento da cardinalidade, que tende a tornar o espaço mais denso. A estabilidade na qualidade dos resultados é alcançada ao utilizar o conjunto de similaridade induzido, de tamanho variável, a partir da distância de cada elemento dominante ao elemento central de consulta.

O próximo experimento é referente à escalabilidade do algoritmo BRAD em relação ao tamanho da dimensão dos elementos no conjunto de dados. O conjunto SintéticoD foi gerado utilizando distribuição Gaussiana. Foram criados conjuntos de dados de 5 a 105 dimensões incrementados de 10 em 10 dimensões com cardinalidade total de 30.000 elementos.

A Figura 5.9(a) apresenta os resultados em relação ao tempo de execução. Como pode ser visto, o comportamento é sub-linear em relação ao aumento da dimensionalidade do conjunto, demonstrando que o algoritmo desenvolvido é escalável em conjuntos de dados de imagens, em 


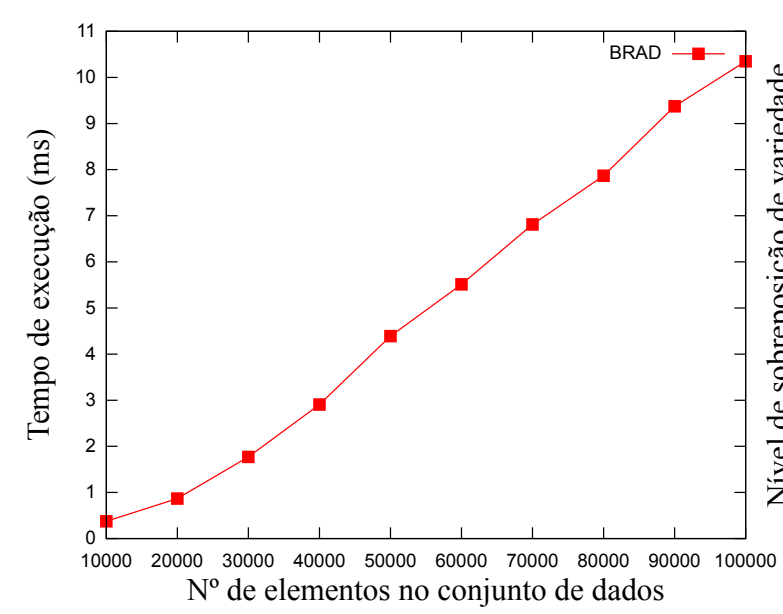

(a) Sintético3D: $S$

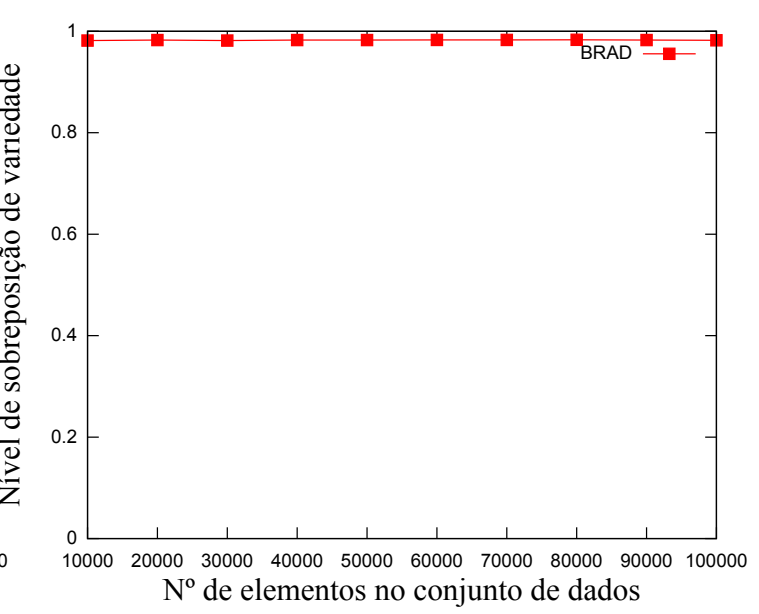

(b) Sintético3D: $(S)$

Figura 5.8: (a) Escalabilidade em relação a cardinalidade do conjunto Sintético3D. (b) Nível de sobreposição de variedade em relação o aumento da cardinalidade do conjunto.

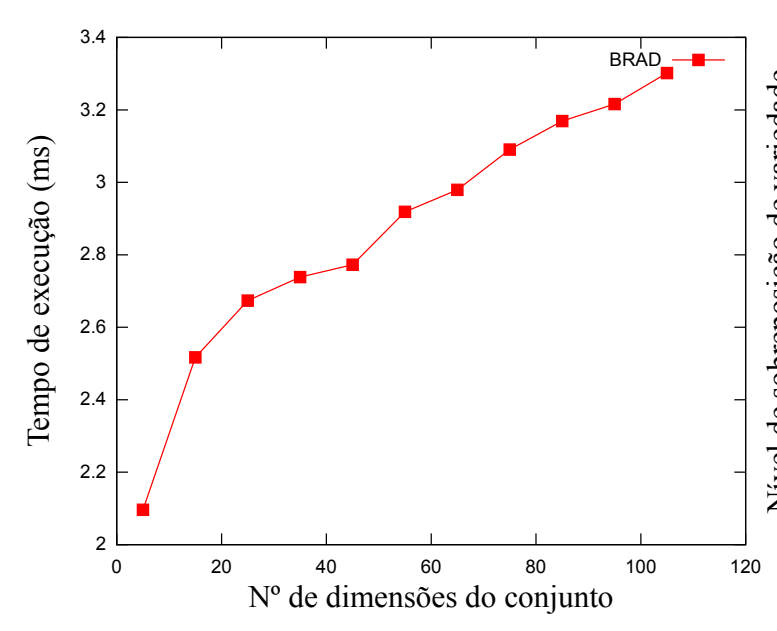

(a) SintéticoD: $S$

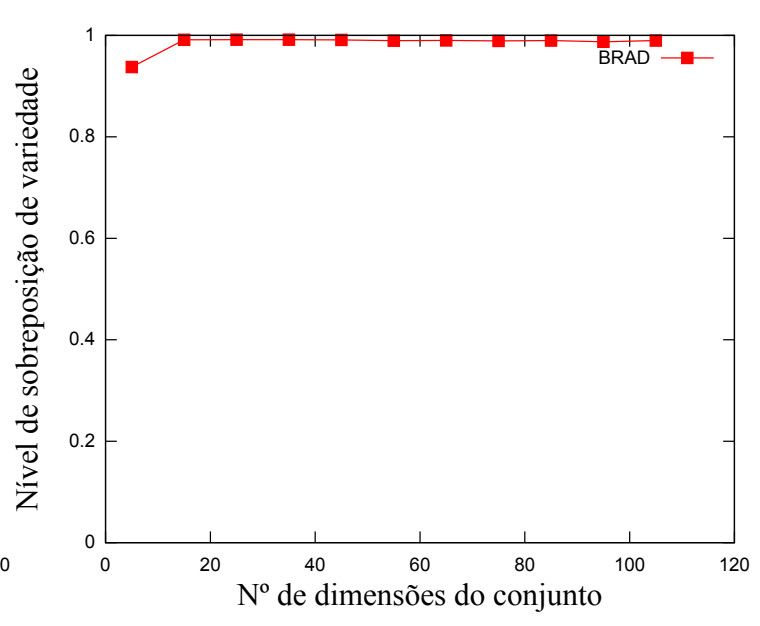

(b) SintéticoD: $(S)$

Figura 5.9: (a) Escalabilidade em relação a dimensionalidade do conjunto SintéticoD. (b) Nível de sobreposição de variedade em relação o aumento de dimensionalidade do conjunto.

que os vetores de característica possuam centenas de dimensões. Em relação a qualidade das respostas, o algoritmo se mostrou estável com a variação da dimensionalidade, como pode ser visto na Figura 5.9(b)

Os experimentos realizados nesta seção mostram que o algoritmo BRAD é tanto escalável em relação ao tamanho do conjunto de dados quanto em relação à quantidade de atributos no vetor de característica. Além disso, o algoritmo é estável em relação à qualidade das respostas retornadas.

\subsection{Considerações Finais}

Este capítulo definiu o ambiente de testes utilizado na avaliação do algoritmo BRAD e descreveu os resultados dos testes de desempenho medido pelo tempo de cálculo das resposta 
e qualidade realizados medido pela medida de variedade normalizada. Os resultados obtidos foram comparados com os algoritmos GMC e GNE, que utilizam heurísticas gulosas e o método GRASP para o problema de diversificação de resultados, os quais representam as abordagens mais recentes para soluções de diversidade como um problema de otimização combinatória. Além desses algoritmos, o algoritmo BRAD foi comparado com o algoritmo FM que representa a estratégia mais similar para diversidade em espaços métricos. Nos testes, foram analisados o tempo de execução e o nível de sobreposição de variedade para consultas $k-N N q$ com variedade e diversidade.

Os testes indicaram que o algoritmo BRAD obteve bons resultados, sendo equivalente em tempo de execução e em todos os casos reduzindo o nível de sobreposição de variedade no conjunto de resposta. Observa-se ainda com os experimentos que, mesmo em situações adversas como no caso de altas dimensionalidades, o desempenho do BRAD foi sempre superior que as abordagens, sendo mais rápido e reduzindo a sobreposição de variedade, sem requerer nenhum atributo especifíco. Dessa forma, pode-se concluir que o algoritmo BRAD é uma técnica robusta, sem restrições com desempenho, domínio de dados e não parametrizado quando comparado com às abordagens existentes que solicitam informações que dependem da cardinalidade e distribuição dos dados, que normalmente, não são intuitivas. 



\section{Capítulo 6}

\section{Conclusões e Trabalhos Futuros}

Intuitivamente, similaridade e diversidade parecem ser dois conceitos antagônicos, e cuidar de ambos em uma única consulta requer estabelecer um compromisso entre esses dois conceitos. De fato, esta abordagem tem sido utilizada pela maioria dos trabalhos que buscam diversificar os resultados de consultas por similaridade. No entanto, apesar da intuição do conceito, a definição de valores de compromisso entre as medidas de similaridade e de diversidade para uma dada consulta não é uma tarefa intuitiva para o usuário, por depender de informação sobre a distribuição dos dados armazenados que o usuário geralmente desconhece ou pode ser difícil de ser obtida e até mesmo de ser representada.

Nesta dissertação foi apresentado um modelo alternativo, em que a similaridade e a diversidade são dois conceitos derivados da própria definição do que é um espaço métrico. Da maneira como o conceito de diversidade foi definido, ele não compete com o conceito de similaridade, permitindo que ambos sejam usados em uma mesma consulta, evitando depender de um valor difícil e não intuitivo que exige do usuário a definição do parâmetro de compromisso entre a similaridade e diversidade.

O conceito de diversidade desenvolvido possui as seguintes propriedades benéficas para sua inclusão em consultas por similaridade que venham a ser inseridas em Sistemas de Gerenciamento de Bases de Dados:

- Independencia de parâmetros - não se requer nenhum parâmetro de configuração, assim a variedade pode ser usada pelo sistema de maneira completamente transparente ao usuário;

- independencia de domínio - a variedade depende apenas que o conjunto de dados a ser pesquisado atenda às propriedades de um espaço métrico, assim ela pode ser aplicada a qualquer conjunto de dados para o qual tenha sido definida uma métrica;

- independencia da operação de busca - a variedade é definida junto com o conceito de similaridade, portanto ela se aplica a qualquer operação de busca que venha a ser usada para recuperar dados por similaridade.

Apoiado no conceito de variedade, foram também definidas duas medidas para avaliar o quanto de variedade a resposta a uma consulta apresenta: a variedade intrínseca e a variedade normalizada de um conjunto qualquer de elementos em referência a um dado elemento. A Variedade Intrínseca permite medir quanto de variedade o conjunto apresenta entre seus 
elementos, enquanto a Variedade Normalizada representa um índice de referência que permite comparar os resultados de variedade inerentes à diferentes consultas que centradas no mesmo elemento.

Os experimentos realizados em conjuntos de dados tanto sintéticos variando a dimensionalidade tanto em dados dimensionais quanto em dados adimensionais, mostraram que o modelo de variedade pode ser utilizado para implementar algoritmos eficientes, sendo escalável para grandes conjuntos de dados. De fato, os resultados mostram que o algoritmo BRAD proposto foi no mínimo uma ordem de grandeza e até mais de até 4 ordens de grandeza mais rápido do que os algoritmos do estado da arte, além de sempre apresentar um resultado melhor em termos de variedade normalizada do que qualquer dos concorrentes.

\subsection{Principais Contribuições}

As principais contribuições decorrentes da realização deste de Mestrado são:

- Modelo de variedade em espaços métricos que produz diversidade em qualquer consulta por similaridade, sendo independente de domínio, de parâmetros e de operações de busca;

- desenvolvimento de um algoritmo incremental para responder as consultas aos $k$-vizinhos variados mais próximos;

- criação de medida para avaliação de sobreposição de variedade para as consultas por similaridade.

\subsection{Contribuições Complementares}

Além das contribuições principais citadas, este trabalho alcançou uma contribuição complementar, derivada de contribuição com outra colega do grupo de pesquisa. A contribuição complementar ocorreu na definição de um conjunto de propriedades algébricas baseadas na relação de inclusão de subconjuntos para possibilitar a re-escrita de planos de consulta envolvendo as consultas por similaridade fundamentais $\left(k-N N q\right.$ e $\left.R_{q}\right)$ com os operadores baseados em atributos tradicionais que seguem as propriedades de relação de ordem total. Os resultados desse trabalho foram publicados no Journal of Information and Data Management (JIDM - (Ferreira et al., 2011)).

\subsection{Proposta para Trabalhos Futuros}

O conceito de variedade desenvolvido nesta dissertação possibilita o desenvolvimento de extensões em pelo menos três frentes de trabalho: Extensões ao conceito de variedade, desenvolvimento de algoritmos que tratem de variedade e extensões de sua aplicação a necessidades específicas. Ambas as frentes são comentadas nas subseções a seguir.

\subsubsection{Extensões ao conceito de variedade}

Explorar as propriedades algébricas do operador dos $k$-vizinhos variados mais próximos: Em aplicações reais, as consultas são compostas por diversos predicados, em que alguns deles podem ser consultas por similaridade. A ordem com que esses predicados são executados 
em muitos casos não influenciam o resultado em si, mas em geral têm impactos significativos no tempo gasto nessa execução. Assim, antes de proceder à execução propriamente dita, os SGBDs geram diversas expressões algebricamente equivalentes da consulta e estimam o tempo que cada uma deve levar para ser executada, escolhendo aquela que se prevê ser a mais rápida, num processo chamado "otimização de consultas". Para isso, é necessario ter um conjunto o mais completo possível de propriedades algébricas envolvendo todos os operadores algébricos envolvidos nas consultas. Por exemplo, é conhecido que o operador de consulta por abrangência é comutativo (não importa a ordem com que uma sequencia de dois desses operadores sejam executados), mas o operador de consultar pelos $k$-vizinhos mais próximos não é (o resultado obtido pela troca da ordem de dois operadores pode ser diferente). Para que operadores de busca por similaridade possam ser tratados nos otimizadores de consulta, é necessário levantar as propriedades que eles apresentam, tanto combinados entre si quanto combinados com qualquer dos demais operadores algébricos da álgebra relacional. Dadas as características do conceito de variedade, prevê-se que pelo menos dois conjuntos de regras devam ser avaliados:

1. Equivalência exata: Regras que permitem obter expressões que retornem conjuntos-repostas idênticos;

2. Equivalência conceitual: Regras que levam a respostas em que os elementos retornados compartilham os mesmos conjuntos de similaridades em ambas as respostas, embora não sejam os mesmos os elementos.

Ponderação entre similaridade e variedade: $O$ conceito de variedade foi definido de maneira absoluta, de maneira que não há a necessidade de se "compensar" entre similaridade de variedade (o que torna a técnica "independente de parâmetros"). Definido dessa maneira, o conceito de variedade também apresenta um comportamento muito útil em aplicações reais, que corresponde a perceber a similaridade de maneira mais sutil entre elementos próximos, de uma maneira que vai se tornando mais difusa conforme os elementos vão ficando distantes. No entanto, o grau de intensidade com que isso ocorre não é controlado, e em determinadas situações (citadas a seguir) isso pode vir a ser necessário. Portanto, pode ser interessante permitir que sejam introduzidos parâmetros que controlem, entre outros:

1. A taxa de expansão da distância de similaridade que define os conjuntos de similaridade;

2. A quantidade máxima de elementos no conjunto resposta que estejam no mesmo conjunto de similaridade (com as respectivas políticas de escolha).

Como a definição desses parâmetros tende a necessitar a interação de um usuário especialista, continua sendo importante que o modelo de variedade produza diversidade sem a necessidade de solicitar informação ao usuário não especialista. Portanto, é importante dispor de mecanismos que possam prover tais parâmetros, pelo menos nas situações mais comuns. Um exemplo, é considerar o fato que o aumento da cardinalidade e dimensionalidade do conjunto de dados pode tornar os elementos mais próximos uns dos outros, tornando a distância de similaridade muito pequena e menos eficiente. Nesse caso seria possível utilizar informação extraída do próprio conjunto de dados, como a dimensão intrínseca do conjunto, para aumentar a distância de similaridade dos elementos possibilitando atuar em enormes quantidades de dados.

Uso de métricas distintas para similaridade e diversidade: Diversas as técnicas existentes para incluir diversidade em consultas por similaridade permitem usar métricas distintas para a similaridade e para a diversidade, mas a técnica apresentada neste trabalho se restrigiu considerar uma única métrica para ambas. A razão inicial para isso foi a decisão de se criar 
um método que seja universal para quaisquer dados representados em um espaço métrico - a Teoria dos Espaços Métricos considera uma única função de distância. No entanto, a literatura mostra que existem várias aplicações em que dispor de métricas distintas para a similaridade e a diversidade é vantajoso. Considerando que a Teoria dos Espaços Métricos trata da composição de múltiplos espaços métricos (por exemplo em conceitos tais como Homomorfismo e espaços métricos produto), é possível desenvolver um modelo de diversidade que estende aquele desenvolvido neste trabalho de tal maneira que ter uma métrica distinta para a similaridade e outra para a diversidade seria apenas um caso particular de um modelo apto a tratar não apenas duas, mas múltiplas métricas. A validação de um tal modelo irá, no entanto, depender da existência de casos de estudo que justifiquem as necessidades e os resultados que venham a ser obtidos.

\subsubsection{Desenvolvimento de algoritmos que tratem de variedade}

Aplicação de técnicas de mineração de dados para a definição de elementos dominantes: Na técnica apresentada, foi estabelecido que uma vez definido o próximo elemento dominante, calcula-se o conjunto de similaridade, assume-se o elemento dominante como o elemento que vai para o conjunto-resposta e essa etapa está concluída. Os resultados apresentados mostraram que o resultado já é consistentemente melhor do que o resultado apresentado por qualquer das outras alternativas existentes, além de ser uma maneira rápida. No entanto, é admissível assumir que possa haver uma fase adicional depois se obter o elemento dominante e respectivo conjunto de similaridade e a escolha do elemento que vai para o conjunto-resposta. Por exemplo, pode-se realizar a busca de um medoide para esse conjunto, ou mesmo pode-se executar um algoritmo de busca por agrupamentos nesse (ou que parte desse) conjunto para identificar o elemento a ser colocado no conjunto resposta. Com certeza, tal variante seria significativamente mais lenta do que a solução apresentada, mas identificar se ela pode levar a soluções ainda melhores é uma tarefa que merece ser avaliada, em particular para necessidades específicas onde o conjunto de dados apresente muitos agrupamentos em diferentes resoluções de distância.

Inclusão de regras de variedade nos algoritmos de busca por similaridade com variedade: Os métodos de indexação usam as propriedades dos espaços de dados e as características das operações que devem ser executadas para evitar (podar) processar todos os elementos armazenados na avaliação da resposta. Assim, cada um dos operadores por similaridade tem algoritmos específicos em cada método de acesso métrico desenvolvido. Operadores de busca por similaridade com variedade requerem que algoritmos específicos venham a ser criados também. Em particular, um método de acesso métrico hierárquico, como por exemplo uma Slim-tree, poderia ter algoritmos específicos que trariam potenciais benefícios na velocidade de execução se os seguintes operadores de busca por similaridade com variedade:

1. Consulta por abrangência: é possível explorar diversas propriedades, como por exemplo podas de sub-árvores que estejam totalmente contidas em um conjunto de similaridade cujo elemento dominante já foi identificado, ou podas de subárvores cuja raiz e raio de cobertura mantenham determinadas relações com os elementos dominantes e os respectivas distâncias de similaridade;

2. consulta pelos $k$-vizinhos mais próximos: além das mesmas propriedades para podas úteis às consultas por abrangência, é possível tratar a ordem de busca das sub-árvores baseadas nessas mesmas propriedades nos algoritmos que exploram a técnica de busca por deep first e fila de prioridade global, visando acelerar a redução do raio dinâmico 
do limiar de busca do algoritmo. Por outro lado, é possível prever que algoritmos de busca incrementais também devem apresentar diversas oportunidades de melhora usando as propriedades da variedade;

3. consulta pelos $k$-vizinhos mais próximos reversos: Durante o desenvolvimento deste projeto de mestrado, foram identificadas várias técnicas que são usadas na literatura para agilizar a busca pelos $k$-vizinhos mais próximos reversos que apresentam potencial para a busca pelos $k$-vizinhos mais próximos com variedade. As avaliações experimentais dessas técnicas para as buscas pelos $k$-vizinhos mais próximos com variedade não se revelaram competitivas com a solução final reportada, e foram descartadas. No entanto, elas não foram exploradas para um possível operador de busca pelos $k$-vizinhos mais próximos reversos com variedade, onde podem vir a se revelar adequadas.

Utilização do operador de consulta por abrangência variada para reduzir a cardinalidade do conjunto de similaridade nos algoritmos GNE e GMC Casos em que o usuário esteja interessado em usar buscas por similaridade com variedade indicando o parâmetro usando as técnicas baseadas na indicação da "preferência de diversidade", que utilizam técnicas tais como GNE e GMC, podem se beneficiar do uso de conjuntos-base recuperados não pela busca por abrangência padrão, mas pela busca por abrangência com variedade definida neste trabalho. Com isso, a cardinalidade do conjunto submetido aqueles algoritmos fica bastante reduzida, o que aumenta muito a eficiência dos mesmos, ao mesmo tempo em que preserva um grau elevado de diversidade nos elementos do conjunto-base de onde a resposta final será obtida. Com isso, é possível agilizar bastante os algoritmos GNE e GMC enquanto se preserva as suas características, como por exemplo a possibilidade de tratar funções de comparação distintas para similaridade e para diversidade e permitir ao usuário controlar o compromisso entre similaridade e variedade tal como definido naquelas técnicas.

\subsubsection{Extensões da variedade a necessidades específicas}

Explorar a utilização de informação extraída do conjunto de dados para melhorar as respostas à consultas por similaridade em enormes quantidades de dados: A aplicação de técnicas de mineração de dados antes de se iniciar o processo de execução da busca por similaridade com variedade pode prover informações sobre o conjunto de dados que podem ser utilizadas em benefício de melhorar tanto a qualidade das respostas quanto a eficiência da execução. O pré-processamento usando técnicas de mineração poderia ser feito ou de maneira independente da consulta (e portanto tendo os resultados armazenados junto aos dados, auxiliando técnicas de indexação), ou de maneira dependente da consulta (caso em que a manutenção de estatísticas sobre os dados podem auxiliar um pré-processamento individual para cada consulta, mas não a exclui por completo). A variedade de opções que se descortina aqui é muito grande, portanto a exploração dessas possibilidades deve ser feita a partir de características particulares dos dados. Os seguintes exemplos dão uma idéia do que pode ser obtido nesta linha de desenvolvimento, tanto para pre-processamento dependente ou independente da consulta:

1. Agrupamento - A identificação prévia de agrupamentos nos dados (usando a mesma métrica ou não) tanto pode facilitar a busca por similariade com diversidade, quanto permite definir regras adicionais, tais como a dispersão positiva ou negativa dos elementos da resposta pelos agrupamento; 
2. Classificação - a introdução de classes nos dados é uma maneira de prover maior diversidade ou de controlá-la em buscas por similaridade, e portanto pode ser usada em conjunto com a técnica proposta neste trabalho;

3. Identificação de Regras de Associação - Tal como no processo de agrupamento, as regras de associação podem ser usadas para dirigir as operações de busca de similaridade com diversidade.

Utilização do conceito de variedade para classificação hierárquica de imagens: $O$ conceito de variedade foi utilizado para melhorar a qualidade das respostas aos $k$-vizinhos mais próximos. No entanto, o conceito apresenta características que podem auxiliar na classificação hierárquica de imagens, ao compor uma consulta mais complexa. Por exemplo, para cada elemento considerado dominante no conjunto de resposta, pode ser realizada outra consulta com esse elemento como o elemento central de consulta sobre o conjunto induzido de similaridade. Desse modo, é possível recursivamente definir os elementos dominantes. A motivação nessa tarefa é criar clusters locais, baseados no posicionamento do elemento central de consulta, sendo portanto relativos a um observador. 


\section{Referências Bibliográficas}

Agrawal, R., Gollapudi, S., Halverson, A., and Ieong, S. (2009). Diversifying search results. In Proceedings of the Second ACM International Conference on Web Search and Data Mining, WSDM '09, pages 5-14, New York, NY, USA. ACM.

Angel, A. and Koudas, N. (2011). Efficient diversity-aware search. In ACM SIGMOD International Conference on Management of Data, SIGMOD'11, pages 781-792, Athens, Greece. ACM.

Beyer, K. S., Goldstein, J., Ramakrishnan, R., and Shaft, U. (1999). When is "nearest neighbor" meaningful? In Proceedings of the 7th International Conference on Database Theory, ICDT '99, pages 217-235, London, UK, UK. Springer-Verlag.

Bozkaya, T. and Ozsoyoglu, M. (1997). Distance-based indexing for high-dimensional metric spaces. SIGMOD Rec., 26:357-368.

Bueno, R., Ferreira, M. R. P., and Traina Jr., C. (2004). Dbgen - manual da ferramenta. (246). ISSN - 0103-2569.

Bueno, R., Traina, A. J. M., and Jr., C. T. (2008). An algorithm for effective deletion and a new optimization technique for metric access methods. In Symposium on Applied Computing (SAC), pages 1034-1035.

Capannini, G., Nardini, F. M., Perego, R., and Silvestri, F. (2011). Efficient diversification of web search results. Proceedings of the VLDB Endowment, 4(7):451-459.

Carbonell, J. and Goldstein, J. (1998). The use of mmr, diversity-based reranking for reordering documents and producing summaries. In Proceedings of the 21 st annual international ACM SIGIR conference on Research and development in information retrieval, SIGIR '98, pages 335-336, New York, NY, USA. ACM.

Chakrabarti, K., Ortega-Binderberger, M., Mehrotra, S., and Porkaew, K. (2004). Evaluating refined queries in top-k retrieval systems. IEEE Trans. on Knowl. and Data Eng., 16:256-270.

Chen, Z. and Li, T. (2007). Addressing diverse user preferences in sql-query-result navigation. In Proceedings of the 2007 ACM SIGMOD international conference on Management of data, SIGMOD '07, pages 641-652, New York, NY, USA. ACM. 
Ciaccia, P., Patella, M., and Zezula, P. (1997). M-tree: An efficient access method for similarity search in metric spaces. In Proceedings of the 23rd International Conference on Very Large Data Bases, VLDB '97, pages 426-435, San Francisco, CA, USA. Morgan Kaufmann Publishers Inc.

Dang, V. and Croft, W. B. (2012). Diversity by proportionality: an election-based approach to search result diversification. In Proceedings of the 35th international ACM SIGIR conference on Research and development in information retrieval, SIGIR '12, pages 65-74, New York, NY, USA. ACM.

Deng, K., Xu, H., Sadiq, S., Lu, Y., Fung, G. P. C., and Shen, H. T. (2009). Processing group nearest group query. Data Engineering, International Conference on, 0:1144-1147.

Deserno, T. M., Antani, S., and Long, R. (2008). Ontology of gaps in content-based image retrieval. Springer Journal of Digital Imaging, 22(2):202-215. Springer On-line First: Friday, February 01, 2008.

Deserno, T. M., Antani, S., and Long, R. (2009). Ontology of gaps in content-based image retrieval. Journal of digital imaging : the official journal of the Society for Computer Applications in Radiology, 22(2):202-15.

Dou, Z., Hu, S., Chen, K., Song, R., and Wen, J. (2011). Multi-dimensional search result diversification. In Proceedings of the fourth ACM international conference on Web search and data mining, pages 475-484. ACM.

Drosou, M. and Pitoura, E. (2010). Search result diversification. ACM SIGMOD Record, 39(1):41-47.

Feo, T. a. (1995). Greedy Randomized Adaptive Search Procedures. Journal of Global Optimization, 68(2):93-133.

Ferreira, M. R. P., Santos, L. F. D., Traina, A. J. M., Dias, I., Chbeir, R., and Jr., C. T. (2011). Algebraic properties to optimize knn queries. JIDM, 2(3):385-400.

Gil-Costa, V., Santos, R. L. T., Macdonald, C., and Ounis, I. (2011). Sparse spatial selection for novelty-based search result diversification. In Proceedings of the 18th international conference on String processing and information retrieval, SPIRE'11, pages 344-355, Berlin, Heidelberg. Springer-Verlag.

Gollapudi, S. and Sharma, A. (2009). An axiomatic approach for result diversification. In Proceedings of the 18th international conference on World wide web, WWW '09, pages 381-390, New York, NY, USA. ACM.

Güld, M., Thies, C., Fischer, B., and Lehmann, T. (2007). A generic concept for the implementation of medical image retrieval systems. international journal of medical informatics, 76(2-3):252-259.

He, X., Cai, D., and Han, J. (2008). Learning a maximum margin subspace for image retrieval. IEEE Transactions on Knowledge and Data Engineering, 20:189-201.

Hu, H. and Lee, D. L. (2006). Range nearest-neighbor query. IEEE Trans. on Knowl. and Data Eng., 18:78-91. 
Jacox, E. H. and Samet, H. (2007). Spatial join techniques. ACM Trans. Database Syst., 32.

Jain, A., Sarda, P., and Haritsa, J. (2004). Providing diversity in k-nearest neighbor query results. In Dai, H., Srikant, R., and Zhang, C., editors, Advances in Knowledge Discovery and Data Mining, volume 3056 of Lecture Notes in Computer Science, pages 404-413. Springer Berlin / Heidelberg. 10.1007/978-3-540-24775-349.

Korn, F. and Muthukrishnan, S. (2000). Influence sets based on reverse nearest neighbor queries. SIGMOD Rec., 29:201-212.

Korn, F., Sidiropoulos, N., Faloutsos, C., Siegel, E., and Protopapas, Z. (1996). Fast nearest neighbor search in medical image databases. In Proceedings of the 22th International Conference on Very Large Data Bases, VLDB '96, pages 215-226, San Francisco, CA, USA. Morgan Kaufmann Publishers Inc.

Levenshtein, V. I. (1966). Binary codes capable of correcting deletions, insertions, and reversals. Cybernetics and Control Theory, 10(8):707-710. Original in Doklady Akademii Nauk SSSR 163(4): 845-848 (1965).

Lima L. Elon (1993). Espaços Métricos. Instituto Nacional de Matemática Pura e Aplicada, Rio de Janeiro, 3 edition.

Liu, Y., Zhang, D., Lu, G., and Ma, W.-Y. (2007). A survey of content-based image retrieval with high-level semantics. Pattern Recognition Letters, 40:262 - 282. Elsevier Ltd.

Mao, Y., Shen, H., and Sun, C. (2012). Diversification of web search results through social interest mining. In Proceedings of the 2012 45th Hawaii International Conference on System Sciences, HICSS '12, pages 3581-3590, Washington, DC, USA. IEEE Computer Society.

McCay-Peet, L. and Toms, E. G. (2010). The process of serendipity in knowledge work. In Proceeding of the third symposium on Information interaction in context, IIiX '10, pages 377-382, New York, NY, USA. ACM.

McNee, S. M., Riedl, J., and Konstan, J. A. (2006). Being accurate is not enough: how accuracy metrics have hurt recommender systems. In CHI 'O6 extended abstracts on Human factors in computing systems, CHI EA '06, pages 1097-1101, New York, NY, USA. ACM.

Papadias, D., Shen, Q., Tao, Y., and Mouratidis, K. (2004). Group nearest neighbor queries. Data Engineering, International Conference on, 0:301.

Qin, L., Yu, J. X., and Chang, L. (2012). Diversifying top-k results. PVLDB, 5(11):1124-1135.

Radlinski, F., Bennett, P. N., Carterette, B., and Joachims, T. (2009). Redundancy, diversity and interdependent document relevance. SIGIR Forum, 43:46-52.

Razente, H. (2009). Adequando consultas por similaridade para reduzir a descontinuidade semântica na recuperação de imagens por conteúdo. Tese de doutorado em ciências de computação e matemática computacional, Instituto de Ciências Matemáticas e de Computação, Universidade de SÃ£o Paulo.

Razente, H. L., Barioni, M. C. N., Traina, A. J. M., Faloutsos, C., and Traina, Jr., C. (2008). A novel optimization approach to efficiently process aggregate similarity queries in metric access methods. In Proceeding of the 17th ACM conference on Information and knowledge management, CIKM '08, pages 193-202, New York, NY, USA. ACM. 
Resende, M. G. (2009). Greedy randomized adaptive search procedures. pages 1460-1469. 10.1007/978-0-387-74759-0_256.

Samet, H. (2005). Foundations of Multidimensional and Metric Data Structures (The Morgan Kaufmann Series in Computer Graphics and Geometric Modeling). Morgan Kaufmann Publishers Inc., San Francisco, CA, USA.

Santos, R. L., Macdonald, C., and Ounis, I. (2010). Exploiting query reformulations for web search result diversification. In Proceedings of the 19th international conference on World wide web, WWW'10, pages 881-890, New York, NY, USA. ACM.

Santos, R. L. T., Macdonald, C., and Ounis, I. (2011). Aggregated search result diversification. In Proceedings of the Third international conference on Advances in information retrieval theory, ICTIR'11, pages 250-261, Berlin, Heidelberg. Springer-Verlag.

Skopal, T., Dohnal, V., Batko, M., and Zezula, P. (2009). Distinct nearest neighbors queries for similarity search in very large multimedia databases. In 11th International Workshop on Web Information and Data Management, WIDM'09, pages 11-14, Hong Kong, China. ACM.

Tao, Y., Yiu, M. L., and Mamoulis, N. (2006). Reverse nearest neighbor search in metric spaces. IEEE Transactions on Knowledge and Data Engineering, 18:1239-1252.

Thonangi, R., He, H., Doan, A., Wang, H., and Yang, J. (2009). Weighted proximity best-joins for information retrieval. In Data Engineering, 2009. ICDE'09. IEEE 25th International Conference on, pages 234-245. IEEE.

Toms, E. (2000). Serendipitous information retrieval. In Proceedings of the First DELOS Network of Excellence Workshop on Information Seeking, Searching and Querying in Digital Libraries, number 1968. Citeseer.

Traina, A. J. M., Traina, Caetano, J., Balan, A. G. R., Ribeiro, M. X., Bugatti, P. H., Watanabe, C. Y. V., and Azevedo-Marques, P. M. d. (2010). Feature extraction and selection for decision making over medical images. In Deserno, T. M., editor, Biomedical Image Processing Methods and Applications, pages 181-209. Springer-Verlag.

Traina, A. J. M., Traina Jr., C., Ciferri, C. D. A., Ribeiro, M. X., and Marques, P. M. A. (2009). How to cope with the performance gap in content-based image retrieval systems. International Journal of Healthcare Information Systems and Informatics (IJHISI), 4(1):47-67.

Traina, Jr., C., Traina, A. J., Faloutsos, C., and Seeger, B. (2002). Fast indexing and visualization of metric data sets using slim-trees. IEEE Transactions on Knowledge and Data Engineering, 14:244-260.

Traina, Jr., C., Traina, A. J. M., Seeger, B., and Faloutsos, C. (2000). Slim-trees: High performance metric trees minimizing overlap between nodes. In Proceedings of the 7th International Conference on Extending Database Technology: Advances in Database Technology, EDBT '00, pages 51-65, London, UK. Springer-Verlag.

Van Leuken, R. H., Garcia, L., Olivares, X., and van Zwol, R. (2009). Visual diversification of image search results. In Proceedings of the 18th international conference on World wide $w e b$, WWW '09, pages 341-350, New York, NY, USA. ACM. 
Vee, E., Srivastava, U., Shanmugasundaram, J., Bhat, P., and Yahia, S. (2008). Efficient computation of diverse query results. In Data Engineering, 2008. ICDE 2008. IEEE 24th International Conference on, pages $228-236$.

Venkateswaran, J., Kahveci, T., Jermaine, C., and Lachwani, D. (2008). Reference-based indexing for metric spaces with costly distance measures. The VLDB Journal, 17:1231-1251.

Vieira, M., Razente, H., Barioni, M., Hadjieleftheriou, M., Srivastava, D., Traina, C., and Tsotras, V. (2011). On query result diversification. In Data Engineering (ICDE), 2011 IEEE 27th International Conference on, pages $1163-1174$.

Welter, P., Fischer, B., Gunther, R. W., and Deserno (n Lehmann), T. M. (2012). Generic integration of content-based image retrieval in computer-aided diagnosis. Computer Methods and Programs in Biomedicine, page to be published.

Wu, L. (2012). Flickr distance: A relationship measure for visual concepts. IEEE Transactions on Pattern Analysis and Machine Intelligence, 34(5):863-875.

Wu, L., Faloutsos, C., Sycara, K. P., and Payne, T. R. (2000). Falcon: Feedback adaptive loop for content-based retrieval. In Abbadi, A. E., Brodie, M. L., Chakravarthy, S., Dayal, U., Kamel, N., Schlageter, G., and Whang, K.-Y., editors, VLDB 2000, Proceedings of 26th International Conference on Very Large Data Bases, September 10-14, 2000, Cairo, Egypt, pages 297-306. Morgan Kaufmann.

Xiao, C., Wang, W., Lin, X., and Shang, H. (2009). Top-k set similarity joins. In Data Engineering, 2009. ICDE'09. IEEE 25th International Conference on, pages 916-927. IEEE.

Yao, B., Li, F., and Kumar, P. (2009). Reverse furthest neighbors in spatial databases. Data Engineering, International Conference on, 0:664-675.

Yianilos, P. N. (1993). Data structures and algorithms for nearest neighbor search in general metric spaces. In Proceedings of the fourth annual ACM-SIAM Symposium on Discrete algorithms, SODA '93, pages 311-321, Philadelphia, PA, USA. Society for Industrial and Applied Mathematics.

Yu, C., Lakshmanan, L., and Amer-Yahia, S. (2009). Recommendation diversification using explanations. In Data Engineering, 2009. ICDE '09. IEEE 25th International Conference on, pages $1299-1302$.

Zezula, P., Amato, G., and Dohnal, V. (2006). Similarity search: the metric space approach. Advances in Database Systems, vol. 32. Database.

Zhang, Y., Callan, J., and Minka, T. (2002). Novelty and redundancy detection in adaptive filtering. Proceedings of the 25th annual international ACM SIGIR conference on Research and development in information retrieval - SIGIR '02, page 81.

Zheng, W., Wang, X., Fang, H., and Cheng, H. (2011). An exploration of pattern-based subtopic modeling for search result diversification. In Proceedings of the 11th annual international ACM/IEEE joint conference on Digital libraries, JCDL '11, pages 387-388, New York, NY, USA. ACM.

Zhou, T., Kuscsik, Z., Liu, J., and Medo, M. (2010). Solving the apparent diversity-accuracy dilemma of recommender systems. Proceedings of the National Academy of Sciences of the United States of America, 107(10):4511-4515. 
Ziegler, C., Lausen, G., and Schmidt-Thieme, L. (2004). Taxonomy-driven computation of product recommendations. In Proceedings of the thirteenth ACM international conference on Information and knowledge management, pages 406-415. ACM.

Ziegler, C.-N., McNee, S. M., Konstan, J. A., and Lausen, G. (2005). Improving recommendation lists through topic diversification. In Proceedings of the 14th international conference on World Wide Web, WWW '05, pages 22-32, New York, NY, USA. ACM. 